\title{
Systematic Interrogation of Protein Refolding Under Cellular-Like Conditions
}

Philip To ${ }^{1}$, Sea On Lee, ${ }^{1}$ Yingzi Xia $^{1}$, Taylor Devlin ${ }^{2}$, Karen G. Fleming ${ }^{2}$, Stephen D. Fried ${ }^{1,2 \star}$

1. Department of Chemistry, Johns Hopkins University, Baltimore, MD 21218, USA

2. Thomas C. Jenkins Department of Biophysics, Johns Hopkins University, Baltimore, MD 21218, USA

*To whom correspondence is due: sdfried@jhu.edu 


\section{SUMMARY}

The journey by which proteins navigate their energy landscapes to their native structures is complex, involving (and sometimes requiring) many cellular factors and processes operating in partnership with a given polypeptide chain's intrinsic energy landscape. The cytosolic environment and its complement of chaperones play critical roles in granting proteins safe passage to their native states; however, the complexity of this medium has generally precluded biophysical techniques from interrogating protein folding under cellular-like conditions for single proteins, let alone entire proteomes. Here, we develop a limited-proteolysis mass spectrometry approach paired within an isotope-labeling strategy to globally monitor the structures of refolding $E$. coli proteins in the cytosolic medium and with the chaperones, GroEL/ES (Hsp60) and DnaK/DnaJ/GrpE (Hsp70/40). GroEL can refold the majority (85\%) of the $E$. coli proteins for which we have data, and is particularly important for restoring acidic proteins and proteins with high molecular weight, trends that come to light because our assay measures the structural outcome of the refolding process itself, rather than indirect measures like binding or aggregation. For the most part, DnaK and GroEL refold a similar set of proteins, supporting the view that despite their vastly different structures, these two chaperones both unfold misfolded states, as one mechanism in common. Finally, we identify a cohort of proteins that are intransigent to being refolded with either chaperone. The data support a model in which chaperone-nonrefolders have evolved to fold efficiently once and only once, co-translationally, and remain kinetically trapped in their native conformations.

\section{HIGHLIGHTS}

- New proteomic methods are developed to probe protein refolding globally and sensitively in a complex background

- The results revise the consensus model of which E. coli proteins require the GroEL chaperonin for efficient refolding

- DnaK (Hsp70) and GroEL refold largely the same clientele, suggesting that these distinct chaperones share a common unifying mechanism

- A small cohort of proteins cannot be fully restored by chaperones. These chaperonenonrefolders tend to be involved in tRNA aminoacylation and glycolysis, and may have kinetically-trapped native states 


\section{INTRODUCTION}

Protein folding represents the culmination of the central dogma of molecular biology enabling the primary information encoded in nucleic acids, translated into polypeptides, to take shape into functional macromolecules. Whilst the striking accuracy of Al-based structure predictors has given new credence to Anfinsen's dogma (that protein three-dimensional structures is encoded at the amino acid sequence level) (Anfinsen, 1973; Jumper et al., 2021) the journey by which proteins navigate their energy landscapes to their native structures is complex, involving (and sometimes requiring) many cellular factors and processes operating in partnership with a given polypeptide chain's intrinsic energy landscape (Balchin et al., 2016; Tyedmers et al. 2010). Traditionally, protein folding assays monitor structure or activity recovered by a denatured protein molecule following dilution from denaturant (Anfinsen, 1961). The extension of these assays in which molecular chaperones are supplied during refolding (Brinker et al., 2001; Kerner et al., 2005; Singh et al., 2020; Viitanen et al., 1990) have convincingly shown that productive folding for certain proteins is dependent on extrinsic factors. Indeed, a recent study (To et al., 2021) estimated that 33\% of soluble E. coli proteins are intrinsically nonrefoldable, meaning they cannot fully reassume their native forms following complete denaturation, even under conditions without any detectable precipitation. These findings suggest that the cellular milieu supplies additional tools, not present during in vitro assays, necessary for many proteins to find safe passage to their native states. Such tools include (but are not limited to): molecular chaperones, the complement of metabolites, ions, and small molecules in the cytoplasm, and vectorial synthesis on the ribosome.

Proteomic and high-throughput approaches have significantly advanced our understanding of protein folding in the past two decades. Pioneering work by Kerner et al. introduced a proteomic method to survey the clients of GroEL/GroES (E. coli's group I chaperonin) by identifying proteins that are enriched in a fraction coprecipitating with chaperonin (Kerner et al., 2005). This pull-down proteomic approach has since been extended to survey several other chaperone systems, such as DnaK (Calloni et al., 2012; Willmund et al., 2013). Complementing these methods are high-throughput measurements of protein precipitation, conducted on individual over-expressed proteins with and without chaperones 
(Niwa et al., 2009; Niwa et al., 2012), or on whole extracts following heat treatment (Mateus et al., 2018; Jarzab et al., 2020).

Nevertheless, systematically dissecting the roles that cellular processes and factors play in various proteins' biogenesis remains challenging, even for the relatively simple proteome of the model bacterium, E. coli. For instance, pull-down proteomic approaches cannot unambiguously assess a protein's dependency (obligatory use) on a cellular factor to refold, since they ultimately measure binding and association, rather than the outcome of the folding process. Indeed, many proteins that were presumed to be obligate chaperonin clients based on their enrichment on chaperonin coprecipitation studies were found to remain soluble in vivo during GroE knock-down (Fujiwara et al., 2010).

To complement these strategies, we developed a limited-proteolysis mass spectrometry (LiP-MS) approach to probe protein structures globally during refolding (Figures $1 \mathrm{~A}$ and S1A) (De Souza and Picotti, 2020; Feng et al., 2014; Park and Marqusee, 2005; Park et al., 2007). In this experiment, E. coli lysates are fully unfolded by overnight incubation in $6 \mathrm{M}$ guanidinium chloride $(\mathrm{GdmCl})$, returned to native conditions by rapid dilution, and the conformational ensembles of the proteins in the mixture probed by pulse proteolysis with proteinase $\mathrm{K}(\mathrm{PK})$. Because PK can cleave peptide bonds between any two amino acid-types but only in regions that are solvent-exposed or flexible, brief incubation leads to hydrolysis at specific sites encoding structural information about the conformations populated by the protein. After quenching PK, a second digest with trypsin generates half-tryptic peptides (HTPs) whose sequences can be used to infer the location of a PK cleavage site. Using liquid chromatography tandem mass spectrometry (LC-MS/MS), we identify and quantify tens of thousands of HTPs, and then compare the proteolysis profile of each protein following refolding to that of its native state, recovered from the original lysate. Critical for the viability of this approach is the preparation of native and refolded samples that are compositionally identical (e.g., contain the exact same proteins, small molecules, and buffer components in the exact same concentrations) but differ only in history (e.g., one was unfolded and refolded, the other was not). This enables differences in the cleavage pattern between the two sample types to be attributed solely to the refolding process. 


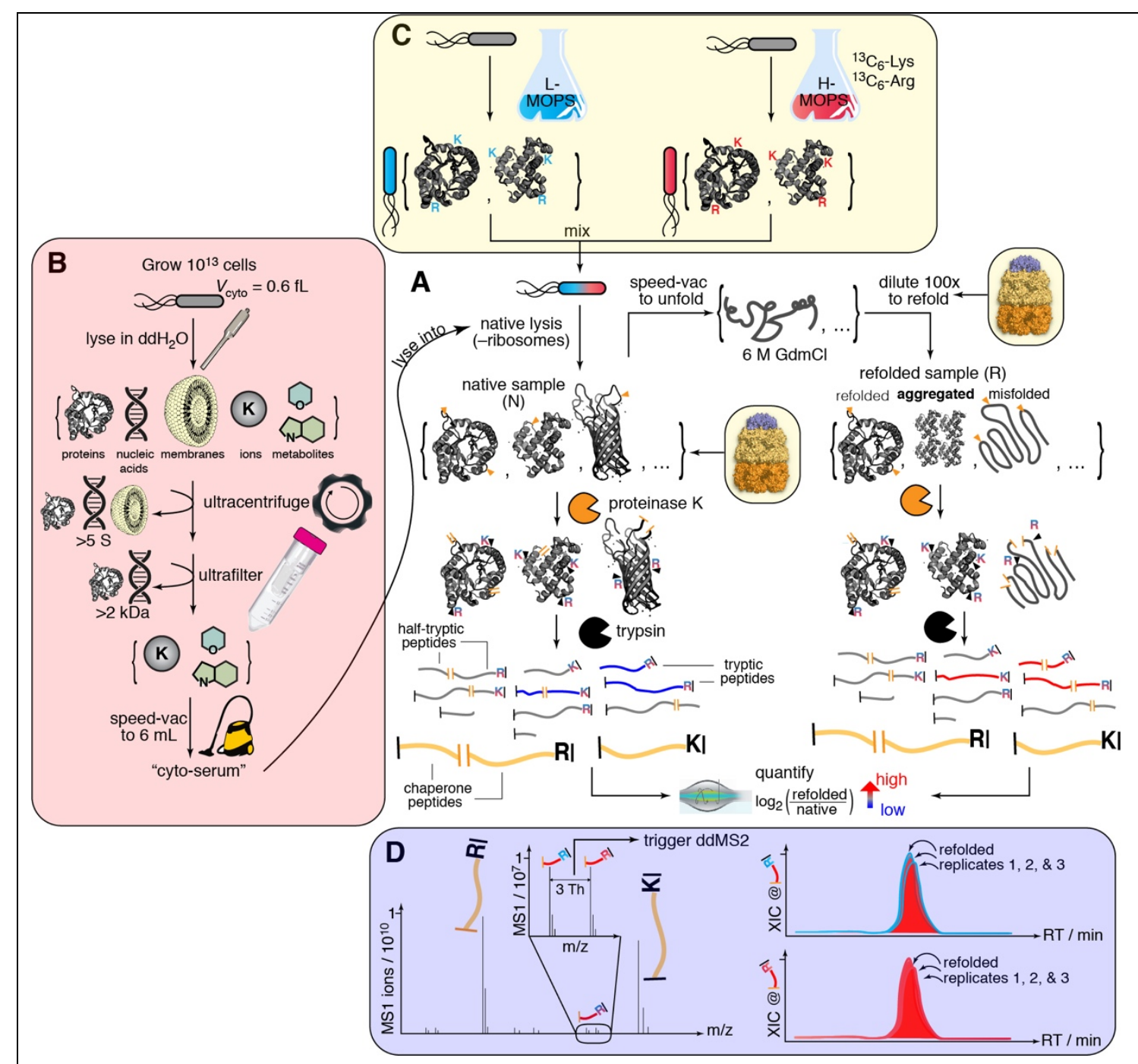

Figure 1. Limited-proteolysis mass spectrometry (LiP-MS) to interrogate the refoldability of the E. coli proteome under cellular-like conditions, highlighting methodological developments (A) The core portion of the experiment. E. coli cells are lysed and ribosomes are depleted from the lysate. Extracts are globally unfolded and refolded by dilution. Proteinase K (PK) selectively cleaves at unstructured/exposed regions of proteins, thereby encoding structural information about the ensemble of protein conformations into cleavage sites. After quenching PK, proteins are fully trypsinized. The refolded/native abundance ratios are measured by label-free quantification (LFQ). (B) Preparation of cyto-serum. Large populations of $E$. coli cells are lysed by sonication into pure water, and all macromolecules are removed by ultracentrifugation and ultrafiltration. The liquid is reduced to the same volume that was enclosed by the original E. coli population's cytoplasms. Cytoserum is used as a lysis buffer for refolding experiments.

(C) In chaperone refolding experiments, large concentrations of chaperone are supplemented into native samples and refolding reactions, which overwhelms the signal from proteome-derived peptides. To make proteome-derived peptides distinguishable, a pseudo-SILAC method is used in which replicate $E$. coli cultures are grown in rich MOPS media with either light $(L)$ or heavy $(H)$ lysine (Lys) and arginine (Arg). L/H pairs of cultures are mixed together and co-lysed. Consequentially, peptides derived from the proteome will exist as isotopomeric pairs.

(D) Co-eluting isotopomer pairs are preferentially isolated for data-dependent MS2 (ddMS2) scans, enabling high coverage of the E. coliproteome during MS analysis. In label-free quantification (LFQ), peptide abundance ratios (refolded/native) are calculated by comparing the area under the curve of the 
extracted ion chromatograms $(\mathrm{XIC})$ at the appropriate retention time (RT) across separately-injected samples. Non-refolding regions of proteins generate half-tryptic fragments that are absent in the native sample. Pseudo-SILAC provides greater confidence that the signal is absent in natives by doubling the number of quantifiable features for each peptide group.

In this work, we sought to extend the LiP-MS approach to interrogate protein refolding under conditions that more closely recapitulate the cellular context, including the cytosolic medium and molecular chaperones (GroEL/ES (Hsp60) and DnaK/DnaJ/GrpE (Hsp70/40)), both of which required introducing methodological developments described in the following sections (Figures 1B-C). We discover that the cytosolic medium makes protein folding more robust and consistent compared to refolding in defined buffer, suggesting that the physicochemical properties of the proteome are adapted to the composition of the solvent in which it naturally occurs. Our chaperone experiments show that GroEL can restore many intrinsically nonrefoldable proteins, a cohort that overlaps extensively with those which DnaK can restore, suggesting unified mechanisms in the operation of these two distinct molecular machines. Finally, our study sheds light on a small group of proteins that are recalcitrant to refolding with either chaperone, a group that most likely is adapted to fold co-translationally and remain trapped in their native states, obviating the need for chaperone assistance under physiological conditions. Structural, mechanistic, and evolutionary aspects of these 'chaperone-nonrefolders' are discussed.

\section{RESULTS}

\section{Refolding the E. coli proteome in E. coli cyto-serum}

The E. coli cytosol is an idiosyncratic medium, predominantly buffered by glutamate, and replete with a wide array of cofactors, metabolites, and ions with concentrations spanning over 6 orders of magnitude (Bennet et al., 2009). To probe the effect this medium exerts on protein folding, we isolated the cytosolic medium by culturing large numbers of cells, and lysing them into pure water (Figure 1B). Macromolecules of all types larger than $2 \mathrm{kDa}$ are depleted by extensive ultra-centrifugation, followed by ultra-filtration of the supernatant (see Methods, Figure S2A). Finally, the filtrate is reduced under vacuum until its volume equaled that of the combined internal volume of the original cellular population (e.g., with $10^{13}$ cells, we would reduce to $6 \mathrm{~mL}$ given the cytoplasm volume of $0.6 \mathrm{fL} / c e l l$ (Philips et al., 2008)). The resulting liquid, which we refer to as 'cyto-serum,' consists of all the ions, metabolites, and cofactors 
present in the E. coli cytosol near their physiological concentrations. Cyto-serum is a nonviscous off-yellow ( $\lambda_{\max } 258 \mathrm{~nm}$ ) liquid with $\mathrm{pH}$ of 7.4 (Figure S2B-E).

We used cyto-serum as a lysis buffer to resuspend separate E. coli cell pellets (grown to the end of log phase in MOPS media (Neidhardt et al., 1974)), which is natively lysed by cryogenic pulverization, a mechanical lysis method chosen because it keeps large and weaklybound protein assemblies intact (Harris, 1987; Wallace et al., 2015) (Figure 1). Use of cytoserum as a lysis buffer enables us to lower protein concentrations to be amenable for refolding, whilst keeping the small molecule constituents of the cytosol at their physiological concentrations. In 'cytosolic' refolding experiments, we reduce ribosome-depleted lysates in vacuo to final concentrations of $11.6 \mathrm{mg} / \mathrm{ml}$ protein, $6 \mathrm{M} \mathrm{GdmCl,} 10 \mathrm{mM}$ DTT, 3.5x cyto-serum, incubate overnight, and then dilute with 99 volumes of $0.974 x$ cyto-serum to refold 0.116 $\mathrm{mg} / \mathrm{ml}$ protein in $60 \mathrm{mM} \mathrm{GdmCl}, 0.1 \mathrm{mM}$ DTT, 1x cyto-serum. In preliminary experiments, we tested whether cyto-serum would be suitable for global refolding experiments by measuring the levels of aggregation that accrue after $2 \mathrm{~h}$. Pelleting assays detected low but non-zero levels of aggregation ( $6 \pm 2 \%$ of protein), in contrast with the buffer conditions we had previously devised (20 mM Tris pH 8.2, $100 \mathrm{mM} \mathrm{NaCl}, 2 \mathrm{mM} \mathrm{MgCl}_{2}, 1 \mathrm{mM}$ DTT) which result in very low levels of precipitation ( $3 \pm 1 \%$, Figure S2D). This difference can be potentially attributed to the more neutral $\mathrm{pH}$ of the cytosol, as previous work has shown that alkaline $\mathrm{pH}$ helps suppress aggregation for many proteins (To et al., 2021; Wang et al., 2017).

To further investigate aggregation (including smaller soluble non-precipitating aggregation), we performed sedimentation velocity analytical ultracentrifugation (AUC) and mass photometry (MP) on these refolding reactions (Figure S3). Time derivative analysis on Tris-refolding samples evinced no features larger than $8 \mathrm{~S}$, and near superposition of the native and refolding traces (Figure S3A-C), confirming the absence of soluble aggregates. Because cyto-serum contains many components with absorption features overlapping with those of proteins (cf. Figure S2C), it is not compatible with AUC. Hence, to probe the potential for protein aggregation in a complex background, we utilized MP, which measures the molecular weight (MW) of single particles interferometrically (Cole et al., 2017; Young et al., 2018). In this technique, the many low-MW but strongly absorbing components in cyto-serum are invisible because their size is too small to scatter incident light. Molecular weight 
distributions between native extracts and those that had been subjected to global refolding reactions were again indistinguishable, in both Tris buffer as well as in cyto-serum (Figure S3D-E). As a caveat, we point out that mass photometry is a single-molecule technique, and hence our refolding reactions were first diluted 100 -fold from the concentrations used in our primary studies before immediately being transferred to the microscope coverslip for analysis. Hence, aggregates that formed during refolding that would be dissolved within a minute following dilution would not be visible. On the other hand, AUC was performed on samples prepared nearly identically to those of our primary mass spectrometry experiments (including their final concentrations; Figures $1 A-B, S 1, S 3 A-C$ ) and also revealed no significant soluble aggregates. On the whole, these studies suggest that complex mixtures of proteins are less aggregation-prone than most of these individual proteins are when they are overexpressed (e.g., Niwa et al., 2009). These findings are consistent with the hypothesis that protein aggregation is driven by homotypic interactions (e.g., between molecules of the same identity (Vecchi et al., 2020)).

We next performed LiP-MS studies on protein extracts refolding in cyto-serum and compared them to analogous experiments conducted in a simple Tris-based ( $\mathrm{pH}$ 8.2) refolding buffer (Figure 2). To summarize these data, we present peptide-level volcano plots and abundance ratio histograms (Figure 2A-B), which evince characteristic trimodal structures. The observation that nearly all HTPs (in blue) are more abundant in the refolded samples than in the native samples $\left(\mathrm{P}<10^{-15}\right.$ for both Tris buffer and cyto-serum by Mann-Whitney U-test) implies that the refolded proteome is globally more susceptible to proteolysis. This is consistent with our other data showing that nonrefoldable proteins under these conditions populate soluble misfolded states that are less well-packed (Singh et al., 2020), but do not precipitate, or at least have not yet precipitated.

Points on the flanking lobes of the volcano plots (Figure 2A-B, red boxes) correspond to peptides that were detected only in the refolded $(\mathrm{R}$, right lobe, solid line) or native ( $\mathrm{N}$, left lobe, dotted line) samples. We refer to these as 'all-or-nothing' peptides, and assign a limit-ofdetection abundance to them in samples where they're not found. All-or-nothing peptides represent nonrefoldable regions within proteins that were completely inaccessible to PK in the native conformation but became proteolytically susceptible when that region failed to refold. 
We note that we employ a stringent filtering process to assess peptides with missing data (see Methods), and are confident in their status based on high reproducibility over nine orders of magnitude across technical replicates of the experiment (Figure S4A-I).

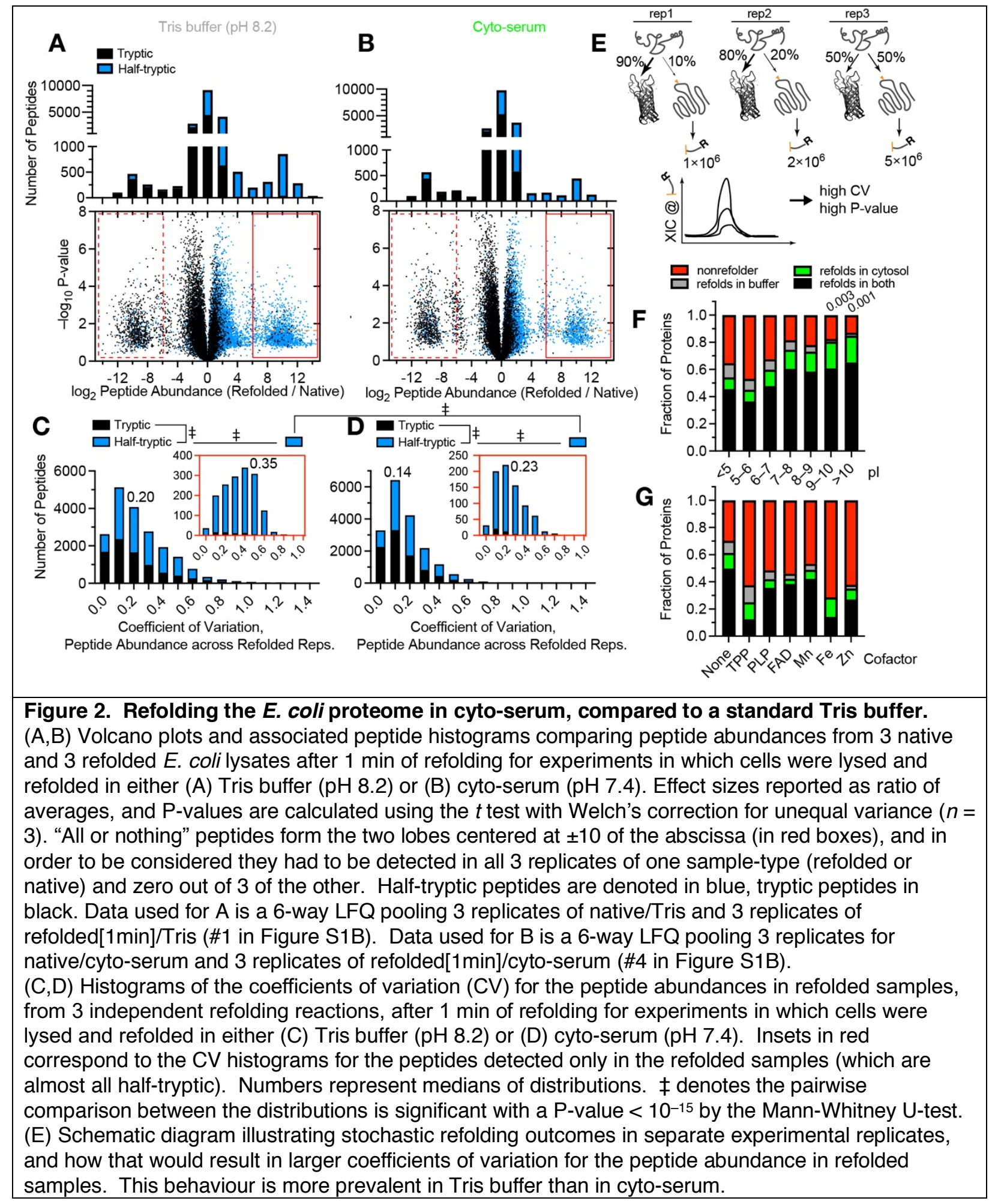


(F) Frequency of proteins that refolded in both conditions, only in Tris buffer, only in cyto-serum, or did not refold in either, separated on the basis of individual proteins' isoelectric points (pl). Data used for $F$ is a 12-way LFQ pooling 3 replicates of native/Tris, 3 replicates of refolded[5min]/Tris, 3 replicates of native/cyto-serum, and 3 replicates of refolded[5min]/cyto-serum (\#b in Figure S1C). Analysis covers 1025 proteins for which at least 2 peptides could be confidently quantified in both conditions. Numbers listed above bars indicate $P$-value by the chi-square test.

(G) Frequency of proteins that refolded in both conditions, only in Tris buffer, only in cyto-serum, or did not refold in either, separated on the basis of which cofactor the protein harbours. Data used for $\mathrm{G}$ is the same 12-way LFQ as panel F.

In cyto-serum the number of all-or-nothing peptides drops by 2-fold from 1583 to 782 , especially those that are only detected in the refolded sample (i.e., number of points in the solid red boxes in Figure 2A-B). We mapped peptides back to their parent proteins, and labeled an individual protein nonrefoldable if we could identify two or more peptides with a significant abundance difference in the refolded samples relative to the native samples $(>2$-fold effect-size, $\mathrm{P}<0.01$ by t-test with Welch's correction for unequal population variances). Based on the qualitative difference in the peptide abundance ratio distributions, we were initially surprised to see that in both conditions, $57-58 \%$ of proteins were refoldable after $5 \mathrm{~min}$ (we chose to focus on the 5 min timepoint because in both cases, it optimized the refoldability (Figure S5A)).

Closer analysis revealed that this occurred because a large number of the peptide quantifications in the Tris-refolded samples failed to meet the statistical cut-offs we require to be used to consider a protein nonrefolding. To probe further, we calculated the coefficient of variation (CV) in peptide abundance across the three independent refolding reactions conducted on three biological replicates, and found that compared to cyto-serum, refolding outcomes are significantly noisier in buffer (Figure 2C-D), as judged by many peptides whose abundances are more variable across replicates (as shown schematically in Figure $2 \mathrm{E}$ ). The increased stochasticity is particularly pronounced for all-or-nothing peptides (cf. insets in Figure 2C-D, which correspond to the same subset of peptides in solid red boxes above), for which the median $C V$ drops from 0.35 to 0.23 moving from Tris to cyto-serum $\left(P<10^{-15}\right.$ by Mann Whitney U-test).

Hence, these data show that cyto-serum compresses the variability of refolding outcomes. These findings suggest that cellular-derived buffers could have advantages relative 
to traditional defined buffers for protein refolding studies. Moreover, we note that these observations were consistent across the time series (Figure S4M-Q).

We next sought to find whether certain classes of proteins refold better in cyto-serum than in buffer. The most interesting trend we observed was with isoelectric point (pl; Figure $2 \mathrm{~F})$ : proteins with high pl refold significantly better in cyto-serum $(\mathrm{pH} \mathrm{7.4)}$ compared to Tris (pH 8.2), particularly the most basic proteins with pl $>9$ (for which $20 \%$ of the cohort exclusively refolded in cyto-serum). It would thus appear that basic proteins have adapted to refold efficiently in general, but particularly in cellular conditions with physiological $\mathrm{pH}$ (where they will be more positively charged). On the other hand, acidic proteins ( $\mathrm{pl}<6$ ) refold the worst in either medium; a point we shall return to in relation to chaperones.

Cofactor-containing proteins did not evince strong medium-dependent effects (Figure 2G). To be sure, most cofactor-containing proteins were less refoldable overall than apo proteins, but no cofactor category refolded significantly better in cyto-serum than in buffer, even though all cofactors would be $\sim 10^{3}$-fold more abundant during refolding experiments in cyto-serum. This suggests that the challenge associated with refolding certain cofactorassociated proteins probably lies more with the protein chain itself (e.g., the PLP-dependent transferase fold) than with cofactor binding (e.g., binding to PLP).

\section{A Method to Interrogate Refolding the E. coli Proteome with Chaperonin}

Encouraged by our findings on refolding the E. coli proteome in cyto-serum, we proceeded to use this as a 'base condition' for further studies on chaperones, which carries the additional benefit that the cytoplasm also contains components necessary for GroEL function $\left(\mathrm{K}^{+}, \mathrm{Mg}^{2+}\right.$, and ATP (Goloubinoff et al., 1989; Viitanen et al., 1990; Philips et al., 2008)). These experiments are conceptually similar to those previously described (Figure 1), except that the cyto-serum used as refolding buffer is supplemented with GroEL and GroES. Because of the importance of comparing compositionally identical samples, we also supplement chaperones into the native samples and equilibrate them together for $90 \mathrm{~min}$ prior to limited proteolysis (cf. Figure 1A). This step is essential because even though native proteins shouldn't "need" GroEL, if a correctly-folded protein has a propensity to associate transiently with GroEL (as a "triage complex" (Gottesman et al., 1997; Powers et al., 2012)), such an interaction would still 
affect its proteolysis profile and therefore needs to be identical in the native and refolded samples.

In preliminary chaperone experiments, we detected very low coverage of the proteome because $>75 \%$ of the total protein content in these refolding reactions are the added chaperone (Figure 3A). To address this challenge, we developed an isotope-labeling strategy to distinguish peptides belonging to refolding clients from those belonging to chaperonin proteins (Figure 1C). Three replicate E. coli cultures are grown in two different MOPS media: one with natural abundance (light) isotopes of Arg and Lys, and a second with $\left[{ }^{13} \mathrm{C}_{6}\right] \operatorname{Arg}$ and $\left[{ }^{13} \mathrm{C}_{6}\right]$ Lys (heavy). Pairs of light and heavy media are mixed together (for each biological replicate) prior to lysis and initiating the unfolding/refolding/LiP-MS workflow. In this way, peptides from client proteins will be present in the sample as a pair of isotopomers that coelute during liquid chromatography and generate a signature twin-peak feature (Figure 1D) that distinguish them from chaperone-derived peptides despite being several orders of magnitude lower in intensity (Figure 3C). The mass spectrometer is then instructed to preferentially select peaks with the correct spacing for data-dependent isolation and MS2 acquisition. Combining this method with the MSFragger spectral search algorithm (Kong et al., 2017), we were able to reproducibly obtain satisfactory number of unique identifications and quantifications (Figure 3A-B). We confirmed that co-eluting isotopomers generate fragmentation spectra with expected mass-shifts in the y-ions (Figure 3D). Moreover, this approach enables us to double the number of independent quantifications used to assess the refolded/native ratio for many peptides, providing additional confidence in our measurements (Figure 3E). This verification is particularly salient for verifying the all-or-nothing peptides which are detected exclusively in the refolded (or native) samples, providing additional weight to the assertion that the missing spectral features constitute evidence of absence (Figure 3F). We refer to this strategy as 'pseudo-SILAC' because it uses stable isotope labeling to direct the mass spectrometer to select the correct features, not to perform the refolded/heavy quantification. Instead, we calculate quantifications by comparing the areas under the curve between runs (known as label free quantification (LFQ), because of its superior dynamic range (Palomba et al., 2021; Nahnsen et al., 2013) and ability to confidently identify when a feature is absent from a particular sample. We note that even though pseudo-SILAC is not necessary for experiments 
without chaperones, we applied it to all conditions in this study uniformly to remove any potential source of bias when comparing chaperone to non-chaperone conditions.

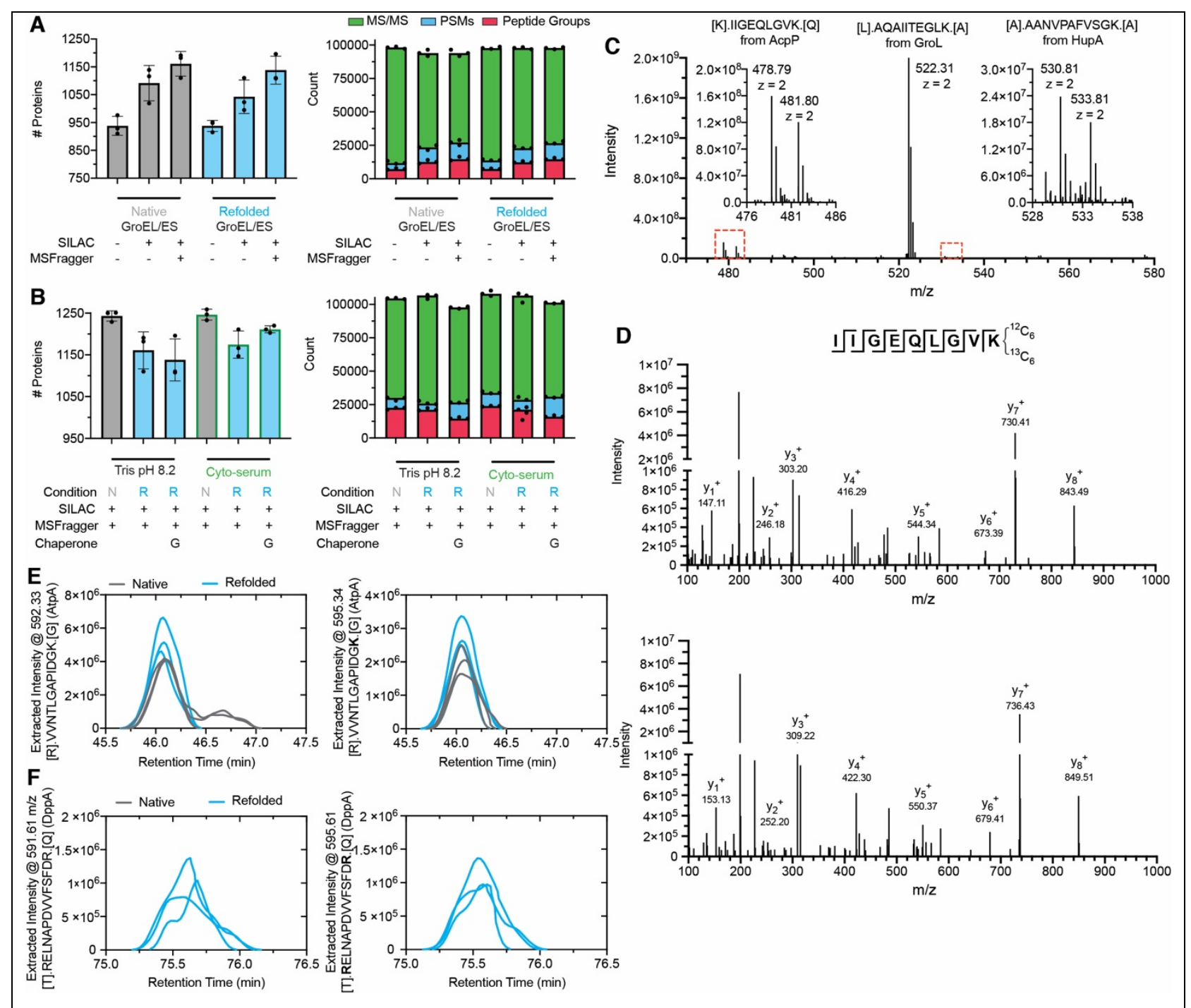

Figure 3. Pseudo-SILAC to distinguish extract-derived peptides from chaperone-derived peptides. (A) Bar charts showing the number of proteins and peptide groups identified, peptide-spectrum matches (PSM), and total MS/MS spectra obtained on individual runs, testing the effect of the pseudo-SILAC method and the MSFragger search algorithm. The number of MS/MS spectra acquired per run is similar, but pseudo-SILAC increases the number of unique PSMs and peptide groups by selecting features that are not chaperonin for data-dependent MS2 acquisition.

(B) Bar charts showing that the combination of pseudo-SILAC and MSFragger results in no significant loss in coverage in experiments conducted in cyto-serum and with GroEL/ES.

(C) A sample MS1 spectrum from a refolding experiment with GroEL/ES in cyto-serum. Peptides derived from refolded proteins, but not from chaperone, display twin-peaks separated by 3 Th (as expected for a doubly-charged peptide).

(D) Sample MS2 fragmentation spectra from two co-eluting peptides that differ only by the isotopic composition of the C-terminal lysine. The $y$-ions (indicated) are all displaced by 6 Th, as expected for singly-charged fragments. 
(E) Extracted ion chromatograms for the peptide indicated (from AtpA) in three replicate native samples and in three replicate refolded samples, at two m/z's corresponding to the light and heavy-substituted isotopes. The abundance of the peptide is similar in the native and refolded forms, in both isotope states, implying that this region of AtpA properly refolded; i.e., had the same PK susceptibility in both forms. (F) Similar to panel E, but for an all-or-nothing peptide from DppA which is not detected in any of the three native replicates at the $\mathrm{m} / \mathrm{z}$ for both the light and heavy-substituted isotope.

\section{GroEL/GroES Rescues Many Nonrefoldable Proteins}

GroEL/GroES significantly remodels the refoldability profile of the E. coli proteome, as a robust and general rescuer of intrinsically nonrefoldable proteins (Figure 4). In the volcano plot of our GroEL/GroES refolding assay (Figure 4A), there are many fewer peptides detected in the flanking robes (1736 (9.5\%) in cyto-serum, 691 (5.6\%) in cyto-serum with chaperonin) representing completely nonrefoldable regions within proteins. We chose to focus on the 5 min timepoint because in both cases, it optimized the proteome's refoldability (Figure S5A). After $5 \mathrm{~min}$, in cyto-serum $60 \%$ of 1080 proteins are refoldable intrinsically, and with the addition of GroEL/GroES, this rises to $85 \%$ of 998 proteins (Figure 4B), using a $\geq 2$ peptide cutoff to call a protein nonrefoldable (as used previously (To et al., 2021)). Overall refoldability rates do depend on this admittedly arbitrary cutoff employed to call a protein nonrefoldable; however, the $\geq 2$ peptide cutoff can be viewed as a sensible compromise between not allowing too much weight to be assigned to a single significant peptide, and not making it too difficult to call a protein nonrefoldable with lower coverage. Importantly, none of the key trends we describe in the following depend sensitively on this choice (Figures 4B, S6G-I).

To contextualize this experiment, we first sought to compare these results to two landmark studies interrogating $E$. coli chaperonin usage across the proteome. Kerner et al. (2005) formalized a classification system based on the enrichment level of various proteins in the fraction that coprecipitates with a tagged GroEL/ES complex. Class I proteins are those that are de-enriched in the GroEL fraction relative to their level in the cytoplasm, whilst class III proteins are those that are highly enriched in the GroEL fraction. Complementing this study, Fujiwara et al. (2010) used an E. coli strain in which GroEL expression is arabinose dependent, and measured which proteins precipitate in the E. coli cytoplasm after GroEL expression is cut off by shifting cells from arabinose to glucose. Many (40\%) of the class III proteins were still soluble in the cytoplasm without chaperonin and were renamed class $\mathrm{III}^{-}$. 


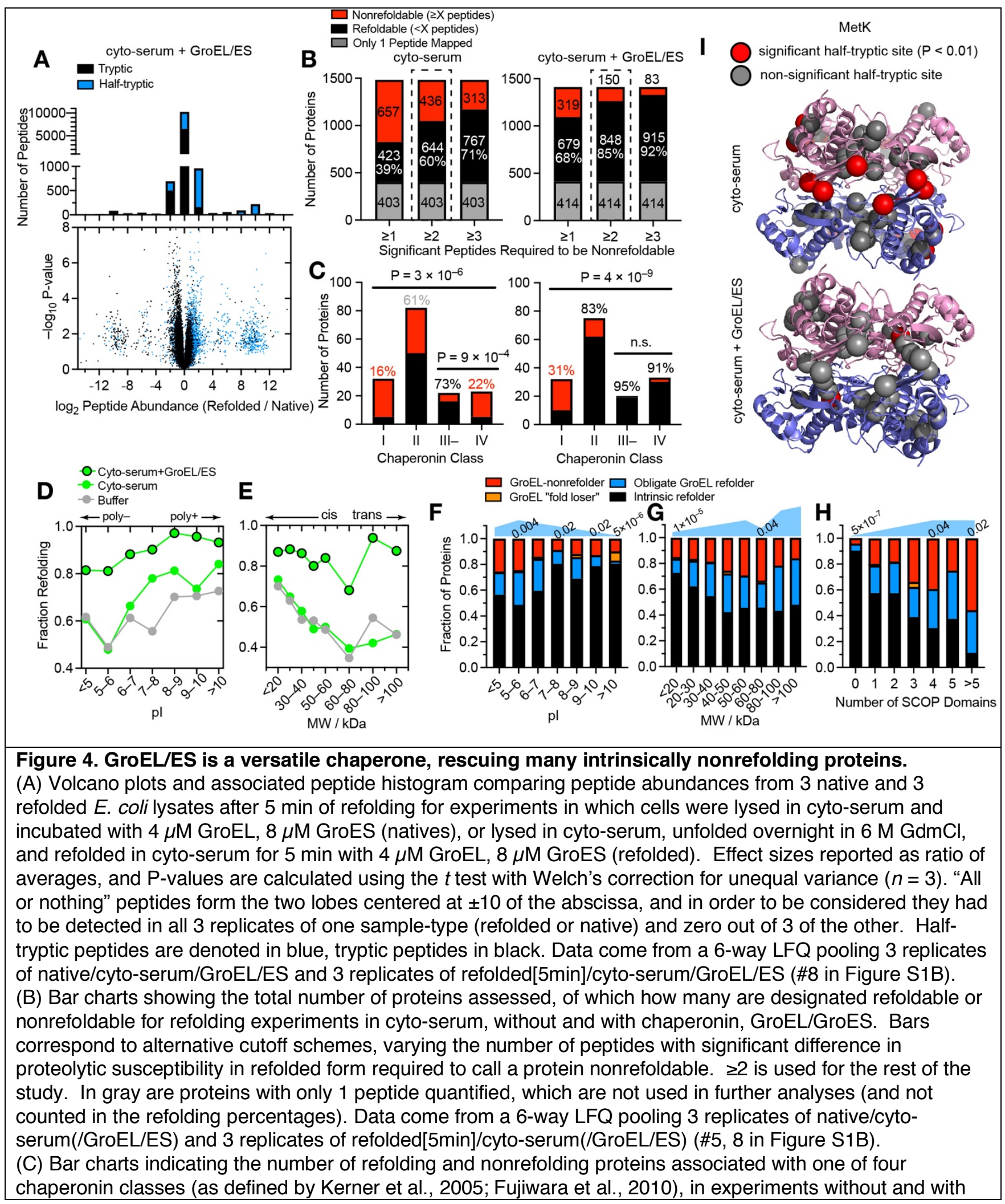


chaperonin. Percents indicate percentage refolding within that category. P-values for the all-way comparison are from chi-square test; for the two-way III- v. IV comparison are from Fisher's exact test. Data come from the same LFQs as the pie charts above.

(D) Fraction of proteins that refold in either Tris buffer (gray), cyto-serum (green), or cyto-serum with GroEL/ES (green, black border), separated on the basis of individual proteins' pl. Data come from 6-way LFQs pooling 3 replicates of either: native/Tris and refolded[5min]/Tris; native/cyto-serum and refolded[5min]/cyto-serum; native/cyto-serum/GroEL/ES and refolded[5min]/cyto-serum/GroEL/ES (\#2, 5, 8 in Figure S1B).

(E) Fraction of proteins that refold in either Tris buffer (gray), cyto-serum (green), or cyto-serum with GroEL/ES (green, black border), separated on the basis of individual proteins' molecular weight (MW). Data come from same LFQs as panel D.

(F) Frequency of proteins that refolded in both conditions (intrinsic refolder; black), only with GroEL/ES (obligate GroEL refolder; blue), only without GroEL/ES (GroEL "fold loser"; orange), or did not refold in either (Nonrefolder; red), separated on the basis of individual proteins' isoelectric points ( $\mathrm{pl}$ ). Data used for $\mathrm{F}$ is a 12way LFQ pooling 3 replicates of native/cyto-serum, 3 replicates of refolded[5min]/cyto-serum, 3 replicates of native/cyto-serum/GroEL/ES, and 3 replicates of refolded[5min]/cyto-serum/GroEL/ES (\#e in Figure S1C). Analysis covers 987 proteins for which at least 2 peptides could be confidently quantified in both conditions. Numbers listed above bars indicate P-value by the chi-square test. Blue shape qualitatively denotes sets with higher need for GroEL.

(G) Frequency of proteins that refolded in both conditions, only with GroEL/ES, only without GroEL/ES, or did not refold in either, separated on the basis of individual proteins' molecular weight (MW). Data used for $G$ is the same 12-way LFQ as panel F.

(H) Frequency of proteins that refolded in both conditions, only with GroEL/ES, only without GroEL/ES, or did not refold in either, separated on the basis of the number of domains in the protein, as defined by the SCOP database. Data used for $\mathrm{H}$ is the same 12-way LFQ as panel $\mathrm{F}$.

(I) Structure of MetK (PDB: 1P7L), a protein that refolds with GroEL, but not without. Top, structure of native MetK illustrating the location of 9 PK cut-sites (based on 9 half-tryptic peptides) with significantly different susceptibility in the refolded sample, after folding in cyto-serum (red spheres). Bottom, same structure but illustrating the location of the one PK cut-site with significantly different susceptibility in the refolded sample, after refolding cyto-serum and GroEL/ES.

Our refolding assay is strikingly consistent with Fujiwara's sub-classification (Figure 4C).

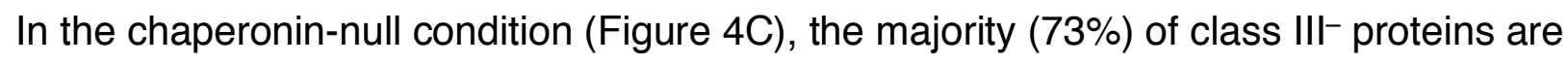
refoldable, whereas only a minority (22\%) of class IV proteins are. The observation concerning class $\mathrm{III}^{-}$proteins implies, intriguingly, that there are many proteins that associate with GroEL in vivo that do not actually require it. The strong alignment between class IV and nonrefoldability implies that most class IV proteins populate misfolded states which aggregate at the high concentrations of the cellular environment, but in our assay instead persist as soluble misfolded states that do not aggregate but also cannot correct themselves. The observation that a few class IV proteins are refoldable in our assay suggests that in these situations, GroEL's function is to serve as an obligatory holdase, a function that is no longer necessary when aggregation is suppressed. With chaperonin added to the refolding reactions, both class $\mathrm{III}^{-}$and class IV proteins are nearly completely refoldable $(95 \%$ and $91 \%$ respectively, Figure $4 \mathrm{C}$ ). This finding implies that the majority of GroEL's obligate clients 
(class IV) require it actively (e.g., either as a foldase or unfoldase), not merely as an infinitedilution chamber (e.g., holdase) (Brinker et al., 2001). We note that class IV proteins are somewhat more refoldable in Tris-buffer (which suppresses aggregation further via $\mathrm{pH}$ ) than in cyto-serum (39\% vs $22 \%$ ), hence in the cytosolic medium, GroEL's assistance is even more needed (because of greater aggregation propensity) than it is in the Tris-based refolding buffer.

Our data further elucidate the types of proteins that tend to be obligate GroEL refolders (Figure 4D-H). In general, GroEL has a disproportionately beneficial effect on protein types that are less intrinsically refoldable. For instance, proteins with lower isoelectric points $(\mathrm{pl}<7)$ tend to be less intrinsically refoldable, but GroEL removes this distinction (Figure 4D, F). Since the cavity walls of GroEL are negatively charged (Tang et al., 2006; Tang et al., 2008), it would be expected to create a 'repulsive field' for acidic proteins that could facilitate their compaction, overcoming the inter-residue electrostatic repulsion within a protein chain that would counter its tendency to compact. Inspection of the distribution of obligate GroEL refolders, broken down by pl range (Figure 4F), shows that obligate GroEL refoldability peaks for mildly acidic proteins $(5<\mathrm{pl}<6 ; 26 \%)$, is lower for proteins that are neutrally-charged in the cytosol $(7<\mathrm{pl}$ $<8 ; 11 \%$ ), and is lowest for basic proteins ( $\mathrm{pl}>10 ; 2 \%)$. Indeed, polybasic proteins $(\mathrm{pl}>10)$ are enriched for the rare category of proteins that lose their intrinsic capacity to refold in the presence of chaperonin (which is $<1 \%$ of all proteins overall). This may be because such proteins would be more likely to get stuck in the cavity. Such a tendency might explain why polybasic proteins were under greater evolutionary pressure to be efficient intrinsic refolders, especially in the cytosol (Figure 4D, F).

Proteins with high molecular weight (MW) tend to be less intrinsically refoldable, but GroEL smooths over this difference (with an important exception for proteins sized 60-80 $\mathrm{kDa}$ ), exerting its most prominent rescuing power on proteins of greatest molecular weight (Figure 4E, G). The discontinuity for proteins sized 60-80 kDa has previously been attributed to the dimensions of the GroEL cavity, which is known not to accommodate proteins larger than $60 \mathrm{kDa}$ (Kener et al., 2005). However, we find that GroEL is extremely effective at assisting the largest $E$. coli proteins, with the highest frequency of obligate GroEL refolders falling into categories $>80 \mathrm{kDa}$ (Figure $4 \mathrm{G}$ ). These observations are consistent with the theory 
that the unsealed trans cavity of GroEL is also an active chaperone, and are consistent with previous works that have found activity of GroEL on large substrates (Chaudhuri et al. 2001; Chaudhuri et al. 2009; Farr et al., 2003; Paul et al., 2007). The large (>80 kDa) obligate GroEL refolders are all (100\%) multi-domain proteins, wherein potentially one non-native domain could fit in the unsealed trans cavity. Indeed, we find a robust trend that proteins with more domains up to 4 become progressively more reliant on GroEL, though proteins with $>5$ domains appear to be poor refolders even with GroEL (Figure 4H). Together, these findings provide strong support for the view that the trans mechanism is effective at resolving misfolded domains in the context of large multi-domain proteins.

All of the trends that we observed for refoldability in relation to $\mathrm{pl}, \mathrm{MW}$, and chaperonin class are statistically significant at the peptide level as well ( $P$-values range from $10^{-5}$ to $10^{-31}$ by the chi-square test), implying that these differences in refoldability cannot be attributed to coverage bias (Figure S6A-C). Furthermore, the protein-level trends are not sensitive to the peptide cutoff to call a protein nonrefoldable (Figure S6G-I). We also found a few intriguing correlations between GroEL usage patterns and subunit composition, cellular location, and cofactors (Figures S6D-F). Monomers and assemblies of all sizes benefit from GroEL's assistance, though with a noticeable dip at dimers and trimers, which is intriguing because these assemblies are the most likely to assemble co-translationally (Shiber et al., 2018; Shieh et al., 2015; Bertolini et al, 2021) (Figure S6D). Tetramers and hexamers are most likely to be obligate GroEL refolders (32\% and 39\% respectively), consistent with several model GroEL clients being tetramers like MetF (Singh et al., 2020) and DapA (Georgescauld et al., 2014; Ambrose et al., 2015) (Figure S7A-B). Proteins in large complexes with $>6$ subunits are the least reliant on GroEL (Figures S6D, S7B). GroEL is effective at recovering proteins in all $E$. coli locations (cytosol, periplasmic space, and membranes; Figures S6F, 7C). Finally, we find that GroEL benefits cofactor-harbouring proteins, particularly proteins that host TPP, PLP, $\mathrm{Fe}^{2+}$, and $\mathrm{Zn}^{2+}$ (Figure S6E), which are generally less refoldable (cf. Figure $2 \mathrm{H}$ and (To et al., 2021)). Indeed, proteins that host these cofactors have the highest propensities to be obligate GroEL refolders (between 38-50\%, Figure S7D). This observation can be explained on account of the fact that $\mathrm{Fe}^{2+}$ and $\mathrm{Zn}^{2+}$ form strong near-covalent linkages with the coordinating 
residues Cys and His. Hence, incorrect coordination would create an energetically entrenched misfolded state that might require energy input to undo.

\section{Effect of Chaperonin on Refolding Kinetics}

Classic protein folding kinetics studies, typically carried out on small single-domain proteins, record folding times on the ms-s timescales (Bartlett and Radford, 2009). Because of the duration of the PK incubation time $(1 \mathrm{~min})$, our experiments do not afford the same level of temporal resolution; however, comparisons between refoldability levels at the 1 min and 5 min timepoints can provide insight into the types of proteins that refold slowly (i.e., require more than $1 \mathrm{~min}$ ) - both with and without chaperonin (Figure 5).

In cyto-serum, overall refoldability increases from $52 \%$ to $60 \%$ from 1 to $5 \mathrm{~min}$, a similar uptick as to what we observe in the chaperonin refolding experiment (77\% to $85 \%$ ). However, the types of proteins that benefit from additional time were distinct in these two settings. From $5 \mathrm{~min}$ to $2 \mathrm{~h}$ the overall refoldability in cyto-serum slightly decreases, which we attribute to a mix of degradation and aggregation (Figure S5A, B, E). On the other hand, with chaperonin, refolding decreases precipitously at $2 \mathrm{~h}$ (down to 74\%), presumably because of depletion of ATP.

In the chaperone-null condition (Figure 5A, C), slow refolders tend to have high pl (>10; Figure 5A) or be class III- (Figure 5A-B). These features are readily explainable: highly polycationic proteins would have significantly more intra-chain repulsion that would slow down

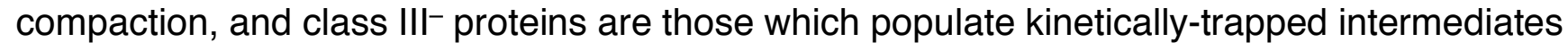
that can, given time, can self-correct. Such proteins employ GroEL in vivo as a non-obligatory holdase. Conspicuously absent from this set are proteins with many domains, high MW, low pl (<6, polyanions), and class IV proteins (Figure 5A, C, E, G). In all cases, it is because rather than fold slowly, these categories tend to be intrinsically nonrefoldable. On the other hand, it is interesting to notice an enrichment for very slow refolding (i.e., requiring more than $5 \mathrm{~min}$ ) for proteins with higher MW (Figure 5E).

With chaperonin, proteins with many domains tend to refold slowly, suggesting that GroEL can resolve misfolded forms populated by these proteins, but likely at the cost of additional annealing cycles (Figure $5 \mathrm{H}$ ). We find few differences in the rate for folding high- 
MW or low-MW proteins, a contrast with chaperone-null conditions in which high-MW proteins that fail to refold quickly generally do not recover within 5 min (Figure 5E-F). Proteins with low pl are still not particularly slow refolding, but now for the opposite reason: because GroEL is unusually expeditious at refolding them, so they have mostly refolded within 1 min (Figure 5B). On the other hand, proteins with very high pl are slow refolders in GroEL (even though they ultimately nearly all refold after $5 \mathrm{~min}$ ). This may be because such proteins would tend to stick to GroEL's negatively charged lumen, which could render it a less efficient chaperone for these clients. Finally, both class III- and class IV proteins are refolded rapidly by GroEL (Figure 5D),

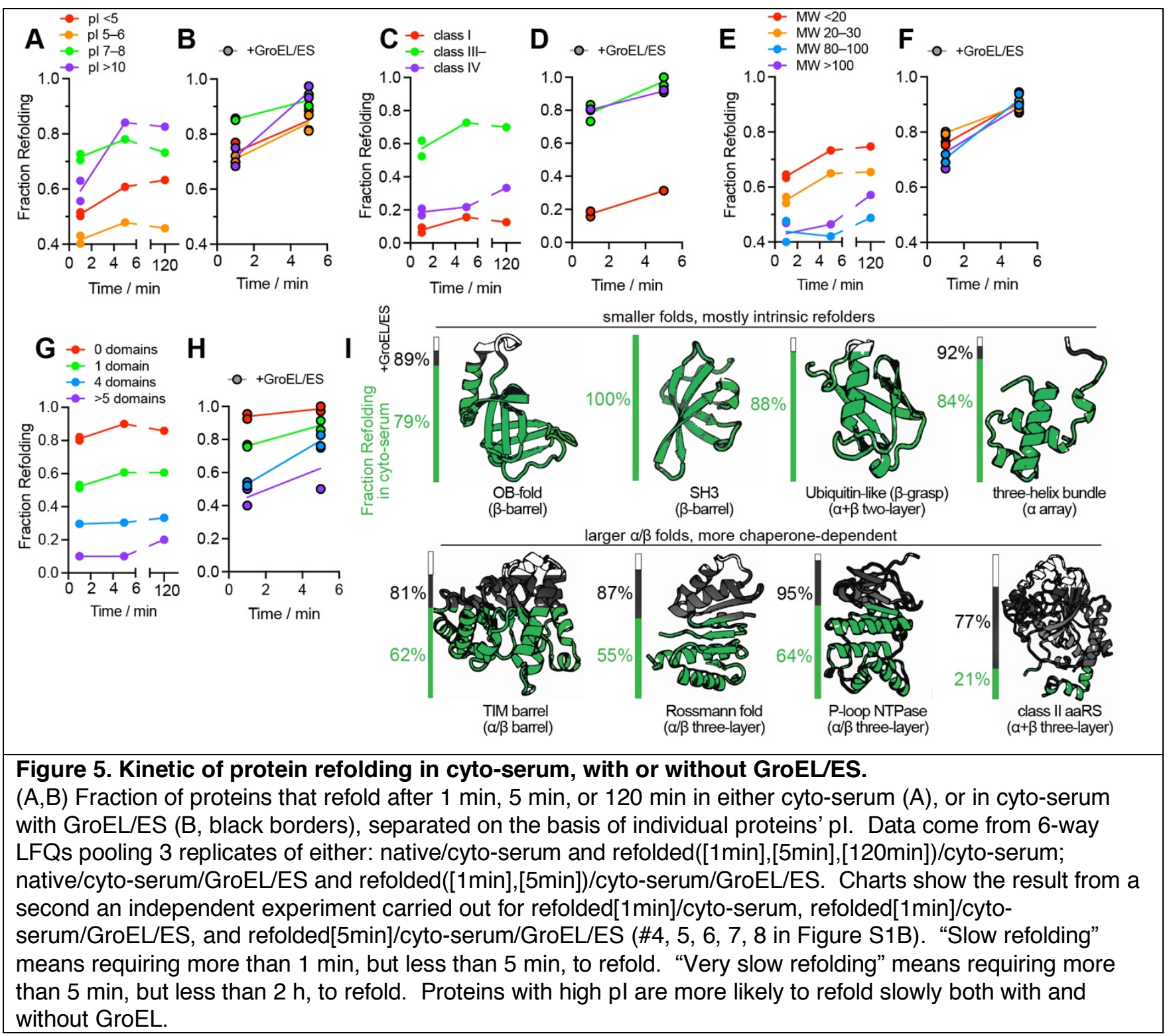


$(C, D)$ Fraction of proteins that refold after $1 \mathrm{~min}, 5 \mathrm{~min}$, or $120 \mathrm{~min}$ in either cyto-serum (C), or in cyto-serum with GroEL/ES (D, black borders), separated on the basis of chaperoin class (Kerner et al., 2005; Fujiwara et al., 2010). Data come from same 6-way LFQs as panels A and B. In cyto-serum, class III- proteins are more likely to refold slowly, and class IV proteins are more likely to refold very slowly; but not with GroELES. $(E, F)$ Fraction of proteins that refold after $1 \mathrm{~min}, 5 \mathrm{~min}$, or $120 \mathrm{~min}$ in either cyto-serum (E), or in cyto-serum with GroEL/ES (F, black borders), separated on the basis of molecular weight (MW). Data come from same 6way LFQs as panels A and B. In cyto-serum, high-MW proteins are more likely to refold very slowly; but not with GroEL/ES.

$(\mathrm{G}, \mathrm{H})$ Fraction of proteins that refold after $1 \mathrm{~min}, 5 \mathrm{~min}$, or $120 \mathrm{~min}$ in either cyto-serum $(\mathrm{G})$, or in cyto-serum with GroEL/ES ( $\mathrm{H}$, black borders), separated on the basis of number of domains, as defined by the SCOP database. Data come from same 6-way LFQs as panels A and B. In cyto-serum, proteins with more than 5 domains are more likely to refold very slowly. With GroEL/ES, proteins with 4 or more than 5 domains are more likely to refold slowly.

(I) Fraction of domains that refold in either cyto-serum (green) or cyto-serum with GroEL/ES (black), separated on the basis of which Fold the domain is assigned to in the SCOP hierarchy. Data come from 6-way LFQs pooling 3 replicates of either: native/cyto-serum and refolded[5min]/cyto-serum; native/cyto-serum/GroEL/ES and refolded[5min]/cyto-serum/GroEL/ES (\#5, 8 in Figure S1B). For these analyses, half-tryptic and tryptic peptides were mapped to the individual domains within a protein, based on residue ranges from alignments to HMMs. Smaller domains, especially those that are primarily $\beta$-sheet, refold well intrinsically. Larger domains with $\alpha / \beta$ three-layer architectures rely more heavily on chaperonin.

consistent with kinetic models that suggest these proteins rapidly sort to GroEL (Powers et al., 2012; Santra et al., 2017). To summarize, GroEL likely requires a greater metabolic cost and more annealing cycles to refold proteins with many domains and with positive charge.

\section{GroEL/ES is Crucial for Folding a/ $\beta$ Folds}

Because our PK susceptibility measurements can be resolved down to individual residue locations, it is possible to assign nonrefolding sites to specific structural domains within proteins. Using the SCOP database (structural classification of proteins (Gough et al., 2001; Pandurangan et al., 2019)), such domains can be grouped into fold-types, reflecting deep evolutionary relationships between domains that share a common topology despite having very different sequences and functions. The intrinsic refoldability levels of different folds in cyto-serum largely preserve trends previously observed (Figure 5I) (To et al., 2021). In particular, small domains with 'simple' topologies (low contact order (Plaxco et al., 1998)) tend to be the most refoldable, such as OB-folds (79\%), 3-helical bundles (84\%), ubiquitin-like folds (88\%), and SH3 barrels (100\%). The specialized folds that are unique to aminoacyl-tRNA synthetases (aaRSs) are generally the least intrinsically refoldable, namely the adenine nucleotide a-hydrolase-like fold (46\%, the core of class I synthetases), and the class II aaRS core fold $(21 \%)$. TIM barrels display slightly lower-than-average levels of refoldability in cytoserum (62\%, average is $64 \%$ ). 
GroEL has a profoundly restorative effective on these fold-types (Figure 5I), elevating the refolding frequencies of the class I and class II aaRS folds to $83 \%$ and $77 \%$ respectively. In our experiment, GroEL rescued many TIM barrels (raising their refolding frequency to $81 \%$ ) which is consistent with the previous observation that GroEL has a strong preference to coprecipitate TIM barrel-containing proteins (Kerner et al., 2005; Georgescauld et al., 2014). However, we found additionally that GroEL had very pronounced effects on assisting Rossmann-folds (of both the NADH-binding (55\% to 87\%) and SAM-binding (73\% to 100\%) sub-lineages), P-loop NTPases (64\% to 95\%), and PRTase-like domains (29\% to 100\%). All of the fold-types that disproportionately benefit from GroEL have $a / \beta$ architectures (Cheng et al., 2014; Schaeffer et al., 2017) (with the exception of the class II aaRS fold, which is $a+\beta$ ). In the presence of GroEL, we find that all fold-types are highly refoldable, implying that GroEL smooths over the intrinsic differences in refoldability associated with different protein topologies.

\section{DnaK is Also a Versatile Chaperone that Complements GroEL}

Along with GroEL/GroES, the other key chaperone in E. coli is DnaK (Hsp70), which operates with its co-chaperone DnaJ (Hsp40) and a nucleotide exchange factor, GrpE (Rosenzweig et al., 2019; Mayer and Gierasch, 2019). In experiments conceptually similar to those described in the previous sections (Figures 6), we performed global refolding assays in which $5 \mu \mathrm{M}$ DnaK, $1 \mu \mathrm{M}$ DnaJ, and $1 \mu \mathrm{M}$ GrpE were supplemented into the cytoserum refolding dilution buffer (as well as to the native samples, as in Figure 1A). Initial analysis provided poor coverage (759 proteins total; Figure S5A-B), owing to the fact that DnaK, DnaJ, and GrpE (abbreviated as DnaK/J/E) are cleaved by Proteinase K at many locations, and accounted for $1038(11 \%)$ of all peptides quantified. To rectify this matter, we performed a 12way LFQ in which raw spectra from the three biological replicates of cyto-serum/GroEL+GroES native and refolded, and the three biological replicates of cyto-serum/DnaK+DnaJ+GrpE native and refolded were analyzed together, and peptides identified and quantified in the 6 DnaK channels were then extracted (see Methods, Figure S1). Through this approach, peptides present in the DnaK/J/E refolding samples 


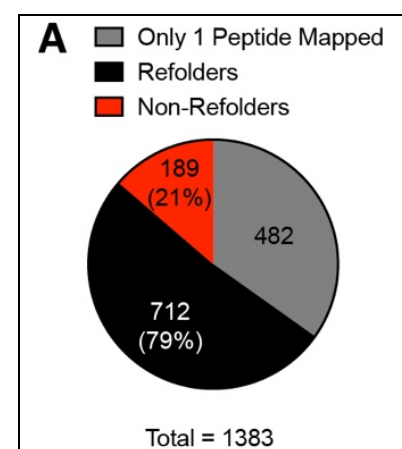

C

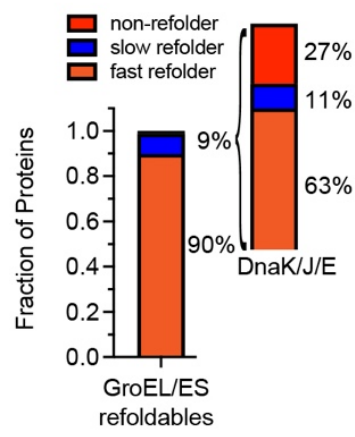

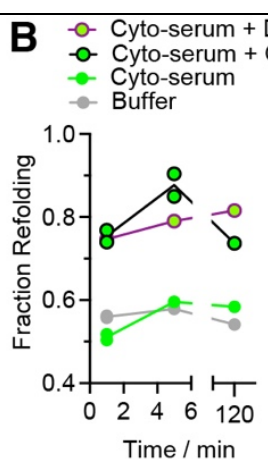

D

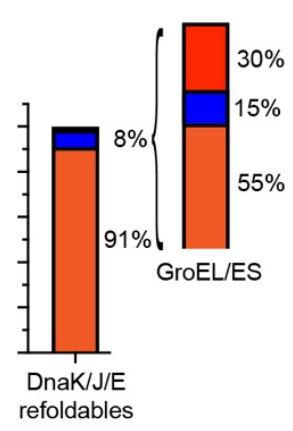

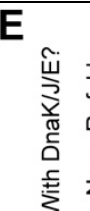
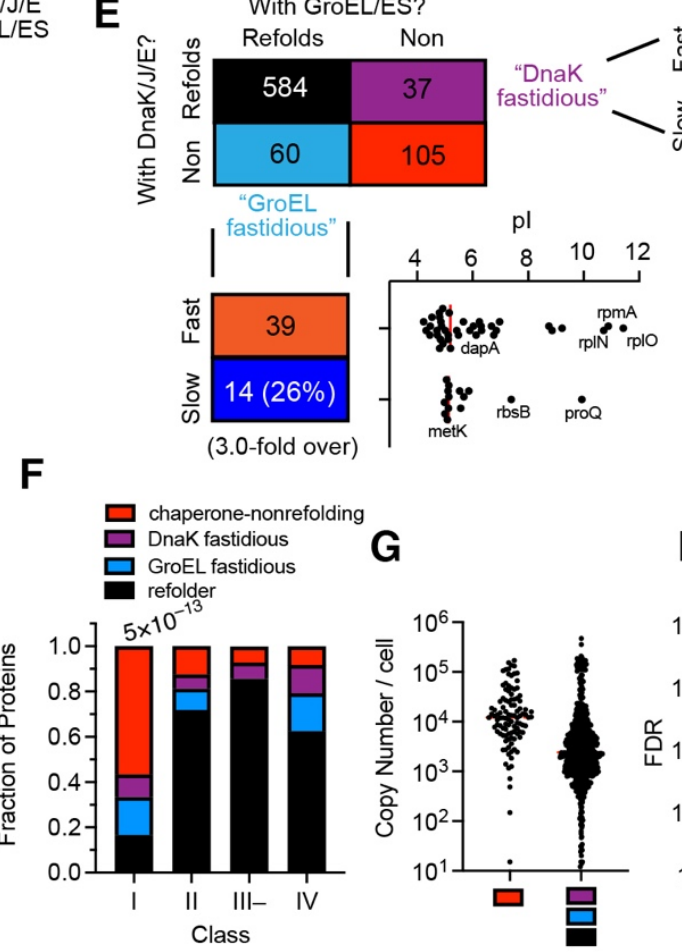

G

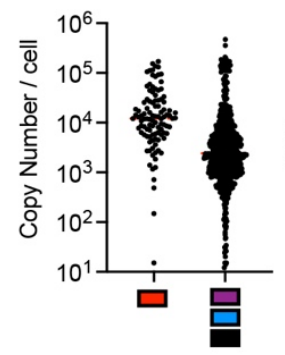

Figure 6. DnaK/DnaJ/GrpE (Hsp70/40) refolds many E. coli proteins, with only a few that are fastidious for one chaperone over the other.

(A) Pie charts showing the total number of proteins assessed, of which how many are designated refoldable (black; 0 or 1 peptides with significant difference in proteolytic susceptibility in refolded form) or non-refoldable (red; 2 or more peptides with significant difference in proteolytic susceptibility in refolded form) for refolding experiments in cyto-serum with DnaK/J/E. In gray are proteins with only 1 peptide quantified, which are not used in further analysis (or counted in the refolding percentages). Data come from a 12-way LFQ pooling 3 replicates of native/cyto-serum/GroEL/ES, 3 replicates of refolded[5min]/cyto-serum/GroEL/ES, 3 replicates of native/cyto-serum/DnaK/J/E, and 3 replicates of refolded[5min]/cyto-serum/DnaK/J/E, with the identifications and quantifications from the 6 DnaK channels extracted out (\#h in Figure S1C).

(B) Fraction of proteins that refold after $1 \mathrm{~min}, 5 \mathrm{~min}$, or $120 \mathrm{~min}$ in either buffer (gray), cyto-serum (green), cyto-serum with GroEL/ES (green, black borders), or cyto-serum with DnaK/J/E (green, purple borders). Uses \#1-9 in Figure S1B and \#g-i in Figure S1C.

(C) Frequency of slow refolding with GroEL/ES. This covers the 740 proteins that refolded within 1 min in the cyto-serum/GroEL/ES experiment (called 'fast refolders') or did not refold within 1 min but did refold within 5 $\mathrm{min}$ in the cyto-serum/GroEL/ES experiment (called 'slow refolders'). Of the 66 proteins that refold slowly with GroEL, the frequency bar to the right shows the frequency of proteins that refolded fast (within $1 \mathrm{~min}$ ), slow (not within $1 \mathrm{~min}$ but within $5 \mathrm{~min}$ ), or not at all in the cyto-serum/DnaK/J/E experiments. Uses \#7, 8 in Figure S1B. (D) Frequency of slow refolding with DnaK/J/E. This covers the 638 proteins that refolded within 1 min in the cyto-serum/DnaK/J/E experiment (fast refolders), or did not refold within $1 \mathrm{~min}$ but did refold within $5 \mathrm{~min}$ in the cyto-serum/DnaK/J/E experiment (slow refolders). Of the 49 proteins that refold slowly with DnaK, the frequency bar to the right show the frequency of proteins that refolded fast, slow, or not at all in the cytoserum/GroEL experiments. Uses \#g, h in Figure S1C.

(E) Truth table summarizing the results of the 12-way LFQ pooling 3 replicates of native/cyto-serum/GroEL/ES, 3 replicates of refolded[5min]/cyto-serum/GroEL/ES, 3 replicates of native/cyto-serum/DnaK/J/E, and 3 replicates of refolded[5min]/cyto-serum/DnaK/J/E (Uses \#h in Figure S1C). Analysis covers 786 proteins for which at least 2 peptides could be confidently quantified in both conditions. Proteins that refold only with GroEL/ES are called "GroEL fastidious" (light blue) and those only with DnaK/J/E are called "DnaK fastidious" (purple). Shown also is, among the DnaK fastidious proteins, how many refold fast or slow with DnaK; and among the GroEL fastidious proteins, how many refold fast or slow with GroEL. pl and MW distributions for the 
GroEL fastidious proteins are given, broken down by whether they are fast GroEL refolders or slow GroEL refolders.

(F) Frequency of proteins that refolded in both conditions (black), only with GroELES (light blue), only without DnaK/J/E (purple), or did not refold in either (chaperone-nonrefolder; red), separated on the basis of

chaperonin class (Kerner et al., 2005; Fujiwara et al., 2010). Data used for F is the same 12-way LFQ as panel E. Numbers listed above bars indicate P-value by the chi-square test.

(G) Abundance of the 105 chaperone-nonrefolding proteins, compared to the other 681 in this analysis, according to Li et al. (2014).

(H) Gene ontology enrichment analysis of the 105 chaperone-nonrefolding proteins, compared to the E. coli genome, using PantherDB (Mi et al., 2019)

that failed to be identified can be identified if they match a feature (in retention time and $\mathrm{m} / \mathrm{z}$ ) that was sequenced in the corresponding GroEL samples. It is important to point out that since our analysis is by LFQ and all samples are injected separately, pseudo-SILAC quantification of DnaK/J/E samples is unaffected by the GroEL samples. With this change, the DnaK experiment's coverage improved: we could quantify 11445 peptides (Figure S5D), making refoldability assessments on 901 proteins (Figure S5C), comparable to that of the GroEL experiment (998 proteins, 12562 peptides).

DnaK results in $79 \%$ of the E. coli proteome refolding after 5 min (Figure 6A), comparable but slightly less to that of GroEL (85\%). Indeed, virtually all of the refoldability trends we found for GroEL were echoed with DnaK. This includes: a flattened pl-dependence (Figure S9A), a flattened MW-dependence with a less pronounced dip at 60-80 kDa (Figure S9B), and very little dependence on subunit count (Figure S9C). The most salient difference is DnaK is somewhat worse at refolding large >80 kDa proteins $(77 \%)$ compared to GroEL (91\%). Class I proteins remain challenging candidates for DnaK (25\% refoldable) and class IV proteins appear to partially benefit from DnaK (refolding at 75\%), though maintain a preference for GroEL (which restores 91\% of them), as expected (Figure S9D).

One feature that is distinct and also quite telling about DnaK is that its time dependence is very different from GroEL's (Figure 6B). At $1 \mathrm{~min}$, its refolding performance on the E. coli proteome is similar to that of GroEL's, and it proceeds to steadily increase up to $2 \mathrm{~h}$. This is unlike GroEL's dependence which shows a major increase at $5 \mathrm{~min}$, and then decreases significantly at $2 \mathrm{~h}$. The latter observation could potentially be explained by pointing out that after $2 \mathrm{~h}$, GroEL exhausts its ATP supply whereas DnaK (which uses 1 ATP per cycle rather than 7) might not. 
Our results suggest that a refolding problem that is 'challenging' for one chaperone is not necessarily challenging for another. For instance, when we look at the minority of GroEL/ES refolders that required more than $1 \mathrm{~min}$ to refold (slow refolders, 66 proteins in total), the majority are refolded quickly by DnaK (Figure 6C). Ipso facto, for the minority of DnaK/J/E refolders that required more than $1 \mathrm{~min}$ to refold (51 proteins in total), the majority are refolded quickly by GroEL (Figure 6D). Hence, the strengths of these chaperones are complementary for certain difficult clients.

In our 12-way LFQ that includes both the GroEL and DnaK refolding conditions at the 5 min timepoint, we identify 786 proteins for which 2 or more peptides were detected in each condition (Figure 6E), thereby permitting an independent of assessment of refoldability under both conditions (see Figure S5F for other timepoints). We find that most proteins that refold under GroEL also refold under DnaK, with only a small subset of proteins that appear to be specialized for GroEL (60 total) or DnaK (37 total). We will refer to the clients that can only refold with one chaperone or the other as 'fastidious' clients.

Whilst the GroEL-fastidious clients mostly refold rapidly with GroEL (74\%), we do find a surprisingly large number that refold slowly with GroEL (26\%), 3-fold more frequent than slow GroEL-refolding in general (cf. Figure 6C). It is instructive to divide the GroEL-fastidious clients into subgroups that refold quickly with GroEL and slowly with GroEL. The fast-refolding GroEL-fastidious clients are disproportionately acidic (the median pl of this group is 5.13 with 3 ribosomal proteins discounted) and low-MW (with 3 exceptions, though these high-MW proteins have many smaller domains). These proteins therefore most likely require GroEL's foldase activity (folding inside the cage (Brinker et al., 2001)). On the other hand, the GroELfastidious clients that refold slowly are perhaps those with highly entrenched misfolded states that require higher energy inputs to unfold and multiple iterative annealing cycles to fully correct. These proteins therefore most likely employ GroEL's stronger unfoldase activity. This hypothesis is supported by the fact that this group includes the well-known obligate GroEL client, MetK (Figure 4I).

DnaK-fastidious clients also have a surprisingly large number of cases that refold slowly with DnaK (29\%), 3.8-fold more frequent than slow DnaK refolding in general. One hypothesis is that these proteins may form misfolded states that aggregate very rapidly, and therefore rely 
on DnaK's disaggregase activity, a function that GroEL lacks. Supporting the theory that DnaK can disaggregate proteins in our refolding experiments is the finding that it almost entirely prevents 'fold-losing' at later time points (Figure S5E, a feature unique to it), and that, where the data was available for comparison, all the DnaK-fastidious proteins (HemB, PyrC, Prs, SerC, Tgt, Ugd) were found to be aggregation-prone in the solubility assays of Chiba et al. (2012).

\section{Chaperone-Nonrefolders}

The most obvious feature of the DnaK/GroEL cross-correlation dataset (Figure 6E) is that there are many proteins that do not refold with either GroEL or DnaK, and in fact the most predictive descriptor for whether a protein cannot refold with GroEL is whether it cannot refold with DnaK and ipso facto (odd's ratio $=51.4$; P-value $<10^{-66}$ by Fisher's exact test). We refer to this cohort of 105 proteins as 'chaperone-nonrefolders.' It should be pointed out that some of these proteins could potentially be refolded by other chaperones (Hsp90 and trigger factor), or require multiple chaperones in combination (Langer et al., 1992). We refer to them in the following as chaperone-nonrefolders for brevity's sake, though what is implied is ‘GroEL/DnaKnonrefolder.'

Class I proteins are highly over-represented in the cohort of chaperone-nonrefolders (Figure 6F): $59 \%$ of class I proteins are chaperone-nonrefolders compared to $14 \%$ in general (4.2-fold enriched, $P$-value $<10^{-13}$ by chi-square test). Class I proteins are those which were found to be de-enriched from the fraction of proteins that co-precipitate with GroEL/ES (Kerner et al., 2005). Because they do not associate strongly with GroEL in vivo, these proteins have historically been construed as efficient intrinsic refolders (Houry et al., 1999; Kerner et al., 2005; Santra et al., 2017). Our data suggests an alternative: that these proteins do not get entrapped within the GroEL/ES cavity because they fold efficiently on the ribosome cotranslationally. In so doing, these proteins bypass GroEL (which is preponderantly a posttranslational chaperone (Balchin et al., 2005)). On the other hand, if these proteins became habituated to folding co-translationally, it would also explain why they are recalcitrant to refolding from a full-length denatured form. Chaperone-nonrefolders are generally very abundant proteins (Figure 6G), and relative to the E. coli proteome, the set is greatly enriched 
for proteins that are involved in core metabolic processes (Figure 6H), such as glycolysis (21fold enriched, FDR $<10^{-7}$ ), fatty-acid biosynthesis (15-fold enriched, FDR $<10^{-5}$ ), and tRNA aminoacylation (13-fold enriched, FDR $<10^{-4}$ ).

We also find that this set of proteins is enriched for 'specialized' fold-types that have not diversified as broadly. For instance, we find that 10 of the 19 glycolytic-related enzymes are chaperone-nonrefolders (Figure 6H). Amongst this group are enzymes like phosphofructokinase (PfkA), phosphoglycerate kinase (Pgk), and malate dehydrogenase (Mdh). These enzymes each feature specialized folds (e.g., phosphofructokinase-like, phosphoglycerate kinase-like, and LDH C-terminal domain-like) of which in the E. coli proteome we only have data on one example, and in all cases that domain is chaperonenonrefolding. There is also a great over-representation of aminoacyl-tRNA synthetases in this group (8 in total), including: AspS, PheT, GlyS, LeuS, ProS, GInS, SerS, ThrS. It is notable that all of these synthetases except LeuS and GInS are class II synthetases. Moreover, previous refolding assays on purified ThrS have shown that no combination of GroEL and DnaK can reactivate it beyond $\sim 50 \%$ (Kerner et al., 2005), consistent with it (and possibly class II synthetases in general) as chaperone-nonrefolding. Hence, we conclude that abundant proteins that perform core metabolic functions in glycolysis and translation are especially likely to be chaperone-nonrefolding.

\section{DISCUSSION}

\section{Revising the Scope of Obligate GroEL Refolders}

Our study is consistent with aspects of, but also necessitates revision to, the consensus model of which E. coli proteins employ GroEL for efficient refolding. The consensus model is strongly influenced by the classic work by Kerner et al. (2005), in which rapid depletion of ATP was used to entrap GroEL clients within the cis cavity of the GroEL/ES complex. Pull-down on a His-tagged GroES then resulted in co-precipitation of GroEL interactors, which were identified with mass spectrometry. Proteins that were highly enriched in the GroEL fraction, which were termed class III proteins, were found to be generally low-abundance, between 30$60 \mathrm{kDa}$, and over-represent TIM barrel folds. By analyzing protein refoldability levels in cyto- 
serum vs. those in cyto-serum supplemented with GroEL and GroES, we can assess which of the proteins that get entrapped with GroEL also depend on it to refold. Our results concur with the finding that TIM barrels tend to be more GroEL-dependent (Figure 5I). On the other hand, the findings that GroEL is particularly important for refolding high-MW and low-pl proteins (Figure 4) are new. Why were these patterns not previously observed? Thoughtful reflection on what pull-down assays can and cannot show is instructive in this matter. High-MW proteins cannot be entrapped within the sealed GroEL/ES cis cavity, and therefore would be systematically excluded from pull-down assays. Indeed, previous work has highlighted a number of examples in which GroEL restored the activity of high-MW proteins that cannot fit inside the cavity, particularly aconitase (AcnB, 93 kDa) (Chaudhuri et al., 2009), which our study confirms can refold to a native structure in the presence of GroEL. Our experiment also confirms DNA gyrase (GyrA (97 kDa) and GyrB (90 kDa)) and MetE (85 kDa) can refold in the presence of GroEL, notable given that these proteins have been previously shown to interact with GroEL in vivo (Houry et al., 1999), even though they do not efficiently co-precipitate with it. Previous work showing that GroEL can refold high-MW proteins has been explained by positing that the trans cavity can also bind misfolded clients (Chaudhuri et al., 2009; Farr et al., 2003). Our results suggest that the trans mechanism represents a critical function of GroEL. Whilst E. coli does not have many high-MW proteins, these observations suggest that GroEL plays a significant role in their biogenesis, echoing the observation that TriC/CCT has been shown to operate on large proteins, which are more frequent in eukaryotes (Yam et al., 2008).

A second key feature that emerges from our set of obligate GroEL-refolders is the outsize role GroEL plays in refolding acidic proteins $(\mathrm{pl}<6)$. These observations can be explained by noting that the negatively charged interior of GroEL would exert a repulsive electrostatic field on acidic proteins, thereby accelerating their compaction. Supporting this view is the further observation that the group of slow GroEL refolders is deprived of proteins with low pl (Figures 5B, 6E). Indeed, the primary work which established the potential foldase activity of the GroEL cavity (Brinker et al., 2001) found that inside the cage, GroEL/ES accelerates productive folding (foldase) of $R$. rubrum RuBisCo but merely prevents aggregation of $B$. taurus rhodanese (holdase). Consistent with our model, RrRuBisCo has a low pl (of 5.6) whilst BtRhodanese does not (6.9). There is a plausible reason why this key 
relationship with pl was not detected previously: because GroEL refolds acidic protein expeditiously, they would not accumulate within it to become a large steady-state fraction of GroEL occupancy. Such assertions raise the obvious question: What about cationic proteins? Our study shows that $E$. coli protein with high $\mathrm{pl}$ are remarkably efficient intrinsic refolders, and particularly so in the cytosolic medium (Figures 2F and 4D, F). Ostensibly, cationic proteins experienced greater evolutionary pressure to be able to refold on their own because they cannot avail themselves of GroEL's foldase activity, and in fact tend to unproductively get stuck in it (Figure 4F). These observations highlight the usefulness of assays which characterizes the impact of chaperones on the structural outcome of their clients, which provide a complementary view to approaches that measure activity, aggregation, or coprecipitation.

\section{DnaK's Powers in Relation to GroEL's}

Hsp70s and the menagerie of co-chaperone J-domain proteins have attracted great interest in recent years, due to their importance in several diseases and the discovery that they can dissolve amyloid fibrils (Rosenzweig et al., 2019; Gao et al., 2015). Whilst several works have characterized the clientele of DnaK (Calloni et al., 2012;), it has not generally been possible to compare the activity of DnaK to GroEL using an identical assay under an identical set of conditions. Our LiP-MS approach provides a means to do this, and the only difference between our DnaK and GroEL experiments (which were conducted simultaneously on the same isotopically-labeled extracts) was which chaperones were supplemented into the native and refolding dilution buffers.

Our study shows that by and large, DnaK and GroEL refold the same clientele, with only a small number that are specialized (fastidious) for one or the other. These observations are consistent with the prevailing idea that the proteostasis network is integrated (Santra et al., 2017) rather than compartmentalized, with a large amount of redundancy built in: there may be proteins that prefer to use DnaK (because it requires less energy), or prefer to use GroEL (because they bind to it more rapidly), but ultimately most clients can use either. This finding is 


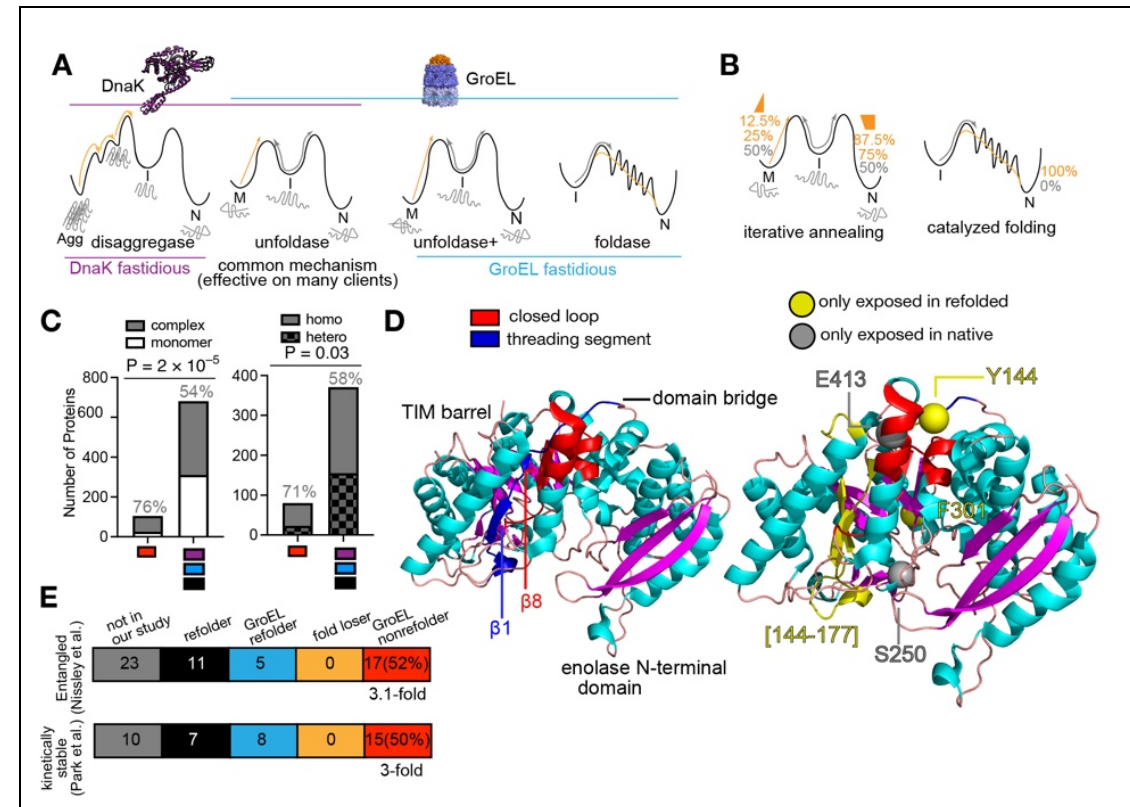

\section{Figure 7. A unified model for chaperone functions in E. coli}

(A) A model for the overlapping, but distinct, activities of DnaK and GroEL. Four chaperone functions are illustrated along with their effect on a protein's folding free energy diagram. Chaperone function shown with orange arrows, whereas intrinsic protein behaviour shown with gray arrows. Both DnaK and GroEL can perform unfoldase activity on misfolded states. DnaK is unique for its disaggregase activity. GroEL is unique because its unfoldase activity is stronger, and can resolve more entrenched misfolded states, and because its charged lumen can act as a foldase and catalyze folding, particularly for acidic proteins.

(B) Unfoldase activity will resolve proteins that kinetically partition into a misfolded state, but demands that the client ultimately has intrinsic capacity to fold itself in the cytosol. Foldase activity, in contrast, can fold proteins with no intrinsic folding capacity at all.

(C) Left, Number of proteins that are monomeric or in constitutive complexes for chaperone-nonrefolding proteins (as defined in Figure 6E) or for the other 681 in the analysis. Gray percentages represent fraction in complexes. P-value according to Fisher's exact test. Right, Number of proteins in complexes that are in homomers or in heteromers for chaperone-nonrefolding proteins or for the other proteins in the analysis. Gray percentages represent fraction in homomers. P-value according to Fisher's exact test. Uses \#h in Figure S1C. (D) Left, structure of E. coli enolase (PDB: 2FYM) showing the N-terminal domain, bridge, and C-terminal TIM barrel. Computational models predict potential formation of an entangled state whereby $\beta 1$ (blue) would thread through a loop closed by $\beta 8$ and the C-terminal a helix (red) (Ritaban et al., 2021). Right, locations of five all-ornothing peptides identified following refolding for $5 \mathrm{~min}$ in cyto-serum with GroEL/ES. Yellow represents regions only susceptible to $\mathrm{PK}$ in the refolded form; gray, only susceptible to $\mathrm{PK}$ in native form.

(E) Further analyses on GroEL-nonrefolding proteins (based on the same 12-way LFQ used for Figures 4F-H (\#e in Figure S1C)), correlating with separate studies which identified proteins that were found in a computational model to form entangled near-native states that would bypass recognition from chaperones (Top; Nissley et al., 2021); or that were found to be kinetically stable by remaining undigested by proteases for days (Bottom; Park et al., 2007). GroEL-nonrefolders are 3.1-fold enriched in the cohort of entangling proteins and 3-fold enriched in the cohort of kinetically stable proteins.

consistent with an emerging view that most chaperones share a common mechanism that can be effective on many clients, namely, unfoldase activity on misfolded states (Figure 7A) (Lin et al., 2008; Balchin et al., 2020; Macošek et al., 2021; Imamoglu et al., 2020), thereby providing 
those molecules with further opportunities to refold properly (the iterative annealing mechanism (Thirumalai and Lorimer, 2001)).

However, DnaK and GroEL also have aspects that make them unique (Figure 7A). In addition to being an unfoldase, DnaK is a disaggregase, whilst GroEL's cavity can also be a foldase (Balchin et al., 2020; Tang et al., 2006). Moreover, GroEL is a stronger unfoldase because its apical domain movements (which couple to unfolding) are driven by cooperative binding/hydrolysis of 7 ATPs. In some cases, GroEL's stronger unfoldase function may be required for a handful of clients that populate misfolded states that are deeply energeticallyentrenched (with MetK and DapA as important examples).

DnaK is also a disaggregase, a critical function that was probably rendered less important in our assay because of the low aggregation levels we encounter thanks to low concentrations and high complexity in our refolding reactions (Figures S2D, S3). It is likely that aggregation occurs less in these complex mixtures compared to experiments with purified proteins because aggregation is more efficient between molecules of the same type (Vecchi et al., 2020; Bianco et al., 2019). The few DnaK-fastidious refolders are likely those whose misfolded states aggregate rapidly enough (on the min-timescale) that GroEL does not have enough time to intercept them.

A further distinction between unfoldase and foldase activities merits discussion. Proteins whose folding employ chaperone unfoldase activity, by definition, must possess some intrinsic potential to fold themselves. Through iterative annealing, the chaperone eventually funnels all molecules into the desired free energy well (Figure 7B). On the other hand, proteins whose folding employ chaperone foldase activity could, in principle, have no ability to fold themselves intrinsically on a biologically-relevant timescale. Our experiment can distinguish between these scenarios because we annotate our peptides into all-or-nothing peptides (which represent regions that were completely inaccessible to PK in the native form and accessible in the refolded form) and peptides whose abundance is significantly different but nevertheless are detected in both sample-types (cf. Figure 2A-B). The former indicates regions that are 'completely nonrefolding' whilst the latter likely indicate regions that are 'partial nonrefolding,' in which the refolding reaction generates a mixture of conformations, wherein some of the molecules become native-like and others not. In cytosol, a minority (3.8\%, 638 in 
total, Figure S5B) of confidently quantified peptides are classified as all-or-nothing, and in turn a minority of proteins (which must have 2 or more all-or-nothing peptides) are classified as completely nonrefolding (151 in total, Figure S5A). As seen in the volcano plot (Figure 4A), GroEL/ES strikingly reduces the number of all-or-nothing peptides (from 638 to 235) and complete nonrefolders (from 151 to 40). In DnaK, many more all-or-nothing peptides are identified compared to GroEL/ES (396, 3.5\% of all confidently quantified peptides) as well as complete nonrefolders (72), despite overall lower coverage in the experiment (Figure S5C-D). Such a profile is consistent with the idea that serial application of unfoldase activity can (over many cycles) assist partial nonrefolders, eventually ratcheting them fully to the native conformation, but will leave behind complete nonrefolders that require foldase activity (Figure 7B). Because GroEL's cavity may be E. coli's only bona fide foldase, this model may explain why some clients are GroEL-fastidious.

\section{Chaperonins Potentiated A Great Expansion of $\alpha / \beta$ Folds}

Are certain types of protein topologies better at folding themselves than others? Our study suggests that under cellular-like conditions, small all- $\beta$ domain refold the best, specifically, ubiquitin-like folds, SH3 barrels, and OB-folds. These findings support the theory that all- $\beta$ domains were the earliest globular proteins, the immediate descendants of amyloids (Petrov et al., 2015; Bowman et al., 2020). On the other hand, the most expansive and versatile folds are all $\alpha / \beta$, and include TIM barrels, Rossmanns, P-loop NTP hydrolases, though these folds all display stronger dependence on GroEL (Cheng et al., 2014). The current view is that Hsp60s are very ancient, and possibly the only chaperone system the last universal common ancestor (LUCA) possessed (Rebeaud et al., 2021). In light of this, our study suggests that these fold-types co-emerged with chaperonin, and hence the emergence of chaperonin led to a great expansion of protein functional space attendant with them (Lindquist, 2009). Once these larger, more topologically complex domains could be efficiently folded, their functional versatility became accessible, and they became the most dominant architectures of the protein world. Our study therefore suggests a revised chronology for early protein evolution. Smaller all- $\beta$ architectures likely preceded the expansion of $\alpha / \beta$ architectures, which were enabled by the emergence of chaperonins and translation. A 
corollary of this thesis is that aminoacyl-tRNA synthetases (often considered as among the most ancient proteins) represent later additions, that emerged in tandem with translation and whose folding is dependent on it (Fried et al., 2021).

\section{Why Are Some Proteins Not Refoldable Even with Chaperones?}

The observation that a few E. coli proteins cannot fully refold from a denatured state with either GroEL or with DnaK invites conversation about how these proteins locate their native states in the first place. Some possibilities include these proteins require HtpG (E. colis Hsp90), trigger factor (TF), a combination of DnaK and GroEL, or the full complement of all $E$. coli chaperones. Whilst these explanations cannot be excluded, we favour a more parsimonious explanation: that these chaperone-nonrefolding proteins have a strong preference to fold cotranslationally on the ribosome. Several lines of evidence support this view.

The majority of these proteins are in complexes (80 out of $105,76 \%$ ), of which the majority (57 out of $80,71 \%$ ) are in homocomplexes (Figure 7C). Homomers have been shown to be the most likely to assemble during translation in a "co-co" fashion (wherein nascent chains assemble whilst both are in translation) (Bertolini et al., 2021). Our study suggests that this mode of assembly may be obligatory in many situations.

Two- and three-domain proteins are not especially represented in this group, suggesting that improper inter-domain compaction can normally be resolved post-translationally with chaperones (Imamoglu et al., 2020). On the other hand, proteins with 4 or more than 5 domains are greatly over-represented in this group (Figure S9F), suggesting that for proteins with high domain counts, the vectorial synthesis of translation to decouple domain folding and preclude inter-domain contacts becomes necessary (Liu et al., 2019; Han et al., 2007).

The possibility of 'obligate' cotranslational folders invites the question as to what makes these proteins challenging for chaperones to rescue them. One potential explanation is that these proteins can populate soluble misfolded states that are 'native-like,' evade detection by chaperones, and are very slow to resolve on their own. A second possibility is that chaperones can identify these states but ultimately cannot repair them, targeting them for degradation. The first scenario has recently been investigated by O'Brien and co-workers 
(Halder et al., 2021), who found computationally that E. coli isochorismate synthase (EntC), enolase (Eno), Galactitol-1-phosphate dehydrogenase (GatD), MetK, and purine nucleoside phosphorylase (DeoD) are prone to form near-native entangled states that bypass GroEL. In agreement, our study identifies Eno and DeoD as chaperone nonrefolders (as for the others: EntC had too low coverage for inclusion; MetK is GroEL-fastidious; GatD was not detected in intrinsic refolding experiments but fully refolded in all chaperone experiments, supporting previous work showing its misfolded states rapidly aggregate (Kerner et al., 2005)).

The authors of the computational study predicted that upon folding, enolase is prone to becoming entangled (Figure 7D, Left), specifically by threading a segment that comprises the interdomain bridge and the first $\beta$-strand of the TIM barrel (residues 141-158, blue) between a closed loop formed by the final $\beta$-strand of the TIM barrel (382-396, red) and the C-terminal helical region (408-416, red). Focusing on the five all-or-nothing peptides detected for this protein in the GroEL/ES-refolding experiment, we find striking agreement with this prediction. Y144 (adjacent to the crossover point) only becomes susceptible to PK in the refolded state, whereas E413 on the surface of the protein is only susceptible to PK in the native state (Figure 7D, Right). This is consistent with the expected structural transformation if the threading region passes through the loop. In the native protein, a long stretch between residues 144177 (that happens to have no Arg or Lys) is immune to PK, and survives as a full-tryptic fragment. It corresponds to a stable structural region corresponding to an antiparallel $\beta$-hairpin within the barrel, an unusual feature since most TIM barrels exclusively have parallel $\beta$ sheets. This full-tryptic fragment disappears in the refolded sample, consistent with the prediction that it would become exposed to proteolysis upon threading. Two further all-or-nothing half-tryptic peptides are identified, mapping to S250 and F301. These do not appear to be related to the local entanglement discussed here, but they are relatively close to each other and may suggest an additional location in enolase prone to misfold.

In a follow-up study, Nissley et al. (2021) computationally probed a larger cohort of $E$. coli proteins, and identified a group of 57 that are expected to bypass chaperones, not aggregate, and not be degraded on account of potentially populating entangled near-native conformations. Our study of obligatory GroEL refolding (cf. Figure 4F-H) covered 33 of these, of which only 11 were found to be intrinsic refolders (33\%), 5 were obligate-GroEL refolders 
(15\%), but 17 were GroEL-nonrefolders (52\%, 3.1-fold overrepresented) (Figure 7E). Twelve were found that also could not refold with DnaK (39\%, 2.9-fold overrepresented). It is possible on one hand that with greater coverage, more of the entangling proteins would also have been found to be chaperone-nonrefolding in our experiment; on the other hand, Nissley's algorithm might overestimate chaperone bypassing. Nevertheless, the sizable enrichment of predicted entangled states in our chaperone-nonrefolding cohort and the structural agreement for enolase provide compelling evidence that entanglement provides some of the structural basis as to why chaperones may not be able to rescue all misfolded proteins.

\section{Chaperone-Nonrefolders May Have Kinetically-trapped Native States, Obviating the Need for Chaperone Intervention}

If a protein cannot be refolded, even with chaperones, does it represent a liability to cell? Not necessarily, as long as the protein: (i) folds efficiently for the first time, on the ribosome; and (ii) has an unfolding rate that is so slow to be negligible on the physiological timescale. Our study supports the view that chaperone-nonrefolding proteins might frequently be trapped in their native states, hence explaining why under physiological conditions they would never require the service of chaperones after their translation. Indeed, half of the highly kinetically stable proteins identified by Marqusee and co-workers (that remain undigested by thermolysin or trypsin over several days; Park et al., 2007) are GroEL-nonrefolding in our study (Figure 7E), a 3-fold enrichment. Ten were found to also not refold with DnaK (40\%, 3-fold enrichment).

The existence of kinetically-trapped native states that are inefficiently refolded from denatured forms poses a number of interesting consequences for how cells maintain proteostasis. For instance, they could potentially explain why such a large fraction of the proteostasis network is dedicated to degradation rather than restoration. Whilst protein degradation represents, on one hand, an important part of gene regulation; it is also possible that in other situations it responds to a biophysical imperative - of a protein that cannot be repaired and must be resynthesized from scratch, to fold co-translationally anew. The slow decay of kinetically-trapped native states out of their prescribed free energy minima could then encode an intrinsic 'expiration date,' effectively defining the desired timescale the protein 
should persist for. In this context, it is sensible why this feature appears to be more common for high-abundance proteins involved in constitutive core metabolic processes.

\section{Limitations of this Study}

The primary limitation in this study is imperfect coverage. The more peptides we quantify per protein, the more potential we have to elucidate nonrefolding regions, and this coverage is not spread equally over all proteins. Fortunately, peptide-level analysis (Figure S6) can assure us that differences in coverage do not bias any of the primary trends we observe with respect to $\mathrm{pl}, \mathrm{MW}$, or chaperonin class. It does however explain imperfect reproducibility at the individual-protein level (Figure S4). The main reason a protein's refoldability status would change in a different experimental replicate is that the protein lies close to the cut-off and a given peptide (that had statistically-significantly different abundance in refolded samples) was detected in one replicate of the experiment but not the another. Continuous improvements in proteomics technologies are expected to mitigate this limitation. 


\section{STAR*METHODS}

Detailed methods are provided in the online version of this paper and include the following:

- Key Resource Table

- Resource Availability

- Experimental Model and Subject Details

- Preparation of E. coli (Strain K12) for Making Cyto-Serum

- Preparation of K12 for Aggregation Studies

- Preparation of K12 for Limited Proteolysis Mass Spectrometry (LiP-MS)

Refolding Studies

- Method Details

- General Preparation of Cyto-Serum

- Characterization of Cyto-Serum

- Preparation of Normalized Lysates

- Methods to Study Aggregation

- Preparation of Cell Lysates

- Sedimentation Velocity Analytical Ultracentrifugation

- Mass Photometry (MP)

- Quantification of Pelleting Aggregates Upon Refolding

- Preparation of Native and Refolded Lysates with and without Molecular Chaperones for Limited Proteolysis Mass Spectrometry

- Limited Proteolysis of Mass Spectrometry Samples Preparation

- Desalting of Mass Spectrometry Samples

- LC-MS/MS Acquistion

- LC-MS/MS Data Analysis

- Refoldability Analysis

- Bioinformatics

- Quantification and Statistical Analysis

\section{ACKNOWLEDGMENTS}

We thank Susan Marqusee, Ed O'Brien, and Dan Nissley for thoughtful discussion. We thank Philip Mortimer for maintaining the Mass Spectrometer Facility at JHU Department of Chemistry, and Ananya Majumdar for expertise on and assistance with NMR experiments. We thank Di Wu and Grzegorz Piszczek at the National Institutes of Health (Bethesda, MD) for expertise on and assistance with mass photometry experiments. S.D.F. acknowledges support from the NIH Director's New Innovator Award (DP2GM140926) and from the NSF Division of Molecular and Cellular Biology (MCB2045844). K.G.F. acknowledges support from NIGMS (R01GM079440). T.D. was supported by an NIH training grant (T32GM008403).

\section{AUTHOR CONTRIBUTIONS}


S.D.F. designed the study. P.T., S.O.L., A.X., T.D., and S.D.F. performed the experiments. All authors analyzed data. P.T. and S.D.F. prepared figures. P.T. and S.D.F. wrote the paper, with consultation from all other authors.

\section{DECLARATION OF INTERESTS}

The authors have no conflicts of interest to disclose.

\section{REFERENCES}

Ambrose, A. J., Fenton, W., Mason, D. J., Chapman, E., Horwich, A. L. (2015). Unfolded DapA forms aggregates when diluted into free solution, confounding comparison with folding by the GroEL/GroES chaperonin system. FEBS Lett. 589, 497-499.

Anfinsen, C. B., Haber, E., Sela, M., and White Jr., F. H. (1961). The kinetics of formation of native ribonuclease during oxidation of the reduced polypeptide chain. Proc. Natl. Acad. Sci. USA 47, 1309-1314.

Anfinsen, C. B. (1973). Principles that govern the folding of protein chains. Science 181, 223230.

Balchin, D., Hayer-Hartl, M., and Hartl, F. U. (2016). In vivo aspects of protein folding and quality control. Science 353, aac4354.

Balchin, D., Hayer-Hartl, M., and Hartl F. U. (2020). Recent advances in understanding catalysis of protein folding by molecular chaperones. FEBS Lett. 594, 2770-2781.

Bartlett Al and Radford SE. (2009). An expanding arsenal of experimental methods yields an explosion of insights into protein folding mechanisms. Nat Struct Mol Biol 16, 582-588.

Bennett, B. D., Kimball, E. H., Gao, M., Osterhout, R., van Dien, S. J., and Rabinowitz, J. D. (2009). Absolute metabolite concentrations and implied enzyme active site occupancy in Escherichia coli. Nature Chem. Biol. 5, 593-599.

Bertolini, M.,... and Kramer, G. (2021). Interactions between nascent proteins translated by adjacent ribosomes drive homomer assembly. Science 371, 57-64.

Bowman, J. C., Petrov, A. S., Frenkel-Pinter, M., Penev, P. I., and Williams, L. D. (2020). Root of the Tree: The Significance, Evolution, and Origins of the Ribosome. Chem. Rev. 120, 48484878.

Brinker, A... (2001). Dual Function of Protein Confinement in Chaperonin-Assisted Protein Folding. Cell 107, 223-233. 
Chaudhuri, T. K., Farr, G. W., Fenton, W. A., Rospert, S., and Horwich A. L. (2001).

GroEL/GroES-Mediated Foldingof a Protein Too Largeto Be Encapsulated. Cell 107, 235-246.

Chaudhuri, T. K., Verma, V. K., and Maheshwari, A. (2009). GroEL assisted folding of large polypeptide substrates in Escherichia coli: Present scenario and assignments for the future. Prog. Biophys. Mol. Biol. 99, 42-50.

Calloni, G., Chen, T., Schermann, S. M., Chang, H., Genevaux, P., Agostini, F., Tartaglia, G. G., Hayer-Hartl, M., and Hartl, F. U. (2012). DnaK Functions as a Central Hub in the E. coli Chaperone Network. Cell Reports 1, 251-264.

Cheng, H., et al. (2014). ECOD: An Evolutionary Classification of Protein Domains. PLOS Comput. Biol. 10, e1003926.

Cole, D., Young, G., Weigel, A., Sebesta, A., and Kukura, P. (2017). Label-Free SingleMolecule Imaging with Numerical-Aperture-Shaped Interferometric Scattering Microscopy. ACS Photonics 4, 211-216.

De Souza, N., and Picotti, P. (2020). Mass spectrometry analysis of the structural proteome. Curr. Opin. Struct. Biol. 60, 57-65.

Farr, G. W., Fenton, W. A., Chaudhuri, T. K., Clare, D. K., Saibil, H. R., and Horwich, A. L. (2003). Folding with and without encapsulation by cis- and trans-only GroEL-GroES complexes. EMBO J. 22, 3220-3230.

Feng, Y., Franceschi, G., Kahraman, A., Soste, M., Melnik, A., Boersema, P. J., de Laureto, P. P., Nikolaev, Y., Oliveria, A. P., and Picotti, P. (2014). Global analysis of protein structural changes in complex proteomes. Nature Biotech. 32, 1036-1044.

Fried, S. D., Fujishima, K., Makarov, M., Cherepashuk, I., and Hlouchova, K. (2021). Peptides Before and During the Nucleotide World: An Origins Story Emphasizing Cooperation between Proteins and Nucleic Acids. J. Roy. Soc. Interface $X X$.

Fujiwara, K., Ishihama, Y., Nakahigashi, K., Soga, T., and Taguchi, H. (2010). A systematic survey of in vivo obligate chaperonin-dependent substrates. EMBO J. 29, 1552-1564.

Gao, X., et al. (2015). Human Hsp70 Disaggregase Reverses Parkinson's-Linked a-Synuclein Amyloid Fibrils. Mol. Cell. 59, 781-793.

Georgescauld, F., Popova, K., Gupta, A. J., Bracher, A., Engen, J. R., Hayer-Hartl, M., and Hartl, F. U. (2014). GroEL/ES Chaperonin Modulates the Mechanism and Accelerates the Rate of TIM-Barrel Domain Folding. Cell 157, 922-934. 
Goloubinoff, P., Christeller, J. T., Gatenby, A. A., and Lorimer, G. H. (1989). Reconstitution of active dimeric ribulose bisphosphate carboxylase from an unfolded state depends on two chaperonin proteins and Mg-ATP. Nature 342, 884-889.

Gottesman, S., Wickner, S., and Maurizi, M. R. (1997). Protein quality control: triage by chaperones and proteases. Genes Dev. 11, 815-823.

Gough, J., Karplus, K., Hughey, R., and Chothia, C. (2001) Assignment of homology to genome sequences using a library of hidden Markov models that represent all proteins of known structure. J. Mol. Biol. 313, 903- 919.

Halder, R., Nissley, D. A., Sitarik, I., and O'Brien E. P. (2021). Subpopulations of soluble, misfolded proteins commonly bypass chaperones: How it happens at the molecular level. bioRxiv 10.1101/2021.08.18.456736.

Han, J.-H., Batey, S., Nickson, A. A., Teichmann, S. A., and Clarke, J. (2007). The folding and evolution of multidomain proteins. Nature Rev. Mol. Cell. Biol. 8, 319-330.

Harris, C. L. (1987). An aminoacyl-tRNA synthetase complex in Escherichia coli. J. Bacteriol. 169, 2718- 2723.

Houry, W. A., Frishman, D., Eckerskorn, C., Lottspeich, F., and Hartl, F. U. (1999). Identification of in vivo substrates of the chaperonin GroEL. Nature 402, 147-154.

Imamoglu, R., Balchin, D., Hayer-Hartl, M., and Hartl, F. U. (2020). Bacterial Hsp70 resolves misfolded states and accelerates productive folding of a multi-domain protein. Nature Comm. 11, 365.

Jarzab, A., et al. (2020). Meltome atlas - thermal proteome stability across the tree of life. Nature Meth. 17, 495-503.

Jumper, J., et al. (2021). Highly accurate protein structure prediction with AlphaFold. Nature 596, 583-589.

Kerner, M. J., et al. (2005). Proteome-wide Analysis of Chaperonin-Dependent Protein Folding in Escherichia coli. Cell 122, 209-220.

Keseler, I. M., et al. (2017). The EcoCyc database: reflecting new knowledge about Escherichia coli K-12. Nucleic Acids Res. 45, D543-D550.

Kong, A. T., Leprevost, F. V., Avtonomov, D. M., Mellacheruvu, D., and Nesvizhskii, A. I. (2017). MSFragger: ultrafast and comprehensive peptide identification in mass spectrometrybased proteomics. Nature Meth. 14, 513-520. 
Kozlowski, L. P. (2017). Proteome-pl: proteome isoelectric point database. Nucleic Acids Res. 45, D1112-D1116.

Laue, T. M., Shah, B. D., Ridgeway, T. M., and Pelletier, S. L. (1992). Computer-aided interpretation of analytical sedimentation data for proteins. In: Harding, S.; Rowe, A.; Hoarton, J., editors. Analytical Ultracentrifugation in Biochemistry and Polymer Science. Royal Society of Chemistry; Cambridge, UK: 1992. p. 90-125.

Li, G.-W., Burkhardt, D., Gross, C., and Weissman, J. S. (2014). Quantifying absolute protein synthesis rates reveals principles underlying allocation of cellular resources. Cell 157, 624635.

Lin, Z., Madan, D., and Rye, H. S. (2008). GroEL stimulates protein folding through forced unfolding. Nature Struct. Mol. Biol. 15, 303-311.

Lindquist, S. (2009). Protein folding sculpting evolutionary change. Cold Spring Harb. Symp. Quant. Biol. 74, 103-108.

Liu, K., Maciuba, K., and Kaiser C. M. (2019). The Ribosome Cooperates with a Chaperone to Guide Multi-domain Protein Folding. Mol. Cell. 74, 310-319.

Macošek, J., Mas, G., and Hiller, S. (2021). Redefining Molecular Chaperones as Chaotropes. Frontiers Mol. Biosci. 8, 683132.

Mateus, A., Bobonis, J., Kurzawa, N., Stein, F., Helm, D., Hevler, J., Typas, A., and Savitski, M. M. (2018). Thermal proteome profiling in bacteria: probing protein state in vivo. Mol. Sys. Biol. 14, e8242.

Mayer, M. P. \& Gierasch, L. M. Recent advances in the structural and mechanistic aspects of Hsp70 molecular chaperones. J. Biol. Chem. 294, 2085-2097 (2019).

Mi, H., Muruganujan, A., Huang, J. X., Ebert, D., Mills, C., Guo, X., and Thomas, P. D. (2019). Protocol Update for large-scale genome and gene function analysis with the PANTHER classification system (v.14.0). Nature Protoc. 14, 703-721.

Nahnsen, S., Bielow, C., Reinert, K., and Kohlbacher, O. (2013). Tools for label-free peptide quantification. Mol. Cell. Proteomics 12, 549-556.

Neidhardt, F. C., Bloch, P. L., and Smith, D. F. (1974). Culture medium for enterobacteria. J. Bacteriol. 119, 736-747. 
Nissley, D., Jiang, Y., Trovato, F., Sitarik, I., Narayan, K., and O’Brien, E. P. (2021). Universal protein misfolding intermediates can bypass the proteostasis network and remain soluble and non-functional. bioRxiv 10.1101/2021.08.18.456613.

Niwa, T., Ying, B.-W., Saito, K., Jin, W., Takada, S., Ueda, T., and Taguchi, H. (2009). Bimodal protein solubility distribution revealed by an aggregation analysis of the entire ensemble of Escherichia coli proteins. Proc. Natl. Acad. Sci. USA 106, 4201-4206.

Niwa, T., Kanamori, T., Ueda, T., and Taguchi, H. (2012). Global analysis of chaperone effects using a reconstituted cell-free translation system. Proc. Natl. Acad. Sci. USA 109, 8937-8942.

Palomba, A., Abbondio, M., Friorito, G., Uzzau, S., Pagnozzi, D., and Tanca, A. (2021). Comparative Evaluation of MaxQuant and Proteome Discoverer MS1-Based Protein Quantification Tools. J. Proteome. Res. 20, 3497-3507.

Pandurangan, A. P., Stahlacke, J., Oates, M. E., Smithers, B., and Gough, J. (2019). The superfamily 2.0 database: A significant proteome update and a new webserver. Nucleic Acids Res. 47, D490- D494.

Park, C., and Marqusee, S. (2005). Pulse proteolysis: A simple method for quantitative determination of protein stability and ligand binding. Nature Meth. 2, 207-212.

Park, C., Zhou, S., Gilmore, J., and Marqusee, S. (2007). Energetics-based Protein Profiling on a Proteomic Scale: Identification of Proteins Resistant to Proteolysis. J. Mol. Biol. 368, 1426-1437.

Paul, S., Singh, C., Mishra, S., and Chaudhuri, T. K. (2007). The 69 kDa Escherichia coli maltodextrin glucosidase does not get encapsulated underneath GroES and folds through trans mechanism during GroEL/ GroES-assisted folding. FASEB J. 21, 2874-2885.

Petrov, A.S. et al. (2015). History of the ribosome and the origin of translation. Proc. Natl. Acad. Sci. USA 112, 15396-15401.

Phillips, R., Kondev, J., and Theriot, J. (2008) Physical Biology of the Cell. Garland Science, New York, NY.

Philo, J. S. (2006). Anal Biochem. 354, 238-246.

Plaxco, K. W., Simons, K. T., and Baker, D. (1998). Contact order, transition state placement and the refolding rates of single domain proteins. J. Mol. Biol. 277, 985-994.

Powers, E. T., Powers, D. L., and Gierasch, L. M. (2012). FoldEco: A Model for Proteostasis in E. coli. Cell Rep. 1, 265-276. 
Rebeaud, M. E., Mallik, S., Goloubinoff, P., and Tawfik, D. S. (2021). On the evolution of chaperones and co-chaperones and the expansion of proteomes across the Tree of Life. Proc. Natl. Acad. Sci. USA 118, e2020885118.

Rosenzweig, R., Nillegoda, N. B., Mayer, M. P. \& Bukau, B. The Hsp70 chaperone network. Nat. Rev. Mol. Cell Biol. 20, 665-680 (2019).

Santra, M., Farrell, D. W., and Dill, K. A. (2017). Bacterial proteostasis balances energy and chaperone utilization efficiently. Proc. Natl. Acad. Sci. USA X, E2654-E2661.

Schaefer, R. D., Liao, Y., Cheng, H., and Grishin, N. V. (2016). ECOD: new developments in the evolutionary classification of domains. Nucleic Acids Res. 45, D296-D302.

Shiber, A., et al. (2018). Cotranslational assembly of protein complexes in eukaryotes revealed by ribosome profiling. Nature $561,268-272$.

Shieh, Y.-W., Minguez, P., Bork, P., Auburger, J. J., Guilbride, D. L., Kramer, G., and Bukau, B. (2015). Operon structure and cotranslational subunit association direct protein assembly in bacteria. Science 350, 678-680.

Singh, A. K., Balchin, D., Immamoglu, R., Hayer-Hartl, M., and Hartl, F. U. (2020). Efficient Catalysis of Protein Folding by GroEL/ES of the Obligate Chaperonin Substrate MetF. J. Mol. Biol. 432, 2304-2318.

Tang, Y.-C., Chang, H.-C., Roeben, A., Wichnewski, D., Wichnewski, N., Kerner, M. J., Hartl, F. U., Hayer-Hartl, M. (2006). Structural features of the GroEL-GroES nano-cage required for rapid folding of encapsulated protein. Cell 125, 903-914.

Thirumalai, D., and Lorimer, G. H. (2001). Chaperonin-mediated protein folding. Annu. Rev. Biophys. 30, 245-269.

To, P., Whitehead, B., Tarbox, H. E., and Fried, S. D. (2021). Nonrefoldability is Pervasive Across the E. coli Proteome. J. Am. Chem. Soc. 143, 11435-11448.

Tyedmers, J., Mogk, A., and Bukau, B. (2010). Cellular strategies for controlling protein aggregation. Nature Rev. Mol. Cell Biol. 11, 777-788.

Vecchi, G., Sormanni, P., Mannini, B., Vandelli, A., Tartaglia, G. G., Dobson, C. M., Hartl, F. U., and Vendruscolo, M. (2020). Proteome-wide observation of the phenomenon of life on the edge of solubility. Proc. Natl. Acad. Sci. USA 117, 1015-1020.

Viitanen, P. V., Lubben, T. H., Reed, J., Goloubinoff, P., O’Keefe, D. P., and Lorimer, G. H. (1990). Chaperonin-Facilitated Refolding of Ribulosebisphosphate Carboxylase and ATP Hydrolysis by Chaperonin 60 (groEL) Are K+ Dependent. Biochemistry 29, 5665-5671. 
Wallace, E. W. J., et al. (2015). Reversible, Specific, Active Aggregates of Endogenous Proteins Assemble upon Heat Stress. Cell 162, 1286-1298.

Willmund, F., del Alamo, M., Pechmann, S., Chen, T., Albanèse, V., Dammer, E. B., Peng, J., and Frydman, J. (2013). The cotranslational function of ribosome-associated Hsp70 in eukaryotic protein homeostasis. Cell 152, 196-209.

Yam, A. Y., Xia, Y., Lin H.-T. J., Burlingame, A., Gerstein, M., and Frydman, J. (2008). Defining the TRiC/CCT interactome links chaperonin function to stabilization of newly made proteins with complex topologies. Nature Struct. Mol. Biol. 15, 1255-1262.

Young, G., et al. (2018). Quantitative mass imaging of single biological macromolecules. Science 360, 423-427. 


\section{STAR ${ }^{\star M E T H O D S}$}

KEY RESOURCE TABLE

\begin{tabular}{|l|l|l|}
\hline Reagent of Resource & Source & Identifier \\
\hline Bacterial Strains & & \\
\hline E. coli (Strain K12) & New England BioLabs & ER2738 \\
\hline & & \\
\hline Chemicals and Reagents & & A2765 \\
\hline Adenosine diphosphate (ADP) & Sigma-Aldrich & \\
\hline $\begin{array}{l}\text { Adenosine Triphosphate (ATP) } \\
10 \text { mM }\end{array}$ & New England BioLabs & P0756S \\
\hline Ammonium Bicarbonate & Acros Organics & 393210050 \\
\hline Dithiothreitol (DTT) & Sigma-Aldrich & D06632 \\
\hline Glycerol & Fisher & G33-1 \\
\hline Guanidium Chloride (GdmCl) & Acros Organics & $50-01-1$ \\
\hline Hydrochloric Acid (HCl) & Fisher Scientific & A142-212 \\
\hline lodoacetamide (IAA) & Acros organics & 122271000 \\
\hline KCI & Fisher & BP366-1 \\
\hline MgCl2 & Fisher & BP214-500 \\
\hline NaCl & Fisher & BP358-212 \\
\hline NAD+ & Sigma-Aldrich & $481911-5 G M$ \\
\hline Sodium dodecyl sulfate (SDS) & Fisher & BP166-500 \\
\hline Tris-Base & Sigma-Aldrich & RD008 \\
\hline Tris-HCl & Sigma & RD009 \\
\hline Tryptone & Fisher & BP1421-2 \\
\hline Urea & Fisher & U17-212 \\
\hline Yeast Extract & Fisher & BP1422-500 \\
\hline & & \\
\hline $\begin{array}{l}\text { Components to Make } \\
\text { Protease Inhibitor Cocktail }\end{array}$ & & \\
\hline AEBSF.HCI & Thermo Scientific & \\
\hline Aprotonin from bovine lung & Sigma Aldrich & 78431 \\
\hline Bestatin & Thermo Scientific & 10820 \\
\hline E-64 & Thermo Scientific & 78433 \\
\hline Leupeptin & Sigma Aldrich & 78434 \\
\hline Pepstatin A & Thermo Scientific & El8 \\
\hline & & 78436 \\
\hline $\begin{array}{l}\text { Components to Make MOPS } \\
\text { MEDIA }\end{array}$ & & \\
\hline 13C6 L-ARGININE-HCL & Fisher Scientific & \\
\hline 13C6 L-LYSINE-2HCL & Fisher Scientific & Pl88433 \\
\hline Adenine & Alfa Aesar & PI89988 \\
\hline Ammonium Chloride & EMD & A14906 \\
\hline Ammonium Molybdate & & AX1270-1 \\
\hline Boric Acid & Fisher Scientific & \\
\hline Calcium Chloride & Acros organics & \\
\hline Calcium Pantothenate & & BP-168-1 \\
\hline & & \\
\hline
\end{tabular}




\begin{tabular}{|c|c|c|}
\hline Cobalt Chloride & Acros & B42357-1000 \\
\hline \multicolumn{3}{|l|}{ Cupric Sulfate } \\
\hline Cytosine & TCl America & $71-30-7$ \\
\hline \multicolumn{3}{|l|}{ di Hydroxy Benzoic Acid } \\
\hline Glucose (Dextrose) (D) & Fisher & D16-3 \\
\hline Guanine & Alfa Aesar & A12024 \\
\hline \multicolumn{3}{|l|}{ Iron Sulfate Stock } \\
\hline L-Alanine & Acros organics & 102831000 \\
\hline L-Arginine $\mathrm{HCl}$ & Alfa Aesar & A14730 \\
\hline L-Asparigine & Alfa Aesar & b21473 \\
\hline L-Aspartic Acid, Potassium Salt & Alfa Aesar & A13520 \\
\hline L-Cysteine $\mathrm{HCl}$ & Alfa Aesar & 106328 \\
\hline $\begin{array}{l}\text { L-Glutamic Acid, Potassium } \\
\text { Salt }\end{array}$ & Alfa Aesar & A15031 \\
\hline L-Glutamine & Alfa Aesar & A14201 \\
\hline L-Glycine & J T Baker & 4059-02 \\
\hline L-Histidine $\mathrm{HCl} \mathrm{H} 2 \mathrm{O}$ & Acros Organics & 166151000 \\
\hline L-Isoleucine & Fisher & bp384-100 \\
\hline L-Leucine & Alfa Aesar & A12311 \\
\hline L-Lysine & Alfa Aesar & $J 62225$ \\
\hline L-Methionine & Alfa Aesar & A10318 \\
\hline L-Phenylalinine & Alfa Aesar & A13238 \\
\hline L-Proline & Fisher & BP-392-100 \\
\hline L-Serine & Acros Organics & 132665000 \\
\hline L-Threonine & Acros Organics & 138931000 \\
\hline L-Tryptophan & Acros Organics & 140590250 \\
\hline L-Tyrosine & Alfa Aesar & A11141 \\
\hline L-Valine & Acros organics & 140811000 \\
\hline Magnesium Chloride & Fisher & BP214-500 \\
\hline \multicolumn{3}{|l|}{ Manganese Chloride } \\
\hline MOPS (MW 209.3) & Sigma LS & RDD0018 \\
\hline para-Amino Benzoic Acid & Sigma Aldrich & 1973 \\
\hline para-Hydroxy benzoic Acid & Alfa Aesar & A13700 \\
\hline Potassium Hydroxide & Fisher & P250-3 \\
\hline Potassium Phosphate Dibasic & Fisher & BP363-1 \\
\hline \multicolumn{3}{|l|}{ Potassium Sulfate } \\
\hline Sodium Chloride & Fisher & BP358-212 \\
\hline Thiamine & Fisher & BP892-100 \\
\hline Tricine (MW 179.2) & Sigma LS & RDD024 \\
\hline Uracil & Alfa Aesar & A15570 \\
\hline Zinc Sulfate & Alfa Aesar & 33399 \\
\hline \multicolumn{3}{|l|}{$\begin{array}{l}\text { Recombinant Proteins and } \\
\text { Enzymes }\end{array}$} \\
\hline DnaK Mix & Cosmo-Biology & GFK-PF003-0.5-EX \\
\hline DNasel from Bovine Pancreas & Sigma Aldrich & 31136 \\
\hline GroEL & Sigma Aldrich & C7688 \\
\hline
\end{tabular}




\begin{tabular}{|c|c|c|}
\hline GroES & Sigma Aldrich & C7438 \\
\hline Endoproteinase LysC & New England BioLabs & P8109S \\
\hline Proteinase $\mathrm{K}$ & Fisher Scientific & BP1700 \\
\hline $\begin{array}{l}\text { Trypsin -ultra, Mass } \\
\text { Spectrometry Grade }\end{array}$ & New England BioLabs & P8101S \\
\hline \multicolumn{3}{|l|}{ Commercial Assays } \\
\hline Rapid Gold BCA Assay (Pierce) & Thermo Scientific & A53225 \\
\hline \multicolumn{3}{|l|}{ LC-MS Reagents } \\
\hline Acetonitrile (HPLC Grade) & Sigma-Aldrich & 34851 \\
\hline $\begin{array}{l}\text { Formic Acid (Optima LC/MS } \\
\text { Grade) }\end{array}$ & Fisher Scientific & A117-50 \\
\hline $\begin{array}{l}\text { Trifluoroacetic acid (TFA) } \\
\text { (HPLC Grade) }\end{array}$ & Alfa Aesar & 44630 \\
\hline Water (Optima LC-MS Grade) & Fisher Scientific & W6500 \\
\hline \multicolumn{3}{|l|}{ Data-Bases } \\
\hline Chaperonin Class Data-Set & Kerner et al. 2005 & N/A \\
\hline DnaK Enrichment Data-Set & Calloni et al. 2012 & N/A \\
\hline EcoCyc & Keseler et al. 2017 & N/A \\
\hline Fujiwara Data Set & Fujiwara et al. 2010 & N/A \\
\hline SCOP Database & Andreeva et al. 2020 & $\mathrm{~N} / \mathrm{A}$ \\
\hline \multicolumn{3}{|l|}{ Instrumentation } \\
\hline 1/4 Inch Probe & QSonica & N/A \\
\hline AN60 Ti Rotor & Beckman Coulter & N/A \\
\hline Ultracentrifuge (Optima XL-A) & Beckman Coulter & N/A \\
\hline Eppendorf Centrifuge (5910R) & Eppendorf & $\mathrm{N} / \mathrm{A}$ \\
\hline OneMP (Mass Photometry) & Refeyn & N/A \\
\hline $\mathrm{pH}$ Meter & Mettler-Toledo & N/A \\
\hline Plate Reader (ID3) & Molecular Devices & N/A \\
\hline Probe Sonicator (Q700R) & QSonica & $\mathrm{N} / \mathrm{A}$ \\
\hline $\begin{array}{l}\text { Q-Exactive HF-X Orbitrap Mass } \\
\text { Spectrometer }\end{array}$ & Thermo Scientific & $N / A$ \\
\hline Rheometer (MC92) & Anton-Parr & $\mathrm{N} / \mathrm{A}$ \\
\hline $\begin{array}{l}\text { SPEX TM Sample Prep Dual } \\
\text { Freezer/Mill }\end{array}$ & SPEX & N/A \\
\hline SW55 Ti Rotor & Beckman Coulter & N/A \\
\hline UltiMate3000 UHPLC & Thermo Scientific & N/A \\
\hline Ultracentrifuge (Optima-XPN) & Beckman Coulter & N/A \\
\hline \multicolumn{3}{|l|}{ Other } \\
\hline $3 \mathrm{~mL}$ Konical Tubes & Beckman Coulter & N/A \\
\hline $\begin{array}{l}5 \mathrm{~mL} \text { ultra-clear } \\
\text { ultrancentrifugation tubes }\end{array}$ & Beckman Coulter & $\mathrm{N} / \mathrm{A}$ \\
\hline
\end{tabular}




\begin{tabular}{|l|l|l|}
\hline JL20 Tubes & Beckman Coulter & N/A \\
\hline Mass Spec Vials & Thermo Scientific & N/A \\
\hline Sep Pak C18 1 cc 50 mg Resin & Waters & 186000308 \\
\hline $\begin{array}{l}\text { Viva-Spin 15R 2K MWCO } \\
\text { Hydrosart }\end{array}$ & Sartorius & VS15RH92 \\
\hline 25 mm plate & Anton-Parr & N/A \\
\hline & & \\
\hline Software and Algorithms & & \\
\hline AcquireMP & Refeyn & N/A \\
\hline AnalyzerV18 & In House & N/A \\
\hline DCDT+ & John Philo & N/A \\
\hline DiscoverMP & Refeyn & N/A \\
\hline MSFragger Node in PD & Nesvizhskii Lab & N/A \\
\hline Proteome Discoverer v 2.4 (PD) & Thermo Scientific & N/A \\
\hline RheoCompass & Anton-Parr & N/A \\
\hline SEDNTERP & John Philo & N/A \\
\hline XCalibur & Thermo Scientific & N/A \\
\hline
\end{tabular}

RESOURCE AVAILABILITY TABLE

\begin{tabular}{|l|l|l|}
\hline Resource & Source & Location \\
\hline $\begin{array}{l}\text { Domain-Summary Files } \\
\left(^{*} \text { domainsummary.xlsx) }\right.\end{array}$ & In House & Available Upon Request \\
\hline Meta-Data Files ( $\left.{ }^{*} . c s v\right)$ & In House & Github.com/FriedLabJHU \\
\hline $\begin{array}{l}\text { PD v2.4 LFQ Output Files } \\
\text { (.pdresult) }\end{array}$ & In House & Github.com/FriedLabJHU \\
\hline $\begin{array}{l}\text { Peptide Quanitifcations } \\
\left(^{*} \text { out.xlsx) }\right.\end{array}$ & In House & PRIDE_AccessionXXX \\
\hline $\begin{array}{l}\text { Protein Summary Files } \\
\left(^{*} \text { proteinsummary.xlsx) }\right.\end{array}$ & In House & Github.com/FriedLabJHU \\
\hline Raw Mass Spectra Files (.raw) & In House & PRIDE_AccessionXXX \\
\hline
\end{tabular}

\section{EXPERIMENTAL MODEL AND SUBJECT DETAILS}

\section{Preparation of E. coli (Strain K12) for Making Cyto-Serum}

$2 \times 1$ L of TB Broth (Cold Spring Harbor Protocols) were inoculated with E. coli (strain K12) cells in $2 \mathrm{~L}$ baffled flask and grown overnight at $37{ }^{\circ} \mathrm{C}$ with agitation $(220 \mathrm{rpm})$ to a final $\mathrm{OD}_{600}$ of 10.0. Cells were harvested by centrifugation at $2000 \mathrm{~g}$ for $15 \mathrm{~min}$ at $4{ }^{\circ} \mathrm{C}$. Supernatants were removed and cells were washed with $200 \mathrm{~mL}$ MPW before centrifuging at $4000 \mathrm{~g}$ for $15 \mathrm{~min}$ at $4{ }^{\circ} \mathrm{C}$. Washed pellets were stored at $-20^{\circ} \mathrm{C}$ until further use.

\section{Preparation of K12 for Aggregation Studies}


K12 cells were grown in $3 \times 50 \mathrm{~mL}$ (biological triplicates) of in-house prepared MOPS EZ rich media (full recipe available upon request; based off of Neidhardt et al., 1977) from saturated overnight cultures with a starting OD600 of 0.05 . Cells were cultured at $37^{\circ} \mathrm{C}$ with agitation $(220$ rpm) to a final $\mathrm{OD}_{600}$ of 0.8 before being transferred to $3 \times 50 \mathrm{~mL}$ falcon tubes and collected by centrifugation at $4000 \mathrm{~g}$ for $15 \mathrm{mins}$ at $4^{\circ} \mathrm{C}$. The supernatants were removed, and cell pellets were stored at $-20^{\circ} \mathrm{C}$ until further use.

\section{Preparation of K12 for Limited Proteolysis Mass Spectrometry (LiP-MS) Refolding Studies}

$\mathrm{K} 12$ cells were grown in 2 sets of $3 \times 50 \mathrm{~mL}$ (biological triplicates) of in-house prepared MOPS EZ rich media(-Arginine/-Lysine) from saturated overnight cultures with a starting $\mathrm{OD}_{600}$ of 0.05. One set was supplemented with $0.5 \mathrm{mM}\left[{ }^{13} \mathrm{C}_{6}\right] \mathrm{L}-A r g i n i n e$ and $0.4 \mathrm{mM}\left[{ }^{13} \mathrm{C}_{6}\right] \mathrm{L}$-Lysine and the other with $0.5 \mathrm{mM}$ L-Arginine and $0.4 \mathrm{mM}$ L-Lysine. Cells were cultured at $37^{\circ} \mathrm{C}$ with agitation $(220 \mathrm{rpm})$ to a final $\mathrm{OD}_{600}$ of 0.8 . Each heavy/light pair was pooled together and then transferred to $2 \times 50 \mathrm{~mL}$ falcon tubes and collected by centrifugation at $4000 \mathrm{~g}$ for $15 \mathrm{mins}$ at $4^{\circ} \mathrm{C}$. The supernatants were removed, and cell pellets were stored at $-20^{\circ} \mathrm{C}$ until further use. Further preparation of cyto-serum, aggregation study samples, and refolding experiment samples are described in method details below.

\section{METHOD DETAILS}

\section{General Preparation of Cyto-Serum}

Washed E. coli pellets were resuspended in MPW to a final volume of $30 \mathrm{~mL}$ and lysed by sonication (QSonica Q700R) using a 1/4 inch probe for 30 mins on time (pulse: $5 \mathrm{sec}$ on / $5 \mathrm{sec}$ off) at 55\% amplitude. Lysed cells were transferred to a JL20 centrifugation tube and clarified at $16000 \mathrm{~g}$ for $15 \mathrm{~min}$ at $4^{\circ} \mathrm{C}$. To deplete large macromolecules, cellular lysates were transferred to $5 \mathrm{~mL}$ ultra-clear ultracentrifugation tubes and ultracentrifuged at $40000 \mathrm{rpm}$ for $20 \mathrm{~h}$ at $4^{\circ} \mathrm{C}$ without sucrose cushion in a SW-55 Ti rotor. Supernatants were then carefully pipetted from the ultracentrifugation tubes to not disturb the pellet and transferred to $2 \mathrm{~K}$ MWCO Vivaspin 15R centrifugal filters (Saratorius). The filters were spin at in an swing bucket rotor (Eppendorf 5910R) centrifuge at $3000 \mathrm{~g}$ for $3 \mathrm{~h}$ at $4^{\circ} \mathrm{C}$ to remove any remaining 
macromolecules. Standard Tris-Glycine SDS-PAGE (6\% stacking, 12\% resolving) was used to confirm the removal of all protein molecules that would be stained by Coomassie. The resulting filtrate was concentrated using a Vacufuge Plus (Eppendorf) to a final volume of $9.6 \mathrm{~mL}$, the total volume enclosed within the collective cytoplasms of the original $E$. coli population, creating cyto-serum ( $2 \mathrm{~L}$ of cells at OD600 10 comprises of $1.6 \mathrm{e} 13$ cells, each cell having $0.6 \mathrm{fL}$ of cytoplasm resulting in $9.6 \mathrm{~mL}$ of collected cyto-serum). The cyto-serum is aliquoted, flash frozen in liquid nitrogen and stored at $-80^{\circ} \mathrm{C}$ until further use. The cyto-serum as prepared above is used effectively as a $1.195 \times$ stock.

\section{Characterization of Cyto-Serum}

Ultraviolet-visible absorption spectra of cyto-serum were obtained with a NanoDrop One (Thermo Scientific) spectrophotometer. The cyto-serum was diluted 60x with MPW prior to analysis and MPW was used as the background. The pH of cyto-serum was measured for three independent preparations of cyto-serum using a $\mathrm{pH}$ meter (Mettler Toledo), using a three-point calibration at $\mathrm{pH} 4.0,7.0$, and 10.0. The viscosity of cyto-serum was measured via a MRC92 rheometer (Anton-Parr) using $25 \mathrm{~mm}$ parallel plates. 25 data points were collected with a point duration of $20 \mathrm{~s}$ with a Shear Rate ranging from .01 to 100 1/s logarithmic.

\section{Preparation of Normalized Lysates}

For proteome-wide aggregation and refolding studies, frozen cell pellets were resuspended in a lysis buffer consisting of either $900 \mu \mathrm{L}$ of Tris pH 8.2 lysis buffer (20 mM Tris pH 8.2, $100 \mathrm{mM}$ $\mathrm{NaCl}, 2 \mathrm{mM} \mathrm{MgCl}_{2}$ and supplemented with DNase I to a final concentration (f.c.) of $0.1 \mathrm{mg} \mathrm{mL}^{-}$ 1) or $900 \mu \mathrm{L}$ of cyto-serum lysis buffer (1× cyto-serum, supplemented with DNase I to a f.c of $0.1 \mathrm{mg} \mathrm{mL}^{-1}$ ). In samples prepared for analytical ultra-centrifugation as described below, $9 \mu \mathrm{L}$ of a 100x protease inhibitor cocktail (100 mM AEBSF.HCL, $80 \mu \mathrm{M}$ Aprotonin, $5 \mathrm{mM}$

Bestatin,1.5 mM E-64.2 mM Leupeptin, and $1 \mathrm{mM}$ Pepstatin A) was added to prevent protein degradation during analysis. Resuspended cells were flash frozen by slow drip over liquid nitrogen and cryogenically pulverized with a freezer mill (SPEX Sample Prep) over 8 cycles consisting of $1 \mathrm{~min}$ of grinding $(9 \mathrm{~Hz})$, and $1 \mathrm{~min}$ of cooling. Pulverized lysates were transferred to $50 \mathrm{~mL}$ centrifuge tubes and thawed at room temperature for $20 \mathrm{~min}$. Lysates were then 
transferred to fresh $1.5 \mathrm{~mL}$ microfuge tubes and clarified at $16000 \mathrm{~g}$ for $15 \mathrm{~min}$ at $4{ }^{\circ} \mathrm{C}$ to remove insoluble cell debris. To deplete ribosome particles, clarified lysates were transferred to $3 \mathrm{~mL}$ konical tubes and ultracentrifuged at $33,300 \mathrm{rpm}$ at $4{ }^{\circ} \mathrm{C}$ for $90 \mathrm{~min}$ without sucrose cushions using a SW55 Ti rotor. Protein concentrations of clarified lysates were determined using the bicinchoninic acid assay (Rapid Gold BCA Assay, Pierce) in a microtiter format with a plate reader (Molecular Devices iD3) using BSA as a calibration standard. Due to the reducing nature of cyto-serum, the $\mathrm{BCA}$ assay is incompatible with it. Hence, to determine protein concentrations in lysates prepared in cyto-serum, cell pellets would be generated from the same original liquid culture but split into two equally sized aliquots. The aliquots are resuspend in equal volumes of lysis buffer, with one of the aliquots lysed in Tris native buffer. The two parallel lysates are simultaneously clarified and ultracentrifuged together. Hence, under these conditions the protein concentration in the Tris-lysed lysate can be used as a surrogate to ascertain protein concentrations in cyto-serum. Generally, the raw the concentrations would be between $3.5-4.0 \mathrm{mg} \mathrm{mL}^{-1}$ for various preparations. Protein concentrations were diluted to a standard concentration of $3.3 \mathrm{mg} \mathrm{mL}^{-1}$ using their respective lysis buffers. This generates the normalized lysates for all downstream workflows.

\section{Methods to Study Aggregation}

\section{Preparation of Cell Lysates}

For soluble and insoluble protein aggregation studies, native samples were prepared as followed: normalized lysates were diluted with their respective native dilution buffers ( $20 \mathrm{mM}$ Tris pH 8.2, $100 \mathrm{mM} \mathrm{NaCl}, 2 \mathrm{mM} \mathrm{MgCl}$, $1.04 \mathrm{mM}$ dithiothreitol (DTT), $62 \mathrm{mM} \mathrm{GdmCl}$; or 1x cyto-serum, $0.1036 \mathrm{mM} \mathrm{DTT}, 62 \mathrm{mM} \mathrm{GdmCl}$ ) to a protein concentration of $0.115 \mathrm{mg} \mathrm{mL}^{-1}$. Following dilution, the final concentrations are: $20 \mathrm{mM}$ Tris $\mathrm{pH} 8.2,100 \mathrm{mM} \mathrm{NaCl}, 2 \mathrm{mM} \mathrm{MgCl}$, $1 \mathrm{mM} \mathrm{DTT}$ and $60 \mathrm{mM} \mathrm{GdmCl}$; or 1x cyto-serum, $0.1 \mathrm{mM}$ DTT and $60 \mathrm{mM} \mathrm{GdmCl}$. Native samples are then incubated overnight at room temperature. The refolding samples were prepared as follows: $600 \mu \mathrm{L}$ of normalized lysates, $100 \mathrm{mg} \mathrm{GdmCl}$ as a solid, and $2.4 \mu \mathrm{L}$ of a freshly prepared $700 \mathrm{mM}$ DTT stock solution were combined into a fresh $1.5 \mathrm{~mL}$ microfuge tube, and solvent was removed using a Vacufuge Plus to a final volume of $170 \mu \mathrm{L}$, such that the final concentrations of all components were $11.6 \mathrm{mg} \mathrm{mL}^{-1}$ protein, $6 \mathrm{M} \mathrm{GdmCl}, 70 \mathrm{mM}$ Tris 
$\mathrm{pH}$ 8.2, $350 \mathrm{mM} \mathrm{NaCl}, 7 \mathrm{mM} \mathrm{MgCl}$, and $10 \mathrm{mM}$ DTT; or $11.6 \mathrm{mg} \mathrm{mL}^{-1}$ protein, 6M GdmCl, 3.5x cyto-serum, and $10 \mathrm{mM}$ DTT. These unfolded lysates were incubated overnight in a sealed container at room temperature to complete unfolding prior to refolding.

\section{Sedimentation Velocity Analytical Ultracentrifugation}

To study the presence of smaller soluble aggregates in refolded extracts using analytical ultracentrifugation, native and unfolded lysates in Tris $\mathrm{pH} 8.2$ were prepared as described above. For analytical ultracentrifugation, all studies were carried out using Tris $\mathrm{pH} 8.2$ refolding buffers as cyto-serum has too many components that absorb at similar wavelengths to proteins (Figure S2D). To prepare refolded samples, $6 \mu \mathrm{L}$ of unfolded lysates were diluted 100x with $594 \mu \mathrm{L}$ refolding dilution buffer (19.5 mM Tris $\mathrm{pH}$ 8.2, $97.5 \mathrm{mM} \mathrm{NaCl}, 1.95 \mathrm{mM} \mathrm{MgCl}$, and 0.91 $\mathrm{mM}$ DTT) and incubated for $2 \mathrm{~h}$ at room temperature. Diluted native and refolded samples (both at $0.115 \mathrm{mg} \mathrm{mL}^{-1}$, final protein concentration) were then transferred to two-sector cells and equilibrated at $20^{\circ} \mathrm{C}$ for $1 \mathrm{~h}$ before being spun at $50000 \mathrm{rpm}$ in a Beckman Optima XL-A analytical ultracentrifuge using two-sector cells in an An60Ti rotor. Sedimentation Velocity (SV) data were analyzed using the time derivative method in dcdt+ (Philo, 2006) to obtain normalized $\mathrm{g}\left(\mathrm{s}^{\star}\right)$ distributions. Refolding buffer density and viscosity was calculated in SEDNTERP (Laue et al., 1992) and an average protein partial specific volume of $0.73 \mathrm{ml} \mathrm{g}^{-1}$ was used to describe the heterogenous cell lysates.

\section{Mass Photometry (MP)}

To monitor smaller soluble aggregates in cyto-serum, Mass Photometry (MP) experiments were conducted on a OneMP instrument (Refeyn) at room temperature. Native samples were prepared in their respective native dilution buffers (either Tris or cyto-serum) as described above. Unfolded samples (either Tris or cyto-serum) were prepared as described above. To prepare refolded samples, $2 \mu \mathrm{L}$ of unfolded extracts were diluted $100 \times$ with $198 \mu \mathrm{L}$ of refolding dilution buffer (19.5 mM Tris pH 8.2, 97.5 mM NaCl,1.95 mM MgCl , and $0.91 \mathrm{mM}$ DTT; or $0.95 \times$ cyto-serum) and incubated at room temperature for $2 \mathrm{~h}$ to allow proteins to refold. To prepare samples for MP, $10 \mu \mathrm{L}$ of native samples or refolding reactions (both at $0.115 \mathrm{mg} \mathrm{mL}^{-1}$ ) were rapidly diluted an additional $100 \times$ by addition to $990 \mu \mathrm{L}$ of Tris lysis buffer and 
immediately transferred to silicone gaskets on microscope coverslips. Acquisition (which takes $2 \mathrm{~min}$ ) was initiated within $1 \mathrm{~min}$ of the additional 100x dilution. To prepare the set up for sample analysis, microscope cover slips were first cleaned by washing with ethanol, isopropanol, and MPW and then dried with $\mathrm{N}_{2}$ gas. Cleaned microscope cover slips were then fitted with a silicone gasket. $10 \mu \mathrm{L}$ of Tris lysis buffer was loaded onto the silicone gasket to focus and sharpen the instrument. $10 \mu \mathrm{L}$ of sample was gently pipetted into the droplet seated in the gasket without disturbing focus. Recordings were acquired using the AcquireMP (Refeyn) software and mass distributions were calculated utilizing the DiscoverMP (Refeyn) software.

\section{Quantification of Pelleting Aggregates Upon Refolding}

To study the amount of insoluble aggregates that form upon global refolding, native samples were prepared in their respective native dilution buffers (either Tris or cyto-serum) as described above. Unfolded samples (either Tris or cyto-serum) were prepared as described above. To prepare refolded samples, $5 \mu \mathrm{L}$ of unfolded extracts were diluted $100 \times$ with $495 \mu \mathrm{L}$ of refolding dilution buffer (19.5 mM Tris $\mathrm{pH}$ 8.2, $97.5 \mathrm{mM} \mathrm{NaCl}, 1.95 \mathrm{mM} \mathrm{MgCl}$, and $0.91 \mathrm{mM}$ DTT; or $0.95 \times$ cyto-serum) and incubated at room temperature for $2 \mathrm{~h}$ to allow proteins to refold. $500 \mu \mathrm{L}$ of native and refolded samples (both at $0.115 \mathrm{mg} \mathrm{mL}^{-1}$, final protein concentration) were centrifuged at $16000 \mathrm{~g}$ for 15 mins at $4^{\circ} \mathrm{C}$ to collect aggregated proteins. The supernatant was carefully removed by pipetting to not disturb the protein pellet. The pellets in all samples were washed with $500 \mu \mathrm{L}$ of Tris lysis buffer to reduce the interference from reducing agents in Tris or cyto-serum refolding buffers with the BCA assay. The washed pellets were then resuspended in $50 \mu \mathrm{L}$ of $8 \mathrm{M}$ urea in MPW and the protein concentrations were quantified with the BCA Assay as described above. The amount of protein in the pellet was determined using the protein concentration and the resuspension volume (50 $\mu \mathrm{L})$ and converted to fractional precipitation by dividing by the initial amount of protein in the refolding reaction $(57.5 \mu \mathrm{g})$. The data are reported as a mean \pm standard deviations from biological triplicates, which were differentiated at the inoculation stage. Statistical significance between samples refolded in either Tris or cyto-serum were assessed using t-tests with Welch's correction for unequal population variances as implemented in Prism 9 (Graphpad). The 
"precipitation" measured for the native samples were treated as the background level of the measurement because they should not possess any precipitated protein.

\section{Preparation of Native and Refolded Lysates with and without molecular chaperones for Limited Proteolysis Mass Spectrometry}

To prepare half-isotopically-labeled native samples for experiments without molecular chaperones, $3.5 \mu \mathrm{L}$ of normalized lysates derived from pellets in which half of the cells were grown with $\left[{ }^{13} \mathrm{C}_{6}\right] \mathrm{L}$-Arginine and $\left[{ }^{13} \mathrm{C}_{6}\right] \mathrm{L}$-Lysine during cell culture and half of the cells were grown with natural abundance L-Arginine and L-Lysine during cell culture, were diluted with $96.5 \mu \mathrm{L}$ of Tris native dilution buffer $(20 \mathrm{mM}$ Tris $\mathrm{pH} 8.2,100 \mathrm{mM} \mathrm{NaCl}, 10.288 \mathrm{mM} \mathrm{MgCl}$, $10.36 \mathrm{mM} \mathrm{KCl}, 2.07 \mathrm{mM} \mathrm{ATP}, 1.04 \mathrm{mM} \mathrm{DTT}, 62 \mathrm{mM} \mathrm{GdmCl}$ ) to a final protein concentration of $0.115 \mathrm{mg} \mathrm{mL}^{-1}$. Following dilution, the final concentrations are $20 \mathrm{mM}$ Tris $\mathrm{pH} 8.2,100 \mathrm{mM}$ $\mathrm{NaCl}, 10 \mathrm{mM} \mathrm{MgCl}_{2}, 10 \mathrm{mM} \mathrm{KCl}, 2 \mathrm{mM} \mathrm{ATP}, 1 \mathrm{mM}$ DTT and $60 \mathrm{mM} \mathrm{GdmCl}$. For the equivalent preparation of native lysates in cyto-serum, $3.5 \mu \mathrm{L}$ of normalized lysates (lysed in cyto-serum) were diluted with $96.5 \mu \mathrm{L}$ of cyto-serum native dilution buffer (1x cyto-serum, $0.1036 \mathrm{mM} \mathrm{DTT}, 62.17 \mathrm{mM} \mathrm{GdmCl}$ ) to a final protein concentration of $0.115 \mathrm{mg} \mathrm{mL}^{-1}$.

Following dilution, the final conentrations are $1 x$ cyto-serum, $0.1 \mathrm{mM} \mathrm{DTT}$ and $60 \mathrm{mM} \mathrm{GdmCl}$. To prepare native samples with the addition of molecular chaperones, $3.5 \mu \mathrm{L}$ of normalized lysates prepared in cyto-serum were diluted with $96.5 \mu \mathrm{L}$ of cyto-serum native dilution buffer (1x cyto-serum, $0.1036 \mathrm{mM} \mathrm{DTT}$ and $62.17 \mathrm{mM} \mathrm{GdmCl}$ supplemented with either $5.19 \mu \mathrm{M}$ DnaK, $1.04 \mu \mathrm{M}$ DnaJ and 1.04 $\mu \mathrm{M}$ GrpE; or $4.15 \mu \mathrm{M}$ GroEL and 8.3 $\mu \mathrm{M}$ GroES) to a protein concentration of $0.115 \mathrm{mg} \mathrm{mL}^{-1}$. Following dilution, the final concentrations are $1 x$ cyto-serum, $0.1 \mathrm{mM}$ DTT, $60 \mathrm{mM} \mathrm{GdmCl}$ and either $5 \mu \mathrm{M}$ DnaK, $1 \mu \mathrm{M}$ DnaJ, $1 \mu \mathrm{M}$ GrpE; or $4 \mu \mathrm{M}$ GroEL, 8 $\mu \mathrm{M}$ GroES. While preparing both native and refolding dilution buffers, molecular chaperones were added as the final component and used immediately to prevent them from prematurely utilizing all available ATP. Native samples were then equilibrated by incubating for $90 \mathrm{~min}$ at room temperature prior to limited proteolysis. We note here as an important detail that because cyto-serum dilution buffers containing chaperones must be used immediately, and because it is important for reproducibility's sake that the same buffer preparation is used for all 
samples, these experiments require three experimentalists working simultaneously to process the three biological replicate samples at the same time.

The refolding samples were prepared as follows: $600 \mu \mathrm{L}$ of normalized lysates, $100 \mathrm{mg}$ of solid $\mathrm{GdmCl}$, and $2.4 \mu \mathrm{L}$ of a freshly prepared $700 \mathrm{mM}$ DTT stock solution were added to a fresh 1.5 $\mathrm{mL}$ microfuge tube, and solvent was removed using a vacufuge plus to a final volume of 170 $\mu \mathrm{L}$, such that the final concentrations of all components were $11.6 \mathrm{mg} \mathrm{mL}^{-1}$ protein, $6 \mathrm{M}$ GdmCl, $70 \mathrm{mM}$ Tris pH 8.2, $350 \mathrm{mM} \mathrm{NaCl}, 7 \mathrm{mM} \mathrm{MgCl}$, and $10 \mathrm{mM}$ DTT; or $11.6 \mathrm{mg} \mathrm{mL}^{-1}, 6 \mathrm{M}^{2}$ GdmCl, 3.5x cyto-serum, and $10 \mathrm{mM}$ DTT. These unfolded lysates were incubated overnight at room temperature to complete unfolding prior to refolding.

As above, refolding samples were prepared with or without the addition of molecular chaperones. To prepare refolding samples without molecular chaperones, $99 \mu \mathrm{L}$ of refolding dilution buffer (19.5 mM Tris pH 8.2, 97.5 mM NaCl, 10.03 mM MgCl, 10.1 mM KCl, 2.02 mM ATP and $.909 \mathrm{mM}$ DTT; or 0.975x cyto-serum) were added to a fresh $1.5 \mathrm{~mL}$ microfuge tube. 1 $\mu \mathrm{L}$ of unfolded extract (Tris of cyto-serum) was then added to the tube containing the matching refolding dilution buffer (Tris or cyto-serum) and quickly mixed by rapid vortexing, diluting the sample by $100 x$, followed by flash centrifugation to collect liquids to the bottom of the tube. The final concentrations were $20 \mathrm{mM}$ Tris $\mathrm{pH} 8.2,100 \mathrm{mM} \mathrm{NaCl}, 10 \mathrm{mM} \mathrm{MgCl}_{2}, 10 \mathrm{mM} \mathrm{KCl}, 2 \mathrm{mM}$ ATP, $1 \mathrm{mM}$ DTT and $60 \mathrm{mM}$ GdmCl; or 1x cyto-serum, $0.1 \mathrm{mM}$ DTT and $60 \mathrm{mM} \mathrm{GdmCl}$. To prepare refolding samples with the addition of molecular chaperones, $99 \mu \mathrm{L}$ of refolding dilution buffer (0.975x cyto-serum supplemented with either $5.05 \mu \mathrm{M}$ DnaK, $1.01 \mu \mathrm{M}$ DnaJ and $1.01 \mu \mathrm{M}$ GrpE; or $4.04 \mu \mathrm{M}$ GroEL and $8.08 \mu \mathrm{M}$ GroES) were added to a fresh $1.5 \mathrm{~mL}$ microfuge tube. $1 \mu \mathrm{L}$ of unfolded lysate was then added to this refolding dilution buffer and quickly mixed by rapid vortexing, diluting the sample by $100 x$, followed by flash centrifugation to collect liquids to the bottom of the tube. The final concentrations were $1 \mathrm{x}$ cyto-serum, 0.1 mM DTT, $60 \mathrm{mM}$ GdmCl and either $5 \mu \mathrm{M}$ DnaK, $1 \mu \mathrm{M}$ DnaJ, $1 \mu \mathrm{M}$ GrpE; or $4 \mu \mathrm{M}$ GroEL, $8 \mu \mathrm{M}$ GroES. Refolded samples were then incubated at room temperature for $1 \mathrm{~min}, 5 \mathrm{~min}$ or $2 \mathrm{~h}$ to allow for proteins to refold prior to limited proteolysis. 


\section{Limited Proteolysis Mass Spectrometry Sample Preparation}

To perform limited proteolysis, $2 \mu \mathrm{L}$ of a PK stock (prepared as a $0.067 \mathrm{mg} \mathrm{mL}^{-1} \mathrm{PK}$ in a $1: 1$ mixture of Tris lysis buffer and $20 \%$ glycerol, stored at $-20^{\circ} \mathrm{C}$ and thawed at most only once) were added to a fresh $1.5 \mathrm{~mL}$ microfuge tube. After refolded proteins were allowed to refold for the specified amount of time ( $1 \mathrm{~min}, 5 \mathrm{~min}$, or $2 \mathrm{~h}$ ), or native proteins were allowed their $90 \mathrm{~min}$ equilibration, $100 \mu \mathrm{L}$ of the native/refolded lysates were added to the PK-containing microfuge tube and quickly mixed by rapid vortexing (enzyme:substrate ratio is a 1:100 w/w ratio (Feng et al., 2014)), followed by flash centrifugation to collect liquids to the bottom of the tube. Samples were incubated for exactly $1 \mathrm{~min}$ at room temperature before transferring them to a mineral oil bath preequilibrated at $110^{\circ} \mathrm{C}$ for 5 min to quench PK activity. Boiled samples were then flash centrifuged (to collect condensation on the sides of the tube), and transferred to fresh $1.5 \mathrm{~mL}$ microfuge tube containing $100 \mathrm{mg}$ urea such that the final urea concentration was $8 \mathrm{M}$ and the final volume was $158 \mu \mathrm{L}$. They are then vortexed to dissolve the urea to unfold all proteins and quench any further enzyme activity indefinitely, and flash centrifuged to collect liquids to the bottom of the tubes. Addition to urea is the only allowed pause point; all samples operate on a strict timetable from the moment they are refolded until this point. Moreover, once chaperones are added to cyto-serum, they must be used immediately: in the case of native samples, cytoserum native dilution buffers are added to proteins immediately after preparation, and then 90 min incubation begins. In the case of refolded samples, cyto-serum refolding buffers are added to unfolded proteins immediately after preparation, and then refolding times ( $1 \mathrm{~min}, 5$ min, $120 \mathrm{~min}$ ) begins. This method generates all limited proteolysis samples for this study. For the final studies used for the primary datasets, 63 separate samples were prepared for this experiment, they include: native and refolded in Tris, native and refolded in cyto-serum with and without molecular chaperones (DnaK/DnaJ/GrpE or GroEL/ES), and the appropriate biological triplicates for each category. In addition, native samples in cyto-serum prepared with and without GroEL/ES were each prepared on two separate occasions, creating a set of technical duplicates. Refolded samples for each of the three refolding timepoints were prepared in biological triplicates. The $1 \mathrm{~min}$ refolding timepoint in cyto-serum with and without GroEL/ES were each prepared on two separate occasions, creating a set of technical duplicates. An additional set was prepared for the 5 min refolding in cyto-serum with the 
addition of GroEL/ES. A representation of all samples prepared for this study is presented in Figure S1. We note here that LiP-MS studies typically prepare a series of parallel 'control' samples in which PK is withheld; these samples are then used for standard quantitative proteomics experiments to measure protein abundance differences across conditions (Feng et al., 2014; To et al., 2021). We opted to not perform this for the current study for the following reasons: (1) there is no practical way native and refolded samples that are compared to each other can have different protein abundances given that they are derived from the sample lysates; indeed, the samples compared to each other for these studies are compositionally identical and differ only in history; (2) our previous study (To et al., 2021) confirmed that refolded/native protein abundance ratios were equal to unity at a frequency higher than the false discovery rate.

All protein samples were prepared for mass spectrometry as follows: $2.25 \mu \mathrm{L}$ of a freshly prepared $700 \mathrm{mM}$ stock of DTT were added to each sample-containing microfuge tube to a final concentration of $10 \mathrm{mM}$. Samples were incubated at $37^{\circ} \mathrm{C}$ for 30 minutes at $700 \mathrm{rpm}$ on a thermomixer to reduce cysteine residues. $9 \mu \mathrm{L}$ of a freshly prepared $700 \mathrm{mM}$ stock of iodoacetamide (IAA) were then added to a final concentration of $40 \mathrm{mM}$, and samples were incubated at room temperature in the dark for 45 minutes to alkylate reduced cysteine residues. To assist trypsin in the digestion of samples with the addition of molecular chaperones, $1 \mu \mathrm{L}$ of $0.4 \mu \mathrm{g} \mu \mathrm{L}^{-1}$ Lys-C (NEB) stock was added (enzyme:substrate ratio of $1: 100 \mathrm{w} / \mathrm{w}$ ) and digestion proceeded for $2 \mathrm{~h}$ at $37^{\circ} \mathrm{C}$. After digestion with Lys-C, $471 \mu \mathrm{L}$ of 100 $\mathrm{mM}$ ammonium bicarbonate $(\mathrm{pH} 8)$ were added to the samples to dilute the urea to a final concentration of $2 \mathrm{M} .2 \mu \mathrm{L}$ of a $0.4 \mu \mathrm{g} \mu \mathrm{L}^{-1}$ stock of Trypsin (NEB) were added to the samples (to a final enzyme:substrate ratio of $1: 50 \mathrm{w} / \mathrm{w}$ ) and incubated overnight $\left(15-16 \mathrm{~h}\right.$ ) at $25^{\circ} \mathrm{C}$ at $700 \mathrm{rpm}$ (not $37^{\circ} \mathrm{C}$, so as to minimize decomposition of urea and carbamylation of lysines).

\section{Desalting of Mass Spectrometry Samples}

Peptides were desalted with Sep-Pak C18 1 cc Vac Cartridges (Waters) over a vacuum manifold. Tryptic digests were first acidified by addition of $16.6 \mu \mathrm{L}$ trifluoroacetic acid (TFA, Acros) to a final concentration of $1 \%$ (vol/vol). Cartridges were first conditioned ( $1 \mathrm{~mL} 80 \%$ 
ACN, $0.5 \%$ TFA) and equilibrated ( $4 \times 1 \mathrm{~mL} 0.5 \%$ TFA) before loading the sample slowly under a diminished vacuum (ca. $1 \mathrm{~mL} / \mathrm{min}$ ). The columns were then washed $(4 \times 1 \mathrm{~mL} 0.5 \% \mathrm{TFA})$, and peptides were eluted by addition of $1 \mathrm{~mL}$ elution buffer ( $80 \%$ ACN, $0.5 \%$ TFA). During elution, vacuum cartridges were suspended above $15 \mathrm{~mL}$ conical tubes, placed in a swingbucket rotor (Eppendorf 5910R), and spun for $3 \mathrm{~min}$ at $350 \mathrm{~g}$. Eluted peptides were transferred from Falcon tubes back into microfuge tubes and dried using a vacuum centrifuge (Eppendorf Vacufuge). Dried peptides were stored at $-80^{\circ} \mathrm{C}$ until analysis. For analysis, samples were vigorously resuspended in $0.1 \%$ FA in Optima water (ThermoFisher) to a final concentration of $0.5 \mathrm{mg} \mathrm{mL}^{-1}$.

\section{LC-MS/MS Acquisition}

Chromatographic separation of digests were carried out on a Thermo UltiMate3000 UHPLC system with an Acclaim Pepmap RSLC, C18, $75 \mu \mathrm{m} \times 25 \mathrm{~cm}, 2 \mu \mathrm{m}, 100 \AA$ column. Approximately, $1 \mu \mathrm{g}$ of protein was injected onto the column. Thecolumn temperature was maintained at $40{ }^{\circ} \mathrm{C}$, and the flow rate was set to $0.300 \mu \mathrm{L} \mathrm{min}$ - $^{-1}$ for the duration of the run. Solvent $A(0.1 \% F A)$ and Solvent $B(0.1 \% F A$ in $A C N)$ were used as the chromatography solvents. The samples were run through the UHPLC System as follows: peptides were allowed to accumulate onto the trap column (Acclaim PepMap 100, C18, $75 \mu \mathrm{m} \times 2 \mathrm{~cm}, 3 \mu \mathrm{m}, 100 \AA$ column) for 10 min (during which the column was held at $2 \%$ Solvent B). The peptides were resolved by switching the trap column to be in-line with the separating column, quickly increasing the gradient to 5\% B over 5 min and then applying a 95 min linear gradient from 5\% B to $25 \%$ B. Subsequently, the gradient was increased from $35 \%$ B to $40 \%$ B over 25 min and then increased again from $40 \%$ B to $90 \%$ B over 5 min. The column was then cleaned with a sawtooth gradient to purge residual peptides between runs in a sequence.

A Thermo Q-Exactive HF-X Orbitrap mass spectrometer was used to analyze protein digests. A full MS scan in positive ion mode was followed by 20 data-dependent MS scans. The full MS scan was collected using a resolution of 120000 (@ m/z 200), an AGC target of 3E6, a maximum injection time of $64 \mathrm{~ms}$, and a scan range from 350 to $1500 \mathrm{~m} / \mathrm{z}$. The datadependent scans were collected with a resolution of 15000 (@ m/z 200), an AGC target of 
1E5, a minimum AGC target of 8E3, a maximum injection time of $55 \mathrm{~ms}$, and an isolation window of $1.4 \mathrm{~m} / \mathrm{z}$ units. To dissociate precursors prior to their reanalysis by MS2, peptides were subjected to an HCD of $28 \%$ normalized collision energies. Fragments with charges of 1 , 6,7 , or higher and unassigned were excluded from analysis, and a dynamic exclusion window of $30.0 \mathrm{~s}$ was used for the data-dependent scans. For pseudo-SILAC samples, mass tags were enabled with $\Delta \mathrm{m}$ of 2.00671 Th, 3.01007 Th, 4.01342 Th, and 6.02013 Th (to account for the fixed 6 or 12 Da mass shifts in different charge states) to promote selection of nonchaperone-derived peptides for isolation and data-dependent MS2 scans.

\section{LC-MS/MS Data Analysis}

Proteome Discoverer (PD) Software Suite (v2.4, Thermo Fisher) and the Minora Algorithm were used to analyze mass spectra and perform Label Free Quantification (LFQ) of detected peptides. Default settings for all analysis nodes were used except where specified. The data were searched against Escherichia coli (UP000000625, Uniprot) reference proteome database. For peptide identification, either the PD Sequest HT node (for non-pseudo-SILAC samples) or PD MSFragger node (pseudo-SILAC) were used, each using a semi-tryptic search allowing up to 2 missed cleavages. A precursor mass tolerance of $10 \mathrm{ppm}$ was used for the MS1 level, and a fragment ion tolerance was set to $0.02 \mathrm{Da}$ at the MS2 level for both search algorithms. For Sequest HT, a peptide length between 6 and 144 amino acid residues was allowed. For MSFragger, a peptide length between 7 and 50 amino acid residues was allowed with a peptide mass between 500 and 5000 Da. Additionally, a maximum charge state for theoretical fragments was set at 2 for MSFragger. Oxidation of methionine and acetylation of the N-terminus were allowed as dynamic modifications while carbamidomethylation on cysteines was set as a static modification. For pseudo-SILAC samples, heavy isotope labeling $\left({ }^{13} \mathrm{C}_{6}\right)$ of Arginine and Lysine were allowed as dynamic modifications. All parameters for Sequest HT and MSFragger search algorithms are provided in the table below. The Percolator PD node was used for FDR validation for peptides identified with the Sequest HT search algorithm. For peptides identified with the MSFragger search algorithm, the Philosopher PD node was used for FDR validation. Raw normalized extracted ion intensity data for the identified peptides were exported from the .pdResult file using a three-level hierarchy (protein 
$>$ peptide group > consensus feature). These data were further processed utilizing custom Python analyzer scripts (available on GitHub, and described in depth previously in To et al., 2021). Briefly, normalized ion counts were collected across the refolded replicates and the native replicates for each successfully identified peptide group. Effect sizes are the ratio of averages (reported in $\log _{2}$ ) and P-values (reported as - $\log _{10}$ ) were assessed using $t$ tests with Welch's correction for unequal population variances. Missing data are treated in a special manner. If a feature is not detected in all three native (or refolded) injections and is detected in all three refolded (or native) injections, we use those data, and fill the missing values with 1000 (the ion limit of detection for this mass analyzer); this peptide becomes classified as an all-ornothing peptide. If a feature is not detected in one out of six injections, the missing value is dropped. Any other permutation of missing data (e.g., missing in two injections) results in the quantification getting discarded. In many situations, our data provide multiple independent sets of quantifications for the same peptide group. This happens most frequently because the peptide is detected in multiple charge states or as a heavy isotopomer. In this case, we calculate effect size and P-value for all features that map to the same peptide group. If the features all agree with each other in sign, they are combined: the quantification associated with the median amongst available features is used and the P-values are combined with Fisher's method. If the features disagree with each other in sign, the P-value is set to 1. Coefficients of variation (CV) for the peptide abundance in the three replicate refolded samples are also calculated. Analyzer returns a file listing all the peptides that can be confidently quantified, and provides their effect-size, $\mathrm{P}$-value, refolded $\mathrm{CV}$, proteinase $\mathrm{K}$ site (if half-tryptic), and associated protein metadata.

\begin{tabular}{|l|l|l|}
\hline & SequestHT & MSFragger \\
\hline Peak Matching and Outputting & & \\
\hline Precursor Mass Tolerance & $10 \mathrm{ppm}$ & $10 \mathrm{ppm}$ \\
\hline Fragment Mass Tolerance & $20 \mathrm{ppm}$ & $20 \mathrm{ppm}$ \\
\hline Use Average Precursor Mass & FALSE & $\mathrm{N} / \mathrm{A}$ \\
\hline Use Average Fragment Mass & FALSE & $\mathrm{N} / \mathrm{A}$ \\
\hline Isotope Error & N/A & $0 / 1 / 2$ \\
\hline Localized Delta Mass & N/A & 0 \\
\hline Delta Mass Exclude Ranges & N/A & $(-1.5,3,5)$ \\
\hline Max. Precursor Charge & N/A & 4 \\
\hline & & \\
\hline Digestion & & \\
\hline Enzyme & & Trypsin (semi) \\
\hline
\end{tabular}




\begin{tabular}{|c|c|c|}
\hline Min. Peptide Length & 6 & 7 \\
\hline Max. Peptide Length & 144 & 50 \\
\hline Max. Missed Cleavage Sites & 2 & 2 \\
\hline Min. Peptide Mass & $\mathrm{N} / \mathrm{A}$ & 500 \\
\hline Max. Peptide Mass & $\mathrm{N} / \mathrm{A}$ & 5000 \\
\hline $\begin{array}{l}\text { Maximum Charge State for } \\
\text { Theoretical Fragments to Match }\end{array}$ & $\mathrm{N} / \mathrm{A}$ & 2 \\
\hline Clip n Term M & $\mathrm{N} / \mathrm{A}$ & TRUE \\
\hline \multicolumn{3}{|l|}{ Spectrum Matching } \\
\hline Use of Neutral Loss a lons & TRUE & $\mathrm{N} / \mathrm{A}$ \\
\hline Use of Neutral Loss b lons & TRUE & $\mathrm{N} / \mathrm{A}$ \\
\hline Use of Neutral Loss y lons & TRUE & $\mathrm{N} / \mathrm{A}$ \\
\hline Use Ranking lons & TRUE & $\mathrm{N} / \mathrm{A}$ \\
\hline Weight of a lons & 0 & $\mathrm{~N} / \mathrm{A}$ \\
\hline Weight of a lons & 1 & $\mathrm{~N} / \mathrm{A}$ \\
\hline Weight of a lons & 0 & N/A \\
\hline Weight of a lons & 0 & $\mathrm{~N} / \mathrm{A}$ \\
\hline Weight of a lons & 1 & $\mathrm{~N} / \mathrm{A}$ \\
\hline Weight of a lons & 0 & $\mathrm{~N} / \mathrm{A}$ \\
\hline \multicolumn{3}{|l|}{ Spectral Processing } \\
\hline Min. Peaks & $\mathrm{N} / \mathrm{A}$ & 15 \\
\hline Min. Fragments Modeling & $\mathrm{N} / \mathrm{A}$ & 2 \\
\hline Min. Ratio & $\mathrm{N} / \mathrm{A}$ & 0.01 \\
\hline Use Top N Peaks & $\mathrm{N} / \mathrm{A}$ & 150 \\
\hline Min. Matched Fragments & $\mathrm{N} / \mathrm{A}$ & 3 \\
\hline Min. Clear m/z Range & $\mathrm{N} / \mathrm{A}$ & 0 \\
\hline Max. Clear m/z Range & $\mathrm{N} / \mathrm{A}$ & 0 \\
\hline Mass Callibration & $\mathrm{N} / \mathrm{A}$ & On and find optimal parameters \\
\hline \multicolumn{3}{|l|}{ Modifications } \\
\hline $\begin{array}{l}\text { Max. Equal Modifications Per } \\
\text { Peptide }\end{array}$ & 3 & N/A \\
\hline Multiple Variable Mods on Residue & $\mathrm{N} / \mathrm{A}$ & TRUE \\
\hline Max. Variable Mods per Peptide & N/A & 3 \\
\hline Max. Variable Mods Combinations & N/A & 5000 \\
\hline Mass Offsets & $\mathrm{N} / \mathrm{A}$ & 0 \\
\hline \multicolumn{3}{|l|}{ Dynamic Modifications } \\
\hline Oxidation & +15.995 Da (M) & +15.995 Da (M) \\
\hline Label: $13 \mathrm{C6}$ & $\mathrm{N} / \mathrm{A}$ & $+6.020 \mathrm{Da}(\mathrm{K}, \mathrm{R})$ \\
\hline Acetyl & +42.011 Da (Any N-Terminus) & +42.011 Da (Any N-Terminus) \\
\hline \multicolumn{3}{|l|}{ Static Modifications } \\
\hline Carbamidomethyl & +57.021 Da (C) & +57.021 Da (C) \\
\hline
\end{tabular}

\section{Refoldability Analysis}


Results from analyzer are digested in the following way. Proteins with only one peptide confidently quantified are discounted; proteins with more than two are kept. Peptides are considered to have significantly different abundance in the refolded sample if the effect size is 2 or greater (more than double or less than half the abundance of native), and the P-value is less than 0.01 by Welch's $t$ test. All-or-nothing peptides must have abundance differences greater than 64-fold, and use a relaxed P-value cut-off of 0.0158 . The number of significant and all-or-nothing peptides is counted for each protein (or, in the case of Figure 5I, for each domain, whose residue ranges are provided and where peptides are only assigned to a given domain if the PK cut site or the full tryptic range falls within the domain boundaries). Proteins (or domains) are deemed nonrefoldable if two or more peptides with significantly different abundances in the refolded sample are identified.

Protein-level refoldability analyses proceed by counting the number of refoldable and nonrefoldable proteins within a set of categories (e.g., $5<\mathrm{pl}<6$ ) associated with a feature (e.g., pl) and calculating the fraction refolding within the category. To determine if there is a significant enrichment for (non-)refolders within certain categories, we calculate the expected number of (non-)refolders for each category by taking the total number of proteins that are assigned a value under the feature in question, times the fraction (non-)refolding, times the fraction of proteins in that category. The chi-square test is used to determine if the observed counts and expected counts significantly differ, for all cases in which the feature has three or more categories. If it only has two, Fisher's exact test is used instead.

Peptide-level refoldability analyses are performed in a similar way. The total number of significant and nonsignificant peptides mapped to proteins within a set of categories associated with a feature are counted and the percentage significant calculated. To determine if there is a significant enrichment for (non-)significant peptides associated with certain categories, we calculate the expected number of (non-)significant peptides for each category by taking the total number of peptides associated with proteins that are assigned a value under the feature in question, times the fraction of peptides that are (non-)significant, times the fraction of peptides associated with that category. The chi-square test is used to determine if 
the observed counts and expected counts significantly differ, for all cases in which the feature has three or more categories. If it only has two, Fisher's exact test is used instead.

For condition comparisons (i.e., comparing Tris to cyto-serum, or refolding with GroEL/ES vs. DnaK/J/E), we performed 12-way LFQs, and created a slightly modified analyzer script that assesses peptide quantifications separately for the six samples associated with condition 1 and the six samples associated with sample 2. The analyzer returns a file listing all the peptides that can be confidently quantified, and provides their effect-size, P-value and refolded CV for condition 1 and 2, proteinase $\mathrm{K}$ site (if half-tryptic), and associated protein metadata. Similar to before the number of significant and all-or-nothing peptides are counted for each protein in condition 1 and 2. Proteins are only admitted into the comparison if 2 or more peptides are identified in both conditions, and are classified as refolding in both, refolding in condition 1, refolding in condition 2, or nonrefolding in both. Proteins are discarded if they are on the border; e.g., one significant peptide assigned in condition 1 and two significant peptides assigned in condition 2.

For these analyses, we count the number of proteins associated with a given category (e.g., 5 $<\mathrm{pl}<6$ ) that refold in both, refold in condition 1, refold in condition 2, or do not refold in either. For each category, expected counts are calculated by taking the total number of proteins in that category times the overall fraction of proteins that refold in both, refold in condition 1 , refold in condition 2, or do not refold in either. The chi-square test is used to determine if the observed counts and expected counts significantly differ. Note that these tests are conducted on individual categories (e.g., the $5<\mathrm{pl}<6$ category is enriched for proteins that refold with GroEL/ES but not without it), whereas previously, the test is conducted on the feature overall (e.g., pl groups do not all refold with the same frequency).

For kinetic comparisons (i.e., comparing proteins that have refolded in cyto-serum for 1 min or $5 \mathrm{~min}$ ), we combined results from the separate timepoints by collecting the subset of proteins that were identified in both experiments and compiling together the number of significant and all-or-nothing peptides that are counted for each protein at timepoint 1 and 2. Proteins are 
only admitted into the comparison if 2 or more peptides are identified at both timepoints, and are classified as refolding in both (fast refolder), refolding at the later timepoint (slow refolder), or refolding at the earlier timepoint (fold loser). Nonrefolders are not used for kinetic comparisons. Proteins are discarded if they are on the border; e.g., one significant peptide assigned at timepoint 1 and two significant peptides assigned in timepoint 2 . The analyses and chi-square tests are done analogously as above, for the condition comparisons.

\section{Bioinformatics}

Ecocyc database (Keseler et al., 2017) was used to obtain information about cellular compartment (cytosol, inner membrane, periplasmic space, outer membrane, ribosome, cell projection), subunit composition, essentiality, copy number, cofactors, and molecular weight (from nucleotide sequence) for each protein. When the information was available, we used Ecocyc's Component Of category to obtain the full constitutive composition of the protomer within a complex.

Copy number information predominantly comes from a single ribosome profiling study by Li and co-workers (2014). We used copy number in Neidhardt EZ rich defined medium because of its similarity to the growth medium used in these studies.

Domain information was based on the SCOP hierarchy and obtained through the Superfamily database (http://supfam.org) (Gough et al., 2001; Pandurangan et al., 2019). We used custom scripts to edit the "raw" file available from supfam. org into a format more usable for our purposes (including the switch from a Uniprot identifier to the gene symbol identifier). This database was used to count the number of domains per protein, and to perform the domainlevel analysis in which peptides are mapped to individual domains within proteins based on residue ranges. Domains are categorized by their 'fold.' Note that in SCOP, folds correspond to collections of superfamilies with similar topologies, and in most situations (but not always) correspond to deep evolutionary relationships (Cheng et al., 2014). 
Gene ontology analysis was conducted using PantherDB (Mi et al., 2019). The set of 105 chaperone-nonrefolders was entered as the test set, and the E. coli proteome used as the reference set. Statistical overrepresentation tests were selected using the complete set of GO biological processes.

Isoelectric effects were obtained from the isoelectric database (Kozlowski, 2017). We downloaded the file corresponding to E. coli K-12 MG1655 and took an average of the isoelectric points calculated by all the algorithms available for each protein. Chaperonin classes were obtained from Kerner et al. (2005). Specifically, we examined Table S3, manually identified the current Uniprot accession code for each of the proteins identified by Kerner et al., and transferred this information into a file that contains the gene symbol, the current Uniprot accession code, and the class assignment. We also compiled information from Fujiwara et al. (2010) which breaks down class III proteins into class III- and class IV.

\section{QUANTIFICATION AND STATISTICAL ANALYSIS}

All analyses of aggregation were conducted on independent refolding reactions from independent biological replicates $(n=3)$. Raw values shown for pelleting assay and significance by $t$ test with Welch's correction for unequal population variances. Analytical ultracentrifugation and mass photometry data shown from representative examples from among replicates.

Standard target-decoy based approaches were used to filter protein identifcations to an FDR < $1 \%$, as implemented by Percolator (when searching with Sequest), or Philosopher (when searching with MSFragger).

All mass spectrometry experiments were conducted on three biological replicates used to generate three native samples and three independent refolding reactions from the same biological replicates. For each peptide group, abundance difference in refolded relative to native was judged by the $t$ test with Welch's correction for unequal population variances. Fisher's method was used to combine P-values when there were multiple quantifiable features per peptide group. P-values less than 0.01 were used as a requirement to consider a region 
bioRxiv preprint doi: https://doi.org/10.1101/2021.11.20 469408; this version posted November 21, 2021. The copyright holder for this preprint (which was not certified by peer review) is the author/funder, who has granted bioRxiv a license to display the preprint in perpetuity. It is made available under aCC-BY-NC-ND 4.0 International license.

structurally distinct in the refolded form. Differences in means of distributions are assessed with the Mann-Whitney rank-sum test. To test whether particular categories are enriched with (or de-enriched with) (non)refoldable proteins, the chi-square test or Fisher's exact test is used.

\section{SUPPLEMENTAL FIGURES}


bioRxiv preprint doi: https://doi.org/10.1101/2021.11.20.469408; this version posted November 21, 2021. The copyright holder for this preprint (which was not certified by peer review) is the author/funder, who has granted bioRxiv a license to display the preprint in perpetuity. It is made available under aCC-BY-NC-ND 4.0 International license.

A

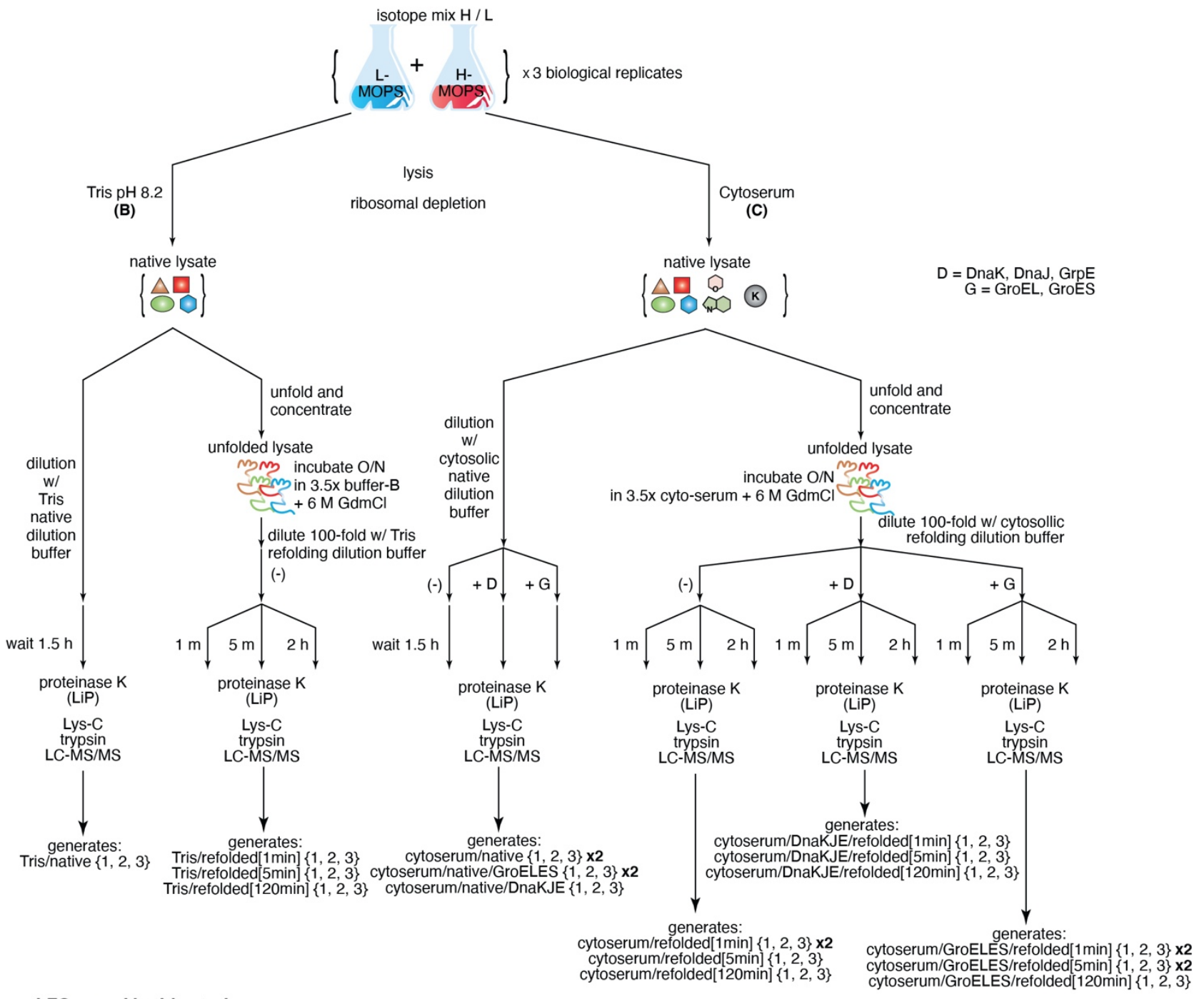

6-way LFQs used in this study

Refolding in Tris

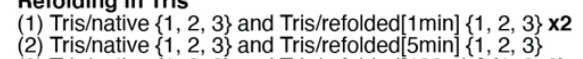

(2) Tris/native $\{1,2,3\}$ and Tris/refolded[5min $\{1,2,3\}$
(3) Tris/native $\{1,2,3\}$ and Tris/refolded[120min] $\{1,2,3\}$

Refolding in cytoserum

(4) cytoserum/native $\{1,2,3\}$ and cytoserum/refolded[1 $1 \mathrm{~min}]\{1,2,3\} \mathbf{x 2}$

(5) cytoserum/native $\{1,2,3\}$ and cytoserum/refolded[5min] $\{1,2,3\}$

(6) cytoserum/native $\{1,2,3\}$ and cytoserum/refolded[120min] $\{1,2,3\}$

\section{Refolding in cytoserum and with GroEL/ES}

(7) cytoserum/native/GroELES $\{1,2,3\}$, and cytoserum/GroELES/refolded[1 $\mathrm{min}]\{1,2,3\} \times 2$

(9) cytoserum/native/GroELES $\{1,2,3\}$, and cytoserum/GroELES/refolded[120min] $\{1,2,3\}$ **

\section{C}

12-way LFQs used in this study

Comparing refolding in Tris vs in cytoserum

(a) Tris/native $\{1,2,3\}$, Tris/refolded[1 $1 \mathrm{~min}]\{1,2,3\}$, cytoserum/native $\{1,2,3\}$, and cytoserum/refolded[1 $\min ]\{1,2,3\}$

(b) Tris/native $\{1,2,3\}$, Tris/refolded[5min] $\{1,2,3\}$, cytoserum/native $\{1,2,3\}$, and cytoserum/refolded[5min] $\{1,2,3\}$

(c) Tris/native $\{1,2,3\}$, Tris/refolded[120min] $\{1,2,3\}$, cytoserum/native $\{1,2,3\}$, and cytoserum/refolded[120min] $\{1,2,3\}$

Comparing refolding in cytoserum with and without GroEL

(d) cytoserum/native $\{1,2,3\}$, and cytoserum/refolded[1 $\mathrm{min}]\{1,2,3\}$, cytoserum/native/GroELES $\{1,2,3\}$, and cytoserum/GroELES/refolded[1 $1 \mathrm{~min}]\{1,2,3\}$
(e) cytoserum/native $\{1,2,3\}$, and cytoserum/refolded[5min $\{1,2,3\}$, cytoserum/native/GroELES $\{1,2,3\}$, and cytoserum/GroELES/refolded[5min] $\{1,2,3\}$

(f) cytoserum/native $\{1,2,3\}$, and cytoserum/refolded[120min] $\{1,2,3\}$, cytoserum/native/GroELES $\{1,2,3\}$, and cytoserum/GroELES/refolded[120min] $\{1,2,3\}$

Comparing refolding in cytoserum with DnaK and with GroEL

(g) cytoserum/native/DnaKJE $\{1,2,3\}$, cytoserum/DnaKJE/refolded[1min] $\{1,2,3\}$, cytoserum/native/GroELES $\{1,2,3\}$, and cytoserum/GroELES/refolded[1min] $\{1,2,3\}$

(h) cytoserum/native/DnaKJE $\{1,2,3\}$, cytoserum/DnaKJE/refolded[5min] $\{1,2,3\}$, cytoserum/native/GroELES $\{1,2,3\}$, and cytoserum/GroELES/refolded[5min] $\{1,2,3\}$

(i) cytoserum/native/DnaKJE $\{1,2,3\}$, cytoserum/DnaKJE/refolded[120min] $\{1,2,3\}$, cytoserum/native/GroELES $\{1,2,3\}$, and cytoserum/GroELES/refolded[120min] $\{1,2,3\}$

Figure S1. Summary of all samples prepared for LC-MS/MS, and their combinations to perform label-free quantification (LFQ) analyses, related to Figures 1, 2, 4, 5, and 6. 
(A) Experimental workflow to prepare the 63 samples for LC-MS/MS used in the final experiments published in this study. See Star*Methods for more details. In brief: three E. coli cultures are grown in light MOPS media and three E. coli cultures are grown in heavy MOPS media. Pairs are mixed together, and cells are gathered by centrifugation. Pellets are either resuspended in Tris lysis buffer (left branch), or cytoserum lysis buffer (right branch). The Tris-lysed samples are either diluted in Tris native dilution buffer to generate the Tris/native samples, or unfolded into $6 \mathrm{M} \mathrm{GdmCl}$, and refolded by 100 -fold dilution into Tris refolding dilution buffer to generate the Tris/refolded samples. The native samples are probed by limited proteolysis (LiP) with proteinase $\mathrm{K}$ (PK) after equilibration. The refolded samples are probed similarly, but at 3 different timepoints following initiation of refolding by dilution ( $1 \mathrm{~min}, 5 \mathrm{~min}$, and $120 \mathrm{~min}$ ). The cytoserum-lysed samples are either diluted in cytoserum native dilution buffer to generate cytoserum/native samples, or diluted in cytoserum native dilution buffers supplemented with GroEL/ES or DnaK/J/E. Following equilibration, they are probed with proteinase K. Alternatively, cytoserum lysates are unfolded into $6 \mathrm{M} \mathrm{GdmCl}$, and refolded by 100 -fold dilution into cytoserum refolding buffer, either supplemented with GroEL/ES, DnaK/J/E, or neither, and given either $1 \mathrm{~min}, 5 \mathrm{~min}$, or 120 min to refold prior to interrogation with PK. In all cases, immediately following 1 min of LiP, samples are quenched by boiling, fully trypsinized with LysC and trypsin, and prepared for LC-MS/MS.

(B) Summary of the nine 6-way LFQs used in this study, and which set of six samples are analyzed together to generate the peptide refolded/native quantifications. Figure 2A,C (1); Figure 2B,D (4); Figure 4A (8); Figure 4B,C (5 left, 8 right); Figure 4D, E (2, 5, 8); Figure 4I (5, 8); Figure 5A,C,E,G (4-both reps., 5, 6); Figure 5B,D,F,H (7both reps., 8-both reps.); Figure 5I (5, 8); Figure 6B (1-9 \& see below); Figure 6C (combination of 7, 8). ${ }^{\star *}$ The $2 \mathrm{~h}$ timepoint for GroELES refolding was generally not used because of ATP depletion.

(C) Summary of the nine 12-way LFQs used in this study, and which set of twelve samples are analyzed together to generate peptide refolded/native quantifications. Figure $2 F, G(b)$; Figure 4F, G, H (e); Figure 6A (h- extracting out the DnaK subexperiment); Figure 6B (g, h, i, \& see above); Figure 6D (combination of g, h); Figure 6E (h), Figure 6F,G,H (h); Figure 7C (h); Figure 7E (e) 


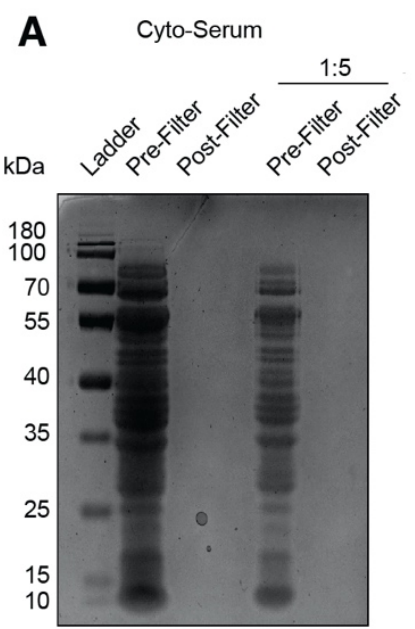

B

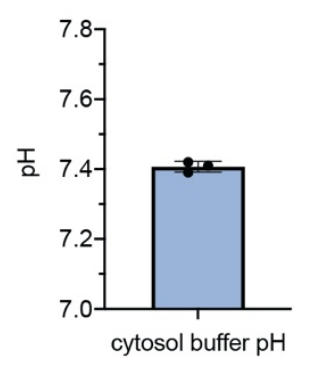

C

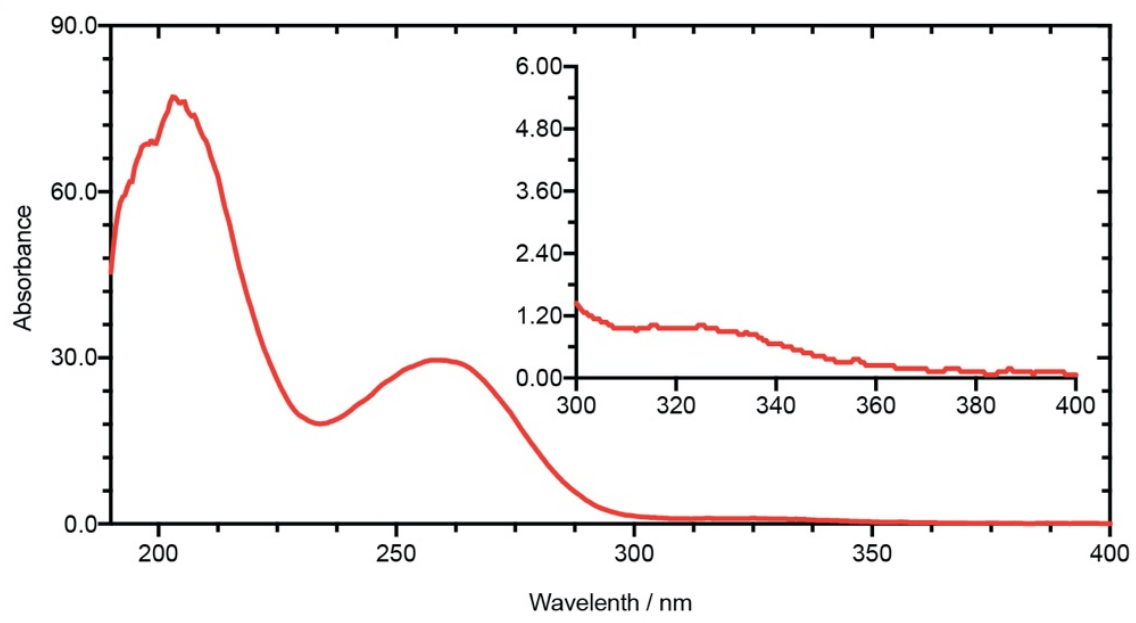

D

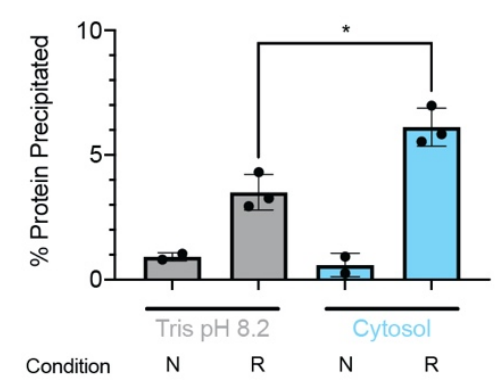

E

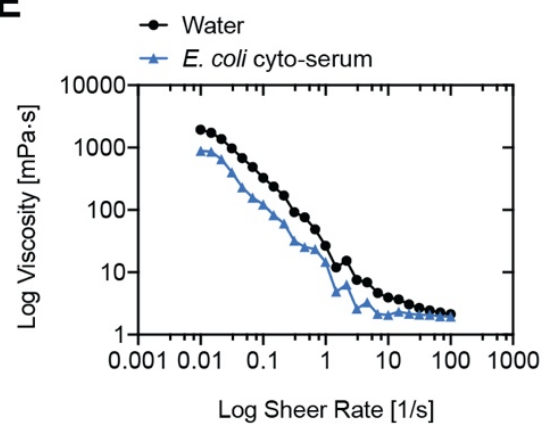

Figure S2. Characterization of cyto-serum, related to Figures 1 and 2.

(A) Coomassie staining of SDS-PAGE of cyto-serum pre and post filtration with Viva-Spin 15R 2K MWCO Filter (Sartorius) as a $1 \mathrm{x}$ and a 1:5 dilution. Filtration effectively removes all macromolecules larger than $2 \mathrm{kDa}$; see experimental procedures.

(B) Bar chart showing the $\mathrm{pH}$ readings of 3 independent preparations of cyto-serum.

(C) UV-VIS spectra obtained of $1 x$ cyto-serum. Cyto-serum is an off yellow liquid with a strong absorbance at 258 $\mathrm{nm}$. Absorbances observed between $200 \mathrm{~nm}-360 \mathrm{~nm}$ indicate the presence of ions, metabolites, and cofactors present in cyto-serum.

(D) Bar charts showing the quantification of protein aggregation of native and refolded samples in Tris $\mathrm{pH} 8.2$ and cyto-serum using BCA Assay. Refolding in cyto-serum resulted in a small but significant increase in detected protein precipitation upon refolding $(\mathrm{P}<0.05$ by Welch's t-test) when compared to refolding in Tris $\mathrm{pH}$ 8.2.

(E) Log-log diagram showing viscosity of cyto-serum and water as a function of sheer rate. E. coli cyto-serum is a non-viscous fluid with rheometric properties similar to water. 
A $\quad$ B
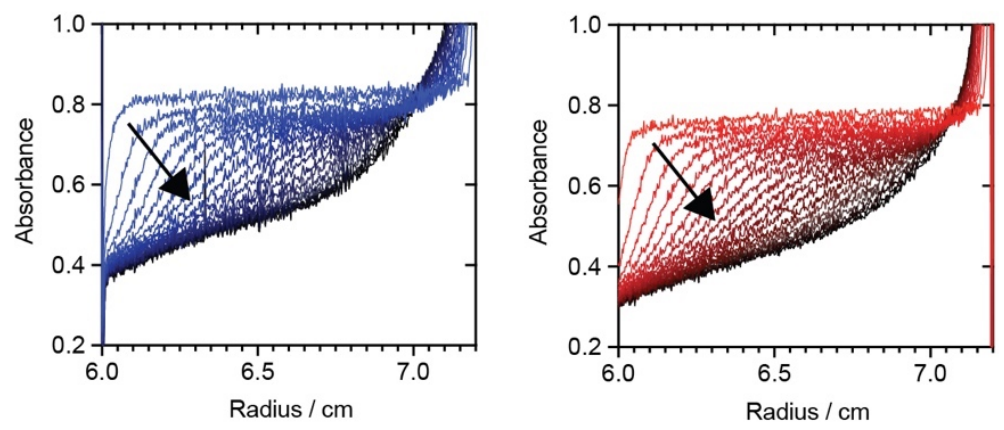

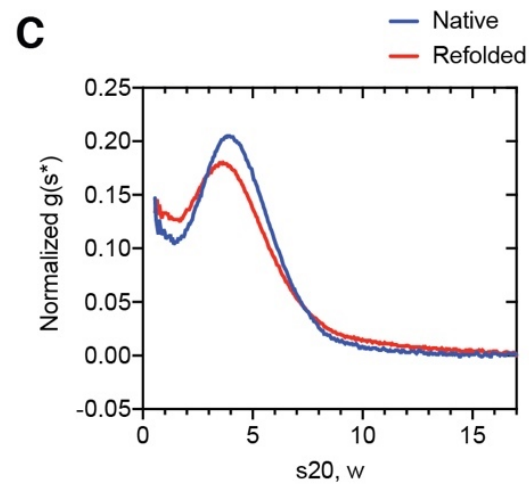

D

$$
\text { - Native }
$$

\section{E}

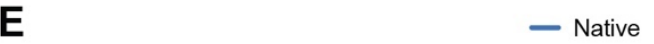

- Refolded $5 \mathrm{~min}$

Tris pH $8.2 \quad-$ Refolded $2 \mathrm{~h}$
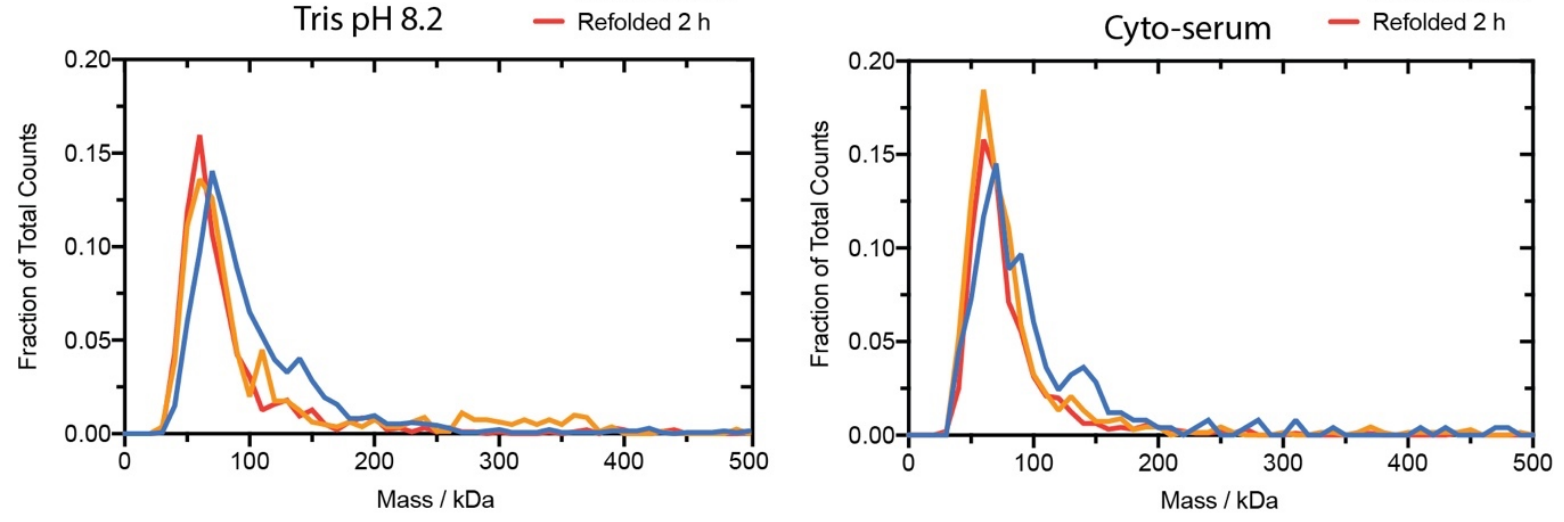

Figure S3. Low aggregation during global refolding reactions in Tris and cytoserum.

(A-B) Absorbance at $280 \mathrm{~nm}$ as a function of radius along the rotor during sedimentation velocity analytical ultracentrifugation of native $(A)$ and refolded $(B)$ E. coli lysates in Tris $\mathrm{pH}$ 8.2. Data from first 100 scans are shown ,with each subsequent line representing every $5^{\text {th }}$ scan in directionality of arrow. These datasets are representative of three independent spins on three separately prepared native and refolded lysates.

(C) Calculated sedimentation coefficient distirbutions of native and refolded $E$. coli lysates in Tris $\mathrm{pH}$ 8.2, as determined by dcdt+ and SEDNTERP. These datasets are representative of three independent spins on three separately prepared native and refolded lysates.

(D-E) Normalized mass distributions of native and refolded $E$. coli lysates ( $5 \mathrm{~min}$ and $2 \mathrm{~h}$ ) in Tris $\mathrm{pH} 8.2$ (D) and cyto-serum (E) as determined by Mass Photometry (MP). All three sample types show overlaying mass distributions in both refolding buffers (Tris or cyto-serum), indicative that there are minimal differences in soluble aggregation between native and refolded samples. 
bioRxiv preprint doi: https://doi.org/10.1101/2021.11.20.469408; this version posted November 21, 2021. The copyright holder for this preprint (which was not certified by peer review) is the author/funder, who has granted bioRxiv a license to display the preprint in perpetuity. It is made available under aCC-BY-NC-ND 4.0 International license.

A Tris buffer $(\mathrm{pH} 8.2)$

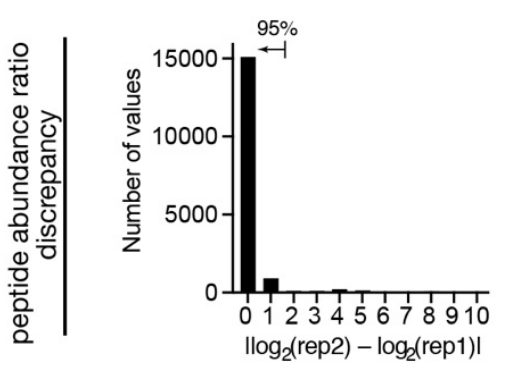

D
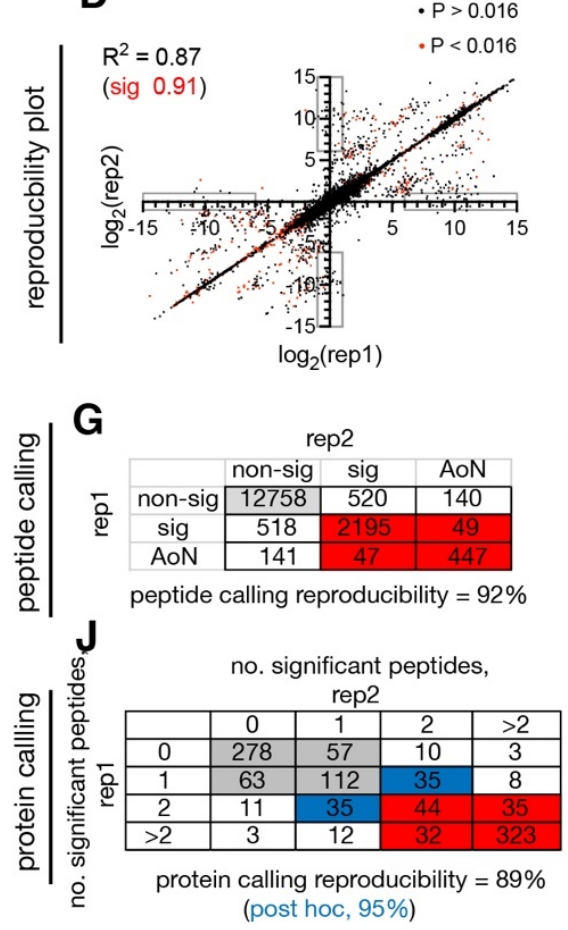

M Tryptic

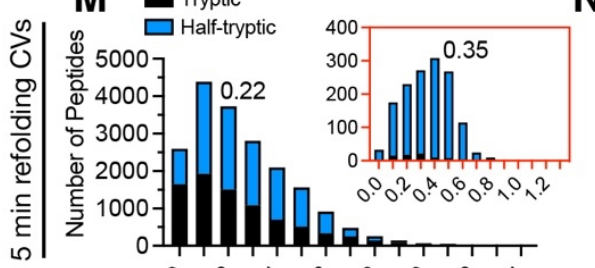

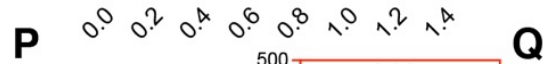

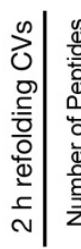

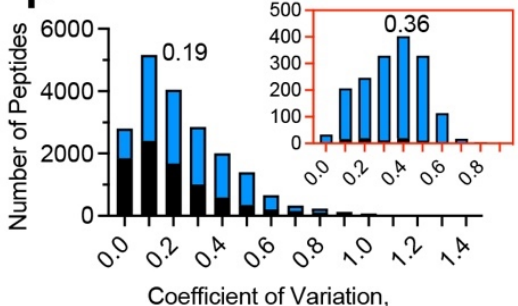

Peptide Abundance across Refolded Reps.
B

cyto-serum

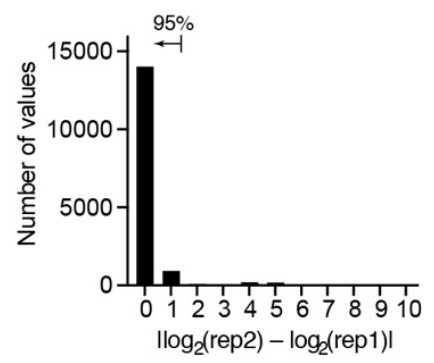

E

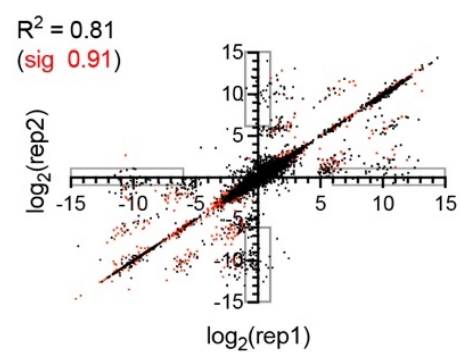

H

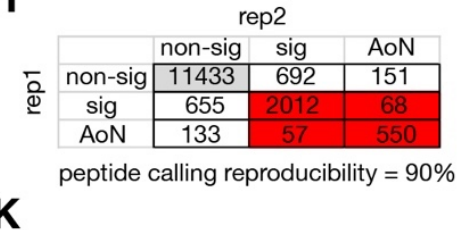

no. significant peptides,

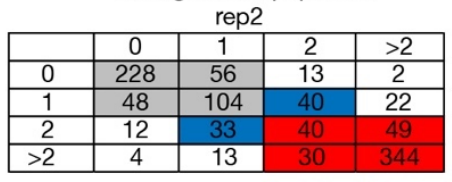

protein calling reproducibility $=87 \%$ (post hoc, 93\%)

$\mathbf{N}$
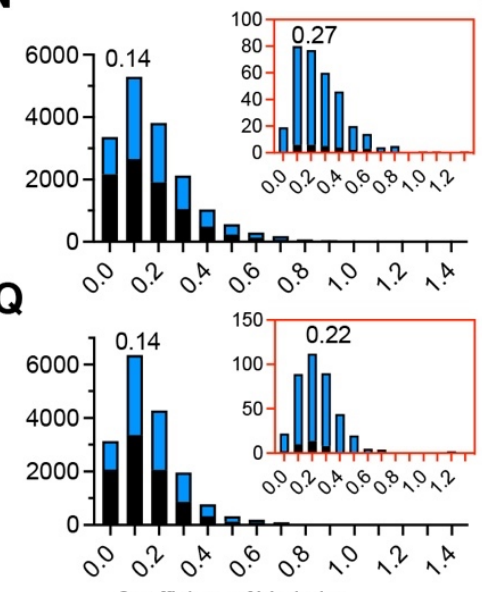

Coefficient of Variation,

Peptide Abundance across Refolded Reps.
C cyto-serum + GroEL/ES

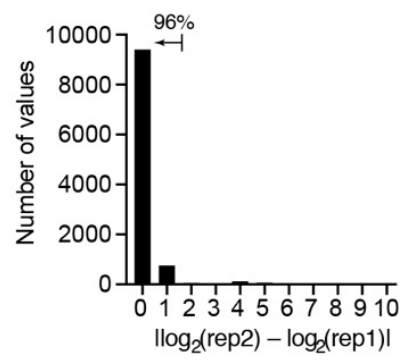

F

$$
R^{2}=0.74
$$

(sig 0.87)

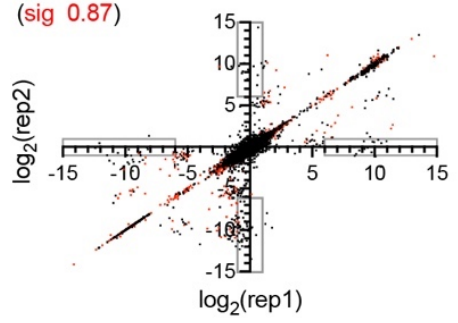

I

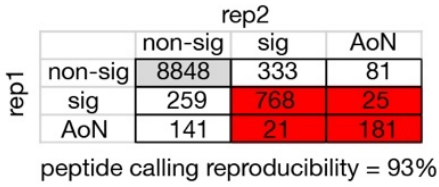

no. significant peptides,

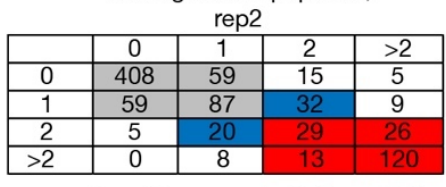

protein calling reproducibility $=89 \%$ (post hoc, 95\%)

0

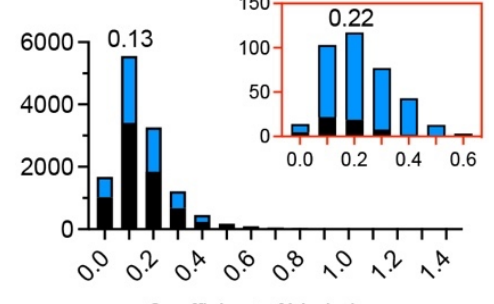

Coefficient of Variation,

Peptide Abundance across Refolded Reps. 


\section{Figure S4. Reproducibility analysis.}

$(A-C)$ Histograms showing the peptide quantification discrepancies between two replicates of the experiment in which proteins were refolded for $1 \mathrm{~min}$ in (A) Tris buffer, (B) cyto-serum, or (C) cyto-serum with GroEL/ES. These correspond to the two replicates of LFQ 1, 4, and 7 from Figure S1B. Note that each of these replicates of the experiment involved three separate biological replicates of native and refolded. Peptides that were identified in both experiments were collected and the refolded/native ratio in each replicate was compared to each other. Histograms show the absolute value of the difference of the log2 quantifications. (A) 16815 peptides were identified in common, of which $90 \%$ were within 1.4 -fold and $95 \%$ were within 3.8 -fold. (B) 15751 peptides were identified in common, of which $89 \%$ were within 1.4 -fold and $95 \%$ were within 3.8 -fold. (C) 10564 peptides were identified in common, of which $89 \%$ were within 1.4 -fold and $96 \%$ were within 3.8 -fold.

(D-F) Scatter plots showing the relationship between the peptide log2(refolded/native) quantification in one replicate versus its value in the other replicate for two replicates of the experiment in which proteins were refolded for $1 \mathrm{~min}$ in (D) Tris buffer, (E) cyto-serum, or (F) cyto-serum with GroEL/ES. Points in red were considered significant $\left(P<0.016\right.$ by Welch's t-test) in both experiments. The coefficients of determination $\left(R^{2}\right)$ are given first for all points in common (black), and then for the subset of points that were considered significant in both replicates of the experiment (red). In all cases, $R^{2}$ is greater when only significant peptides are considered (which are the only ones used to call a protein non-refoldable). The gray boxes demarcate regions in which upon separate performances of the experiment, an all-or-nothing peptide is categorized as nonsignificant in the other. Importantly, these boxes have very few red points.

(G-I) Calling reproducibility of peptides (classified as either non-significant, significant, or all-or-nothing (AoN)) between two replicates of the experiment in which proteins were refolded for $1 \mathrm{~min}$ in $(\mathrm{G})$ Tris buffer, $(\mathrm{H})$ cytoserum, or (I) cyto-serum with GroEL/ES.

$(\mathrm{J}-\mathrm{L})$ Calling reproducibility of proteins between two replicates of the experiment in which proteins were refolded for 1 min in (J) Tris buffer, (K) cyto-serum, or (L) cyto-serum with GroEL/ES. Rows correspond to the number of peptides that were significantly different between native and refolded samples in the first replicate of the experiment, and columns correspond to the number of peptides that were significantly different in the duplication. Numbers in the table correspond to the number of proteins with that many significant peptides in each replicate. Gray cells correspond to proteins that would be called refoldable in both iterations. Red cells correspond to proteins that would be called nonrefoldable in both iterations. Cells in white would have been called differently, resulting in reproducibility from $87-89 \%$. In all comparisons, we exclude proteins that only differ by one significant peptide at the cut-off, shown as blue cells. With these proteins removed post hoc, reproducibility increases to $93-95 \%$.

(M-O) Histograms of the coefficients of variation (CV) for the peptide abundances in refolded samples, from 3 independent refolding reactions, after $5 \mathrm{~min}$ of refolding for experiments in which cells were lysed and refolded in either (M) Tris buffer (pH 8.2), (N) cyto-serum, or (O) cyto-serum with GroEL/ES. Insets in red correspond to the $\mathrm{CV}$ histograms for the peptides detected only in the refolded samples (which are almost all half-tryptic). Numbers represent medians of distributions.

(P-Q) Same as panels $M$ and $N$, except for refolding after $2 \mathrm{~h}$. 


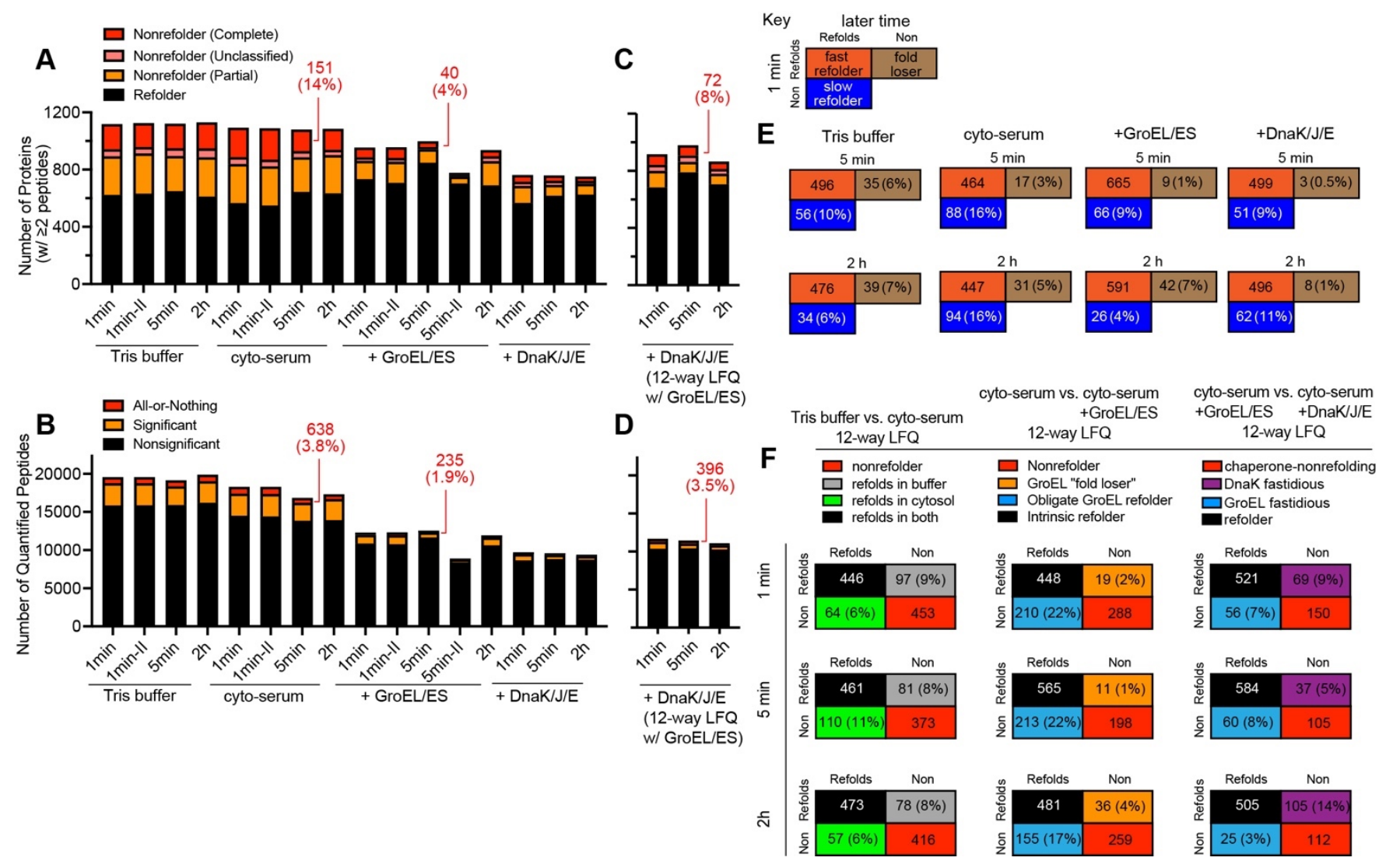

Figure S5. Summary statistics of all 6-way LFQs, kinetic comparisons, and truth tables for condition comparisons based on 12-way LFQs, related to Figures 2, 4, 5, 6.

(A) The number of proteins assessed in each 6-way LFQ, categorized as either refolding (0 or 1 peptide quantified with significantly different abundance between native and refolded), partial nonrefolding (2 or more peptides quantified with significantly different abundance between native and refolded but fewer than 2 all-ornothing peptides), and complete nonrefolding (2 or more all-or-nothing peptides). Some nonrefolding proteins do not classify between the subcategories (if they have 1 significant and 1 all-or-nothing peptide). Proteins with only 1 peptide quantified are not included. Bars correspond in order to 6-way LFQs labeled \#1-9 in Figure S1B. 6way LFQs for DnaK/J/E are not used for analysis (see main text and methods). In red, are number (and percentage) of proteins that are judged complete nonrefolding.

(B) The number of peptides confidently quantified in each 6-way LFQ, categorized as either nonsignificant, significant, or all-or-nothing. Bars correspond in order to the 6-way LFQs labeled \#1-9 in Figure S1B. In red, are number (and percentage) of peptides that are all-or-nothing.

(C) The number of proteins assessed in each 12-way LFQ (\#g-i in Figure S1C), with the identifications and quantifications for the DnaK channels extracted out, done to increase coverage in the DnaK experiments (see main text). Categorizations same as panel $A$.

(D) The number of peptides confidently quantified in each 12-way LFQ (\#g-i in Figure S1C), with the identifications and quantifications for the DnaK channels extracted out, done to increase coverage in the DnaK experiments (see main text). Categorizations same as panel B. 
bioRxiv preprint doi: https://doi.org/10.1101/2021.11.20.469408; this version posted November 21,2021 . The copyright holder for this preprint (which was not certified by peer review) is the author/funder, who has granted bioRxiv a license to display the preprint in perpetuity. It is made available under aCC-BY-NC-ND 4.0 International license.

(E) Summary of all kinetics experiments. To assess kinetics, we perform a comparison of two 6-way LFQs that correspond to distinct refolding timepoints but for otherwise identical conditions. To be included, a protein must have two or more confidently quantified peptides at both timepoints, be assessed as refoldable in one of the two time points, and cannot differ by only one significant peptide between the two timepoints. Each protein is designated as either a fast refolder, slow refolder, or fold loser; the number of such proteins is given for each kinetic comparison, according to the key. For the top row, from left to right, the data used for each comparison correspond to: \#1 \& 2; \#4 \& 5; \#7 \& 8 (Figure S1B) and \#g \& h (Figure S1C). For the bottom row, from left to right, the data used for each comparison correspond to \#1 \& 3; \#4 \& 6; \#7 \& 9 (Figure S1B) and \#g \& i (Figure $\mathrm{S1C})$

(F) Summary of all condition comparison experiments. To assess the effect of changing refolding condition, we perform 12-way LFQs that merge the native and refolded (at a given timepoint) replicates for the two conditions being compared. To be included, the protein must have two or more confidently quantified peptides in both conditions, and cannot differ by only one significant peptide between the two conditions. Three types of comparisons were performed (columns): Tris buffer v. cyto-serum, cyto-serum with and without GroEL/ES, GroEL/ES vs. DnaK/J/E in cyto-serum. The color code for the designations associated with each comparison are given, and the truth tables give the number of proteins in each designation. Each comparison was conducted at three timepoints. The data used correspond to \#a-i (Figure S1C). 


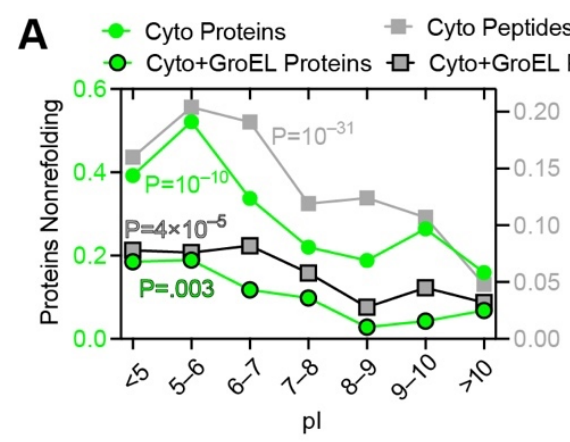

D
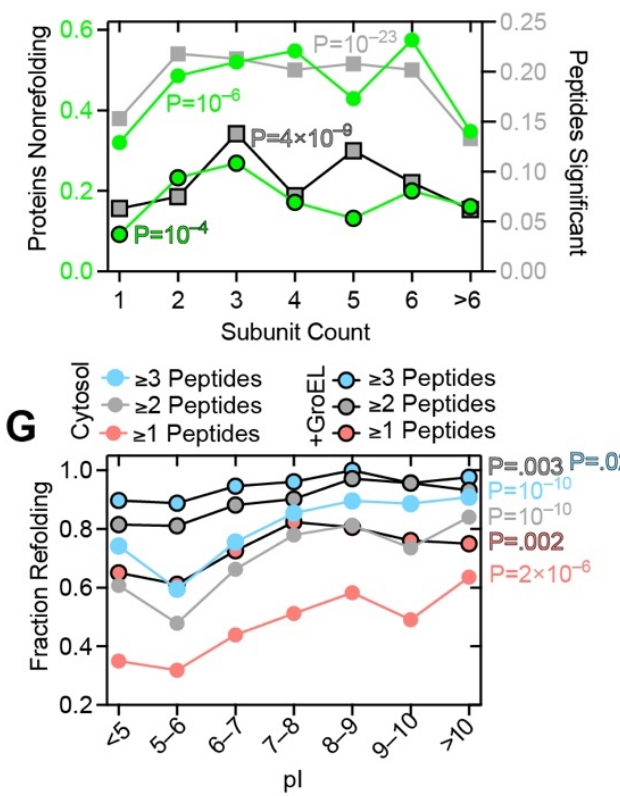

B

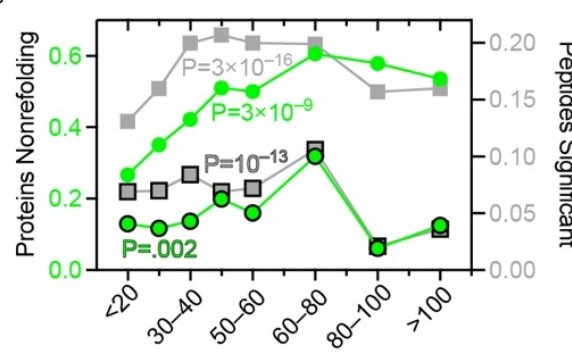

E

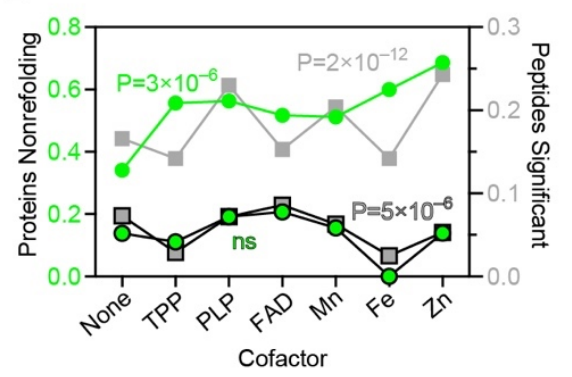

H

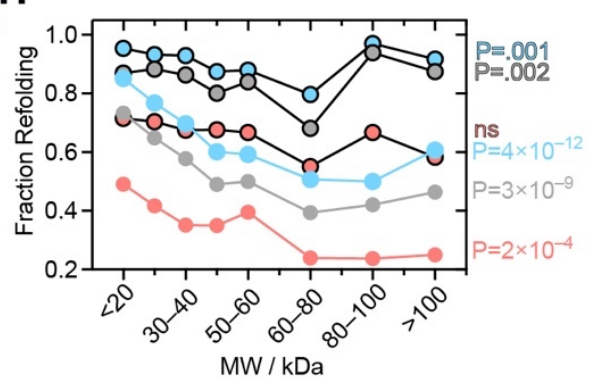

C

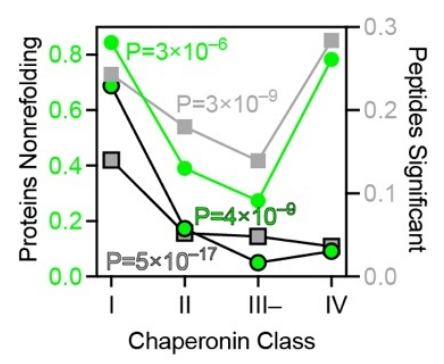

$\mathbf{F}$

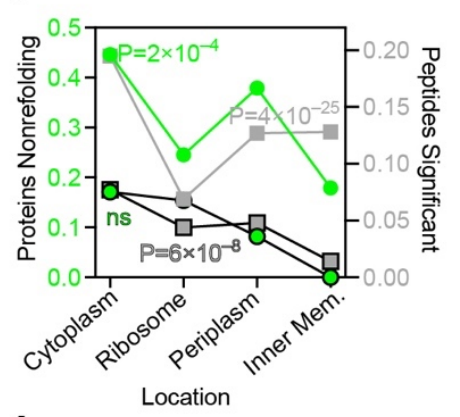

I

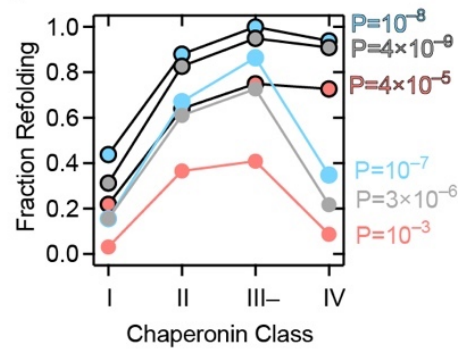

Figure S6. Peptide-level analyses and comparison to the protein-level, related to Figure 2, 4.

(A) Fraction of proteins that do NOT refold in either cyto-serum (green circles), or cyto-serum with GroEL/ES (green circles, black border), separated on the basis of individual proteins' isoelectric point (pl) (left y-axis).

Additionally shown is fraction of peptides that have significantly different abundance in refolded samples, lumped together for all proteins within the given pl tranche (in either the cyto-serum experiment (gray boxes) or the cytoserum with GroEL/ES experiment (gray boxes, black border)) (right y-axis). P-values according to the chi-square test are given on the protein frequencies in green (black border for GroEL/ES) and on the peptide frequencies in gray (black border for GroEL/ES). Proteins with low pl tend to be more nonrefoldable and tend to generate significant peptides at a much higher frequency; the trend prevails across the series with protein nonrefoldability fraction tracking closely with the peptide significance rate. This implies that the trend is robust, and not a coverage artefact. Data come from 6-way LFQs pooling 3 replicates of either: native/cyto-serum and refolded[5min]/cyto-serum; native/cyto-serum/GroEL/ES and refolded[5min]/cyto-serum/GroEL/ES (\# 5, 8 in Figure S1B).

(B) Same as panel A, except proteins and peptides are separated on the basis of the protein's molecular weight (MW). Trends associated with MW are robust. Data come from same 6-way LFQs as panel A.

(C) Same as panel A, except proteins and peptides are separated on the basis of the protein's chaperonin class (Kerner et al., 2005). Trends associated with chaperonin class are robust. Data come from same 6-way LFQs as panel A. 
bioRxiv preprint doi: https://doi.org/10.1101/2021.11.20.469408; this version posted November 21,2021 . The copyright holder for this preprint (which was not certified by peer review) is the author/funder, who has granted bioRxiv a license to display the preprint in perpetuity. It is made available under aCC-BY-NC-ND 4.0 International license.

(D) Same as panel A, except proteins and peptides are separated on the basis of the protein's subunit count. In the cytosol, monomeric and large complexes refold the most efficiently, a robust trend. With GroEL/ES, overall trends with respect to subunit count are less substantial, though it appears to have an outsized importance on tetrameric and hexameric proteins. Data come from the same 6-way LFQs as panel A.

(E) Same as panel A, except proteins and peptides are separated on the basis of the which cofactors the protein harbours. In the cytosol, apo-proteins refold the best and Fe \& $\mathrm{Zn}$ metalloproteins refold the worst, although due to low counts the trends are not robust (the protein and peptide level results do not track together). With GroEL/ES, overall trends with respect to subunit are less substantial, though it appears to have an outsized importance holo-proteins over apo-proteins. Data come from the same 6-way LFQs as panel A.

(F) Same as panel A, except proteins are peptides are separated on the basis of the protein's cellular localization. Trends associated with location are robust. GroEL/ES is effective on proteins in all locations, except ribosomal proteins.

(G-I) Sensitivity analyses showing the fraction of proteins refolding in either cyto-serum (solid circles) or in cytoserum with GroEL/ES (solid circles, black borders), as a function of the number of significant peptides required to call a protein nonrefoldable ( $\geq 1$, red; $\geq 2$, gray (the standard cutoff); $\geq 3$, blue). P-values according to the chisquare test are given in matching colors (for the various cutoff schemes) and with black borders for GroEL/ES. Whilst all trends are maintained irrespective of cutoff, statistical significances generally fall with the $\geq 1$ cutoff (red), likely because it assigns too much weight to a single significant peptide. 


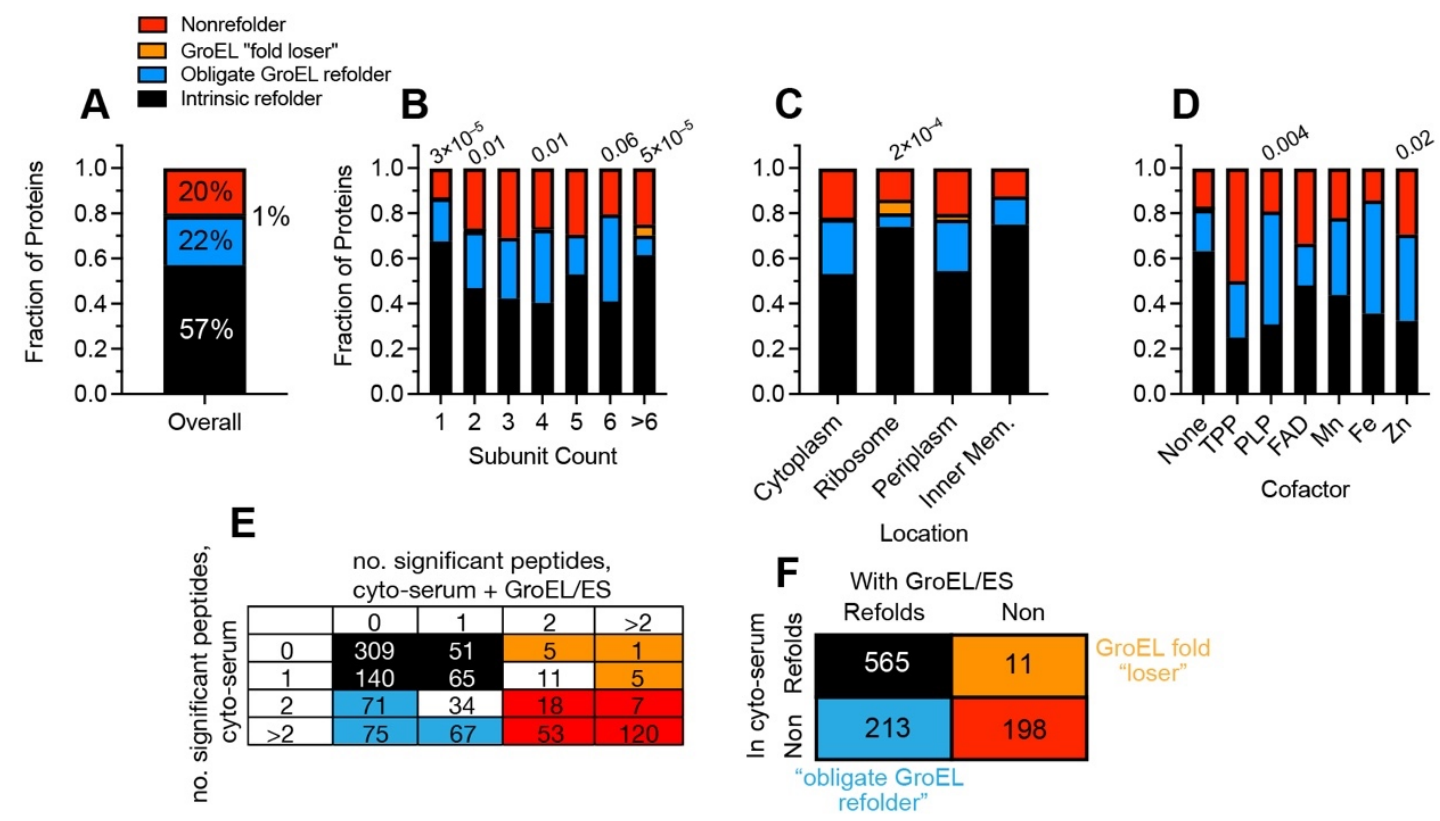

Figure S7. Further properties of obligate GroEL refolders, related to Figure 4.

(A) Overall frequency of proteins that refolded in both conditions (intrinsic refolder; black), only with GroELES (obligate GroEL refolder; blue), only without GroEL/ES (GroEL "fold loser"; orange), or did not refold in either (Nonrefolder; red). Data used is a 12-way LFQ pooling 3 replicates of native/cyto-serum, 3 replicates of refolded[5min]/cyto-serum, 3 replicates of native/cyto-serum/GroEL/ES, and 3 replicates of refolded[5min]/cytoserum/GroEL/ES (\#e in Figure S1C).

(B) Frequency of proteins that refolded in both conditions, only with GroEL/ES, only without GroEL/ES, or did not refold in either, separated on the basis of proteins' subunit count. Data used for B is the same 12-way LFQ as panel A. Numbers listed above bars indicate P-value by the chi-square test. Monomers and large complexes (with $>6$ subunits) are significantly enriched for intrinsic refolders and de-enriched for obligate GroEL refolders. Tetramers and hexamers are significantly enriched for obligate GroEL refolders.

(C) Frequency of proteins that refolded in both conditions, only with GroEL/ES, only without GroEL/ES, or did not refold in either, separated on the basis of proteins' locations. Data used for $C$ is the same 12-way LFQ as panel A. Numbers listed above bars indicate P-value by the chi-square test. All locations benefit from GroEL, except ribosomal proteins, which are enriched for GroEL fold-losers and de-enriched for obligate GroEL refolders.

(D) Frequency of proteins that refolded in both conditions, only with GroEL/ES, only without GroEL/ES, or did not refold in either, separated on the basis of which cofactor the protein harbours. Data used for $D$ is the same 12way LFQ as panel A. Numbers listed above bars indicate P-value by the chi-square test. PLP-, Fe-, and Znproteins are the most likely to be obligate GroEL refolders, though the enrichment is only weakly significant for PLP and $Z n$ due to small counts.

(E) The truth table used for the cyto-serum with and without GroEL/ES comparison, with the same color code as panel A. Note the cells with white background which are discounted, because they only differed by one peptide across the comparison (see Figures S4J-L, S5F).

(F) Simplified truth table, reproduced from Figure S5F for reference. 

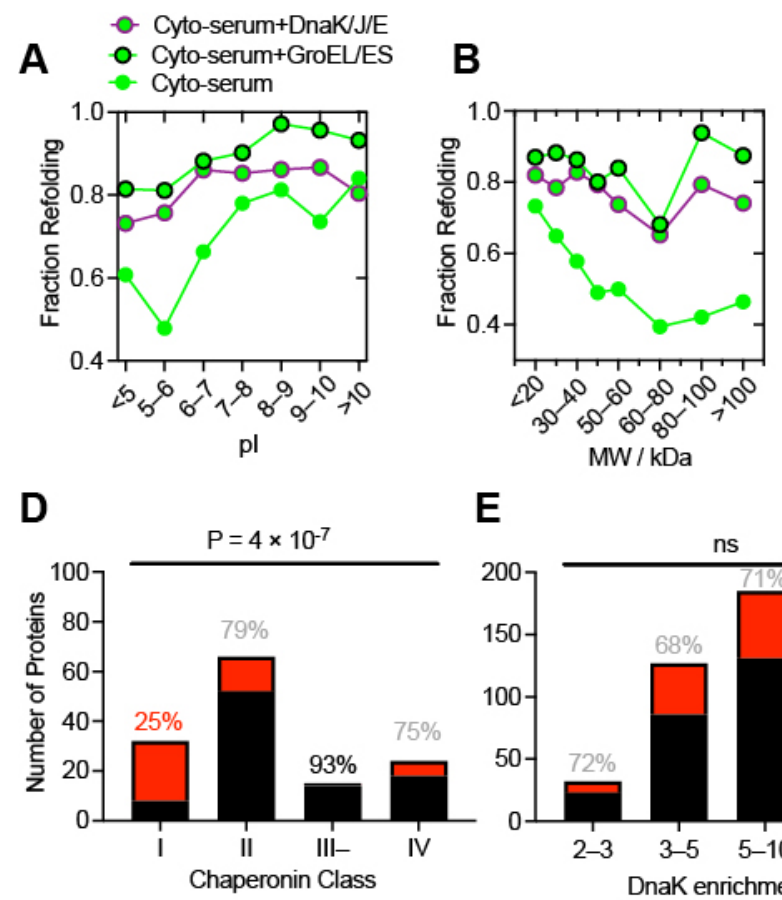

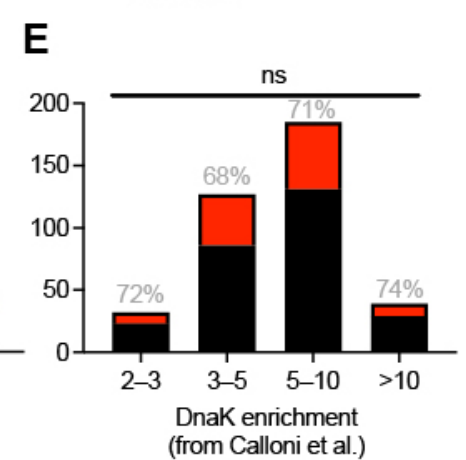

C
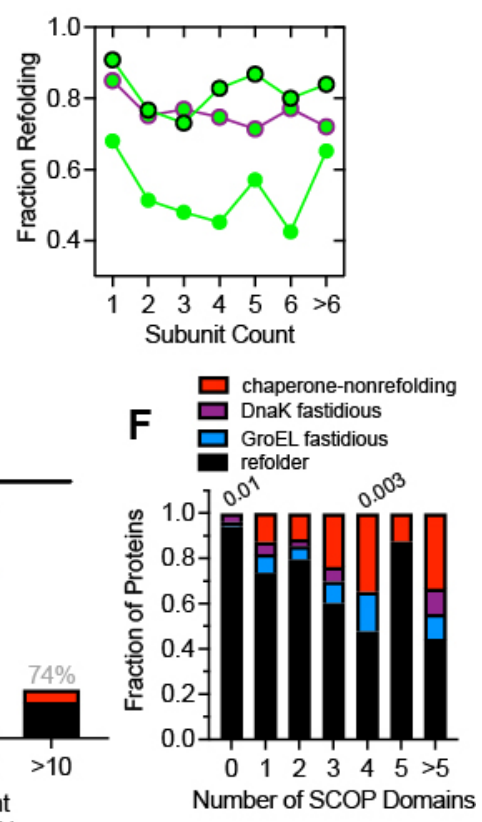

Figure S9. Further properties of DnaK refolders, related to Figures 6 and 7.

(A) Fraction of proteins that refold in either cyto-serum (green), cyto-serum with GroEL/ES (green, black border), or cyto-serum with DnaK/J/E (green, purple borer) separated on the basis of proteins' pl. Data come \#5, 8 in Figure S1B and \#h in Figure S1C.

(B) Fraction of proteins that refold in either cyto-serum (green), cyto-serum with GroEL/ES (green, black border), or cyto-serum with DnaK/J/E (green, purple borer) separated on the basis of proteins' molecular weight (MW).

Data used for B is the same LFQs as panel A.

(C) Fraction of proteins that refold in either cyto-serum (green), cyto-serum with GroEL/ES (green, black border), or cyto-serum with DnaK/J/E (green, purple borer) separated on the basis of proteins' subunit count. Data used for $C$ is the same LFQs as panel $A$.

(D) Bar charts indicating the number of refolding (black) and nonrefolding (red) proteins associated with one of four chaperonin classes (as defined by Kerner et al., 2005; Fujiwara et al., 2010), during refolding experiments in cyto-serum with DnaK/J/E. Percents indicate percentage refolding within that category. P-value is from the chisquare test. Data come from a 12-way LFQ pooling 3 replicates of native/cyto-serum/GroEL/ES, 3 replicates of refolded[5min]/cyto-serum/GroEL/ES, 3 replicates of native/cyto-serum/DnaK/J/E, and 3 replicates of refolded[5min]/cyto-serum/DnaK/J/E, with the identifications and quantifications from the 6 DnaK channels extracted out (\#h in Figure S1C).

(E) Bar charts indicating the number of refolding (black) and nonrefolding (red) proteins, separated by their enrichment level in DnaK pull-down assays (as defined by Calloni et al., 2012), during refolding experiments in cyto-serum with DnaK/J/E. Percents indicate percentage refolding within that category. No significant differences are detected by the chi-square test. Data used for $E$ is the same 12-way LFQ as panel D.

(F) Frequency of proteins that refolded in both conditions (black), only with GroELES (light blue), only without DnaK/J/E (purple), or did not refold in either (chaperone-nonrefolder; red), separated on the basis of the number of domains in the protein, as defined by the SCOP database. Data used for $F$ is the same 12-way LFQ as panel D. Numbers indicate P-values according to the chi-square test. 
bioRxiv preprint doi: https://doi.org/10.1101/2021.11.20.469408; this version posted November 21, 2021. The copyright holder for this preprint (which was not certified by peer review) is the author/funder, who has granted bioRxiv a license to display the preprint in perpetuity. It is made available under aCC-BY-NC-ND 4.0 International license.

basis of chaperonin class (Kerner et al., 2005; Fujiwara et al., 2010). Data used for F is the same 12-way LFQ as panel E. Numbers listed above bars indicate P-value by the chi-square test. 